\title{
To test or not to test : guideline-based automated feedback on test ordering in general practice
}

Citation for published version (APA):

Bindels, R. (2003). To test or not to test : guideline-based automated feedback on test ordering in general practice. [Doctoral Thesis, Maastricht University]. Universiteit Maastricht.

https://doi.org/10.26481/dis.20030606rb

Document status and date:

Published: 01/01/2003

DOI:

10.26481/dis.20030606rb

Document Version:

Publisher's PDF, also known as Version of record

\section{Please check the document version of this publication:}

- A submitted manuscript is the version of the article upon submission and before peer-review. There can be important differences between the submitted version and the official published version of record.

People interested in the research are advised to contact the author for the final version of the publication, or visit the DOI to the publisher's website.

- The final author version and the galley proof are versions of the publication after peer review.

- The final published version features the final layout of the paper including the volume, issue and page numbers.

Link to publication

\footnotetext{
General rights rights.

- You may freely distribute the URL identifying the publication in the public portal. please follow below link for the End User Agreement:

www.umlib.nl/taverne-license

Take down policy

If you believe that this document breaches copyright please contact us at:

repository@maastrichtuniversity.nl

providing details and we will investigate your claim.
}

Copyright and moral rights for the publications made accessible in the public portal are retained by the authors and/or other copyright owners and it is a condition of accessing publications that users recognise and abide by the legal requirements associated with these

- Users may download and print one copy of any publication from the public portal for the purpose of private study or research.

- You may not further distribute the material or use it for any profit-making activity or commercial gain

If the publication is distributed under the terms of Article $25 \mathrm{fa}$ of the Dutch Copyright Act, indicated by the "Taverne" license above, 


\section{TO TEST OR NOT TO TEST?}

Guideline-based automated feedback on test ordering in general practice 
The studies described in this thesis were performed at the Care And Public Health Research Institute (CAPHRI), which participates in the Netherlands School of Primary Care Research (CaRe), acknowledged in 1995 by the Royal Dutch Academy of Science (KNAW).

ISBN 90-9016875-3

Printed by PrintPartners Ipskamp, Enschede Cover design by Copyshop 't Hoekje, Gennep

Printing of this thesis was financially supported by Medecs, Eurogenerics and Stichting BAZIS.

(C) 2003 Rianne Bindels 


\title{
TO TEST OR NOT TO TEST?
}

\author{
Guideline-based automated feedback on \\ test ordering in general practice
}

\section{Proefschrift}

Ter verkrijging van de graad van doctor aan de Universiteit Maastricht, op gezag van de Rector Magnificus, Prof. Dr. A.C. Nieuwenhuijzen Kruseman, volgens het besluit van het College van Decanen, in het openbaar te verdedigen op vrijdag 6 juni 2003 om 14.00 uur

door

\section{Rianne Bindels}

geboren op 14 augustus 1972

te Nijmegen 


\section{Promotor}

Prof. dr. ir. A. Hasman

\section{Co-promotores}

Ir. J.W.J. van Wersch

Dr. R.A.G. Winkens

\section{Beoordelingscommissie}

Prof. dr. H.F.J.M. Crebolder (voorzitter)

Prof. dr. F. Buntinx

Dr. H.M. Goldschmidt

Prof. dr. J. van der Lei

Erasmus Universiteit Rotterdam

Prof. dr. G.G. van Merode 


\section{CONTENTS}

Chapter 1 General Introduction

PART I - Development and Validation

Chapter 2 The impact of and satisfaction with real-time clinical decision support systems that produce on screen recommendations - A literature review

Chapter 3 GRIF: A test ordering system with automated feedback

Chapter 4 The reliability of assessing the appropriateness of 59 requested diagnostic tests

Chapter 5 Validation of GRIF

\section{PART II - Evaluation}

Chapter 6 Evaluation of GRIF in a laboratory setting

Chapter 8 Ordering laboratory tests according to practice guidelines or not: Does the fraction of abnormal test results differ?

Chapter 9 User satisfaction with GRIF: a quantitative and qualitative evauation

Chapter 10 General Discussion

Apendices

Summary

Samenvatting

Dankwoord

Curriculum vitae

Publications 


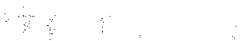




\section{ChAPTER 1}

GENERAL INTRODUCTION 


\section{Test ordering in general practice}

Laboratory tests can be a valuable tool for a physician. These laboratory tests are requested in about four percent of the patient consultations of Dutch general practitioners (1). In the Netherlands, the number of requested tests in secondary health care has increased over the past years (2). Part of the increase in test consumption can be explained by the ageing of the patient population and by the growth in the number of preventive tasks in the physician's practice. Moreover, part of the increase is caused by a growing demand for care by the patients and the increased availability of new diagnostic tests $(3,4)$ of which the appropriateness is not always clear (5). On an international level, the tendency to order tests to prevent lawsuits is also growing, especially in the USA (6). Uncertainty and the wish not to miss a severe diagnosis even encourages physicians to use diagnostic tests in situations where its usefulness is questionable $(3,7)$.

Possible negative consequences of ordering inappropriate diagnostic tests are an increase of expenses for medical care and the generating of abnormal test results in the absence of a disease. These abnormal test results - in turn - might increase uncertainty and stimulate further unnecessary test ordering $(6,8)$. Therefore, it is legitimate to encourage appropriate test ordering and to develop means to influence the physician's test ordering behaviour (9).

\section{Influencing test ordering behaviour}

Various strategies have been applied to guide physicians to use the most appropriate tests. Methods such as continuing medical education (10, 11), redesigning the request form $(5,12,13)$ and peer review, audit and feedback on number, rationality (14) or costs (15) of the requested tests were used. In review articles that compare different strategies to modify the test ordering patterns of clinicians (16-18) it was concluded that a wide range of interventions is possible but that there are 'no magic bullets' as Oxman eloquently pointed out (16).

Appropriate use of diagnostic tests is also stimulated by the Dutch College of General Practitioners. It has been developing national practice guidelines $(19,20)$ to achieve a more appropriate and uniform care by GPs. These practice guidelines have been published in 'Huisarts en Wetenschap': the journal of the Dutch College of General Practitioners.

Several reviews showed that the use of practice guidelines improved the quality of care $(21,22)$. However, the implementation and use of these practice guidelines in daily practice is still a point of concern $(23,24)$. Not being able to find the right guideline, to read the information of the guideline during patient consultation and/or to apply this information to a specific patient are a few of the problems mentioned in the literature $(25,26)$. To overcome these shortcomings it is important to develop tools which facilitate the application of these guidelines by physicians. 


\section{Feedback in the Maastricht region}

In 1979, the Dutch Ministry of Education and Science initiated the start of a Diagnostic Centre in the Maastricht region. The aim of the centre has been to coordinate test facilities for primary care and to enhance the co-operation between primary and secondary health care $(27)$. Regional practice guidelines were formulated by specialists together with expert general practitioners (GPs) during the initial experimental phase of the Diagnostic Centre (1979-1983) (28). These guidelines covered a variety of diagnostic questions. After approval, they were distributed to the GPs in the Maastricht region. Based on these guidelines, the Diagnostic Centre in Maastricht started to provide feedback on the appropriateness of the requests for diagnostic tests by the GPs. Feedback is described as a way to "control a system by reinserting into the system the results of its performance" (29). After a short period of providing feedback on a group level, the Diagnostic Centre started with individual feedback in 1985. Twice a year, each GP in the Maastricht region (about $90 \mathrm{GPs}$ ) received a structured feedback report with critical comments on the requested tests in a previous month. The individual feedback was based on a comparison of request forms (including diagnostic tests and clinical data provided by the GPs) with accepted national or regional guidelines. Studies showed that this feedback led to a test ordering behaviour of GPs that was more in accordance with the guidelines and that the feedback was appreciated by the GPs $(14,27,30)$.

At present, the Diagnostic Centre is named Transmural Care Unit (TCU) and focuses on many aspects of transmural care (health care activities at the interface between primary and secondary care). The TCU focuses its continuing medicall education on many topics such as: test ordering, prescribing drugs and referring to the hospital. The TCU stimulates the formation of groups of GPs which discuss their test ordering behaviour and drug prescribing behaviour, provides individual written feedback on diagnostic test ordering and on referrals by GPs to specialists of the University Hospital Maastricht. Finally, the TCU stimulates initiatives to produce automated feedback while ordering diagnostic tests and/or prescribing drugs.

\section{The GRIF automated feedback system}

The individual written feedback improved the quality of the GPs' test ordering behaviour and was appreciated by GPs in the Maastricht region. However, the TCU wanted a more direct and less laborious method of feedback. It was suggested that a clinical decision support system (CDSS) should be developed that would directly assist in the GP's test ordering process. The review by Oxman et al. on strategies to modify the test ordering patterns of clinicians concluded that the use of CDSSs in this area is promising (16). A CDSS can be based on various modes of operation: passive, pro-active and re-active. Passive systems require the physician to take action to access information, such as textbook information. Pro-active systems give 
comments or provide suggestions before the user takes any action and re-active systems give comments after the user has entered e.g. a request for a tests but before the test is ordered.

The Department of Medical Informatics of the Maastricht University and the TCU had previous experience with CDSSs to improve test ordering behaviour of GPS. Dupuits et al. developed a prediction instrument that determined TSH test adequacy on the basis of acquired patient related data (31) and de Wilde et al. studied the effect of automated feedback on the rationality of TSH test requests (32). These systems provided feedback after the test requests were submitted to the TCU. Based on these experiences it was decided to develop a re-active CDSS named GRIF ${ }^{1}$.

A computerised CDSS can only be introduced in daily practice when an information system is in routine use. This prerequisite is met in Dutch primary care. The introduction of GP information systems in general practice started around 1980 with a small group of computer pioneers (33). In 2001, 97\% of the GPs had a GP information system. Ninety-four percent of these GPS used the medical module of their GP information system as an electronic patient record during patient consultation to review and record patient related medical information. Only $25 \%$ of the GPs used ICPC codes to describe the working hypothesis frequently (in 80$100 \%$ of the patient consultations) (34).

The GRIF system provides feedback to the GP in the form of patient-specific on screen recommendations during patient consultation so that the request for a diagnostic test can be modified according to the suggestions of the system. The aim of the GRIF system is to improve the application of the national and regional practice guidelines by GPS. The TCU opted for the development of a critiquing system that provides automated feedback after the GP has indicates the required tests to be applied on the request form: a re-active decision support system. Critiquing systems evaluate the appropriateness of the decision the clinician takes, and (if possible) generate an alternative suggestion. This type of system was chosen as it resembles the way the written feedback was given (namely after the GP had performed an action). A re-active system does not interrupt the routine procedure of ordering diagnostic tests by GPS when the test request is in accordance with the practice guidelines. In addition, a re-active CDSS is less likely to induce a checklist effect, as might be the case when a pro-active approach is used. The aim of the GRIF automated feedback system is - comparable with the written feedback - to stimulate a more rational use of practice guidelines regarding diagnostic test ordering.

"GRIF is the Dutch acronym for Geautomatiseerde Reminders als Interactieve Feedback' (Automated Reminders as Interactive Feedback). 
The objectives were to develop, implement and evaluate an automated feedback system that provides immediate recommendations to GPs about the appropriateness of the requested tests during the test ordering procedure. The hypothesis is that implementing an automated feedback system that is based on practice guidelines will lead to more appropriate test ordering behaviour and may lead to a reduction of the number of requested tests.

The aim of the present research project is to develop, validate, implement and evaluate an automated feedback system to be used by GPs in daily practice. The main research question of this thesis is:

- What is the impact of an automated feedback system on the test ordering behaviour of general practitioners?

\section{Outline of this thesis}

To answer this research question, the GRIF system had to be developed, the recommendations from the paper guidelines had to be implemented into the system and knowledge stored in the knowledge base of the system had to be validated. These steps are described in the first part of this thesis (Chapters 2 to 5). The research question of this part of the thesis is:

- What is the accuracy of the feedback produced by the GRIF system?

In the second part (Chapters 6 to 9) the impact of the GRIF system in a laboratory setting as well as in daily practice is presented. The research questions in the second part of the thesis are:

- What consequences does GRIF have for GPS and their daily work?

- What reasons do GPS have to ignore computer-generated recommendations?

\section{Development and validation of GRIF}

The literature on systems that display patient-specific on screen and real-time feedback recommendations to physicians is reviewed in Chapter 2. This chapter shows the methods used to evaluate these systems and highlights the aspects that have been studied infrequently or have not been studied at all.

Chapter 3 describes the development of the GRIF automated feedback system. First the selection of guidelines and the translation of these guidelines into computerised rules are discussed. Then, the development of the request module, the implementation of the computerised rules in a knowledge base (KB) and the verification of this $\mathrm{KB}$ are described. 
To validate the knowiedge base of the GRIF system a reference standard was necessary. The assessments of appropriateness of test requests by three experts was used as a reference standard. Chapter 4 examines the reliability of these assessments and the results of the validation study are presented in Chapter 5 .

\section{Evaluation of GRIF}

Four aspects of the GRIF system were evaluated:

- the effect on test ordering behaviour in a laboratory setting and in daily practice,

- the probability to reject tests of which the results would have had clinical impact,

- the reasons why recommendations of the system are not followed and

- the user satisfaction and experiences with the system.

The efficacy of the GRIF system in a laboratory setting is studied in Chapter 6 . The effectiveness of GRIF in daily practice is investigated in Chapter 7 ; an analysis of usage behaviour, the quality of information provided and the percentage of recommendations foliowed, is presented.

In Chapter 8 the fraction of abnormal test results in tests ordered according to the practice guidelines is compared with the fraction of abnormal test results in tests ordered not in accordance with the practice guidelines. The outcome of laboratory tests can seldom be equated with a diagnosis, while the outcome of imaging tests is often diagnostic. Hence, test requests of both domains are studied separately. The results on laboratory tests are described in Chapter 8 and the results on imaging tests in Appendix III.

The user satisfaction with, experiences with and the views on the GRIF system are described in Chapter 9 . This chapter combines the results of the trial in a laboratory setting (Chapter 6) as well as the trial in daily practice (Chapter 7 ). The chapter also deals with the motives of the GPs for not following the recommendations presented by the GRIF system.

Finally, Chapter 10 presents the conclusions and discusses general aspects of the study results, including recommendations for further implementation in daily practice and future research.

\section{References}

1. Leurcuin $P$, van Casteren $\mathrm{V}$, Dde Maeseneer J. Use of blood tests in general practice: A collaborative study in eight European countries. British Journal of General Practice $1995 ; 45: 21-25$.

2. van der Ham PJ. Het Diagnostisch Centrum als centraal loket. Medisch contact $1999 ; 54(40)$.

3. Kassirer JP. Our stubborn quest for diagnostic certainty. New England Journal of Medicine 1989;320:1489-1491. 
4. Mandell HN. Technological imperative. Or, when your tool is a hammer, everything looks like a nail. Postgraduate Medicine 1983;74(2):24-26.

5. Wang ET, Lincoln TL. Ready! Fire! ... Aim! Journal of the American Medical Association 1983;250(18):2510-2513.

6. DeKay ML, Asch DA. Is the defensive use of diagnostic tests good for patients, or bad? Medical Decision Making 1998;18(1):19-18.

7. Zaat JOM. General practitioners' uncertainty, risk preference and use of laboratory tests. Medical Care 1992,30(9):846-854.

8. DeKay ML, Asch DA. Offensive testing - Te balancing act; the evil twin, and the pure play. Medical Decision Making 1998;18(1):35-36.

9. Buntinx $F$, Winkens $R$, Grol $R$, Knottnerus JA. Influencing diagnostic and preventive performance in ambulatory care by feedback and reminders. A rewew. Familly Practice $1993 ; 10(2): 219-228$

10. Eisenberg JM. An educational program to modify laboratory use by house staff. Journal of Medical Education 1977;52:578-581.

11. Davis DA, Thomson MA, Oxman AD, Haynes RB. Changing physician performance: $A$ systematic review of the effect of continuing medical education strategies. Journal of the American Medical Association 1995,274(9):700-705.

12. Zaat JO, wan Eijk JT, Bonte HA. Laboratory test form design influences test ordering by general practitioners in The Netherlands. Medical Care 1992;30(3):189-98.

13. Smithuis LOMJ, van Geldrop WJ, Lucassen PLBJ. Beperking van het laboratoriumonderzoek door een probleemgeorienteerd aanvraagfoimulier. Huisarts en Wetenschap 1994;37(11):464-466.

14. Winkens RAG, Pop P, Bugter-Maessen AMA, Grol RPTM, Kester ADM, Beusmans $\mathrm{GHMI}_{3}$ et al. Randomised controlled trial of routine individual feedback to improve rationality and reduce numbers of test request. The Lancet 1995,345:498-502.

15. Tierney WM, Miller ME, McDonald CJ. The effect on test ordering of informing physicians of the charges for oulpatient diagnostic tests. New England Journal of Medicine 1990;322(21):1499-1504

16. Oxman $A D$, Thomson MA, Davis DA, Haynes RB. No magic bullets: $A$ systematic review of 102 trials of interventions to improve professional practice. Canadian Medical Association Journal 1995;153(10):1423-1431.

17. Fraser CG, Woodford FP. Strattegies to modify the test-requesting patterns of clinicians. Annals of Clinical Blochemistry 1987;24(Pt 3):223-31.

18. Axt-Adam $P_{i}$, van der Wouden $J C$. Influencing behavior of physicians ordering laboratory tests; A literature study. Medical Care 1993;31(9):784-794.

19. Rutten GEHM, Thomas S. NHG-Standaarden voor de huisarts. Utrecht: Bunge; 1993.

20. Thomas S. NHG-standaarden voor de huisarts II. Utrecht: Bunge; 1996.

21. Grimshaw JM, Russell IT. Effect of clinical guidelines on medical practice: a systematic rewiew of rigorous ewaluations. Lancet 1993;342:1317-1322.

22. Wensing $M$, wan der Weijden $T$, Grol $R$. Implementing guidelines and innovations in general practice: which interventions are effective? British Journal of General Practice 1998;48:991-997.

23. Grol $R$, Eccles $M$, Maisonneuve $H_{1}$ Woolf $S$. Develloping clinical practice guidelines: The European experience. Disease Management and Health Outcomes 1998:4 
15):255-266.

24. Woolf SH. Practice guidelines: A new reality in medicine. Archives of Internal Medicine $1990 ; 150,1811-1818$.

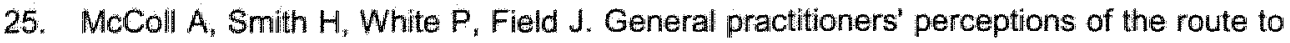
evidence based medicine: a questionnaire survey. British Medical Journal 1998;316 $(7128) \cdot 361-365$

26. Cabana MD, Rand CS, Powe NR, Wu AW, Wilson MH, Abboud PC, et al. Why don't physicians follow clinical practice guidelines?: A framework for improvement. Journal of the American Medical Association 1999;282:1458-1465.

27. Pop P, Winkens RAG. A diagnostic centre for general practitioners: results of individual feedback on diagnostic actions. Jounnal of Royal College of General Practitioners 1989;39:507-508.

28. Beusmans GHMI, Does RJMM. Werkafspraken in het Diagnostisch Centrum Maastricht. Huisarts en Wetenschap 1988;31:154-158.

29. Ende J. Feedback in clinical medicall education. Journal of the American Medical Association 1983:250:777-781.

30. Winkens RAG, Pop P, Grol RPTM, Bugter-Maessen AMA, Kester ADM, Beusmans GHMI, et al. Effects of routine individual feedback over nine years on general practitioners' requests for tests. British Medical Journal 1996;312:490.

31. Dupuits FMHM, Pop $P$, Hasman A, Schouten HJA. A rational request behavior: The development of prediction instruments regarding thyroid function tests in primary care. Methods of Information in Medicine 1999;38(1):31-36.

32. de Wilde EJL, Pop P. Hasman A, Blom "JA. OpenLabs services for ordering laboratory investigations. Computer Methods and Programs in Biomedicine 1996;50:135-141.

33. Höppener P. Automatisering en wetenschappelijk onderzoek in de huisartspraktijk. Maastricht; 1990.

34. Wolters $I$, van den Hoogen $H$, de Bakker D. Evaluatie invoering Elektronisch Voorschrijf Systeem. Monitoring: situatie in 2001. Utrecht: Nivel; 2002. 


\section{PART I}

\section{DEVELOPMENT AND VALIDATION}




$$
8 \div
$$




\section{CHAPTER 2}

THE IMPACT OF AND SATISFACTION WITH REAL-TIME CLINICAL DECISION SUPPORT SYSTEMS THAT PRODUCE ON SCREEN RECOMMENDATIONS: A LITERATURE REVIEW

R. Bindels, A. Hasman, J. Talmon, J.W.J. van Wersch, R.A.G. Winkens

The impact of and satisfaction with real-time clinical decision support systems that produce on screen recommendations: a literature review 


\section{Introduction}

Practice guidelines are developed to improve quality of care (1-3), but their implementation and use in dally practice is still problematic (4-6). The use of clinical decision support systems (CDSSs) to improve the adherence to practice guidelines has the potential to be an effective implementation strategy $(7,8)$. CDSSs may have different modes of operation: alerting, reminding, critiquing and suggesting and may address different clinical tasks such as prediction, diagnosis and treatment $(9,10)$. Alerting, reminding and critiquing are closely related functions and will be the focus of this chapter. Alerting systems monitor a continuous signal or stream of data and generate a message (an alert) in response to items or patterns that might require action on the part of the care provider (11), for example presenting alerts for critical laboratory results. Reminder systems notify clinicians about important tasks that need to be done before an event occurs. When the clinician has made a decision and the computer evaluates that decision and generates an appropriateness rating or alternative suggestion, the decision support approach is called critiquing. Examples are messages presenting information about drug interactions, drug allergies or decisions that are not in accordance with practice guidelines. Suggesting systems produce an advice for appropriate care after collecting information on specific patient variables. The distinction between suggesting and critiquing decision support systems is that suggesting systems help to formulate the clinical decision, whereas critiquing programs have no part in suggesting the order or plan but evaluate the plan, after it has been entered, against an algorithm in the computer $(9,10)$.

Over the past 10 years, an increased use of decision support systems in medicine has been observed. In this period, several review articles, about different aspects of CDSSs were published. Some authors focused on effects of CDSSs on physician performance (12-15), some on patient outcomes $(12,14)$, on effects in primary care (16) and on guideline implementation systems in general $(17,18)$. Other reviews focused more on methodological aspects such as evaluation methods $(19,20)$ or on the application of clustering in the analysis of the trials included (21).

Three review articles focused purely on reminder systems in preventive care (2224). These three reviews concluded that reminder systems are effective and improve preventive care by physicians. Five other review articles described more than one system type (such as reminder, alerting, critiquing and/or diagnostic systems) $(13,14,18,19,25)$. None of these reviews directly compared the effectiveness of these different types of CDSSs. This review - on the other hand reports on the effectiveness of the different types of feedback systems and (like other reviews also did $(14,18,25)$ ) analyses the impact on the physician, patient and organisation. Concerning the impact on the physician, only the review of 
Shiffman et al. described the satisfaction with CDSSs (18). Their review focused on computer-based guideline implementation systems while this review only focuses on systems that produce on screen advice. The present review also takes into account effectiveness of, acceptance of and/or satisfaction with the CDSSs, because acceptance or satisfaction only need not indicate an effective system. Dissatisfaction, however, is likely to lead to rejection of the system and thus no effects will be measured. Finally, the review focuses on systems used in daily practice, which produce real-time, patient-specific advice via on screen recommendations to physicians because this technique has probably the highest potential to change physician's behaviour. Therefore, systems which print computer generated recommendations on paper were excluded. So far, no review articles focused on CDSSs that produce on screen recommendations and compared the effectiveness of different types of systems.

\section{Methods}

\section{Identification of studies}

We searched Medline and EMBASE using the following terms: guideline ${ }^{*}$ or standard $^{*}$, computer ${ }^{*}$ or automat*, evaluat ${ }^{*}$ or accept $t^{*}$ or satisfact* or impact* or attitude ${ }^{*}$, remind ${ }^{*}$ or alert* or critique ${ }^{*}$ or feedback ${ }^{*}$ or physician order entry system in all possible combinations. Journal articles published from January 1991 until December 2001 in English or Dutch were selected. In addition, the Medline search was extended with the following MeSH terms: computer assisted decision making, computer assisted therapy, clinical decision support system, practice guideline, guideline adherence, guidelines, reference standard, and evaluation studies. Relevant articles before 1991 were searched using the method of reference checking. The first author reviewed the abstracts of all retrieved references.

Studies were included for further analysis if a) the article contained a system description, a description of the evaluation methodology and an analysis of results and b) the evaluation study concerned a CDSS (reminder, alerting, suggesting or critiquing systems) which presented real-time and on screen comments to physicians. All types of study designs (as described in more detail by Grimshaw and Russell (3)) were included, because we wanted to have an overview of publications that measured different aspects of the impact of the CDSS. For example user satisfaction with the system might be reported more frequently in descriptive or case studies.

Review articles, studies that contained only a system description, that described electronic patient records, imaging systems, systems that only generated printed reminders, suggestions or summaries, systems that only generated reminders to non-physicians (patients, nurses or pharmacists), and duplicates were excluded. 


\section{Data extraction and analysis}

Full articles of the selected abstracts were retrieved for in-depth review.

The following aspects were taken into account:

- what aspects were measured to evaluate the effectiveness

- how these aspects were measured

- the design of the studies

The most important recorded items were the setting, study design, unit of allocation, unit of analysis, data collection method and outcome measures.

Studies before 1998 were compared with studies from 1998 and afterwards, because we were interested in the changes in the number of publications about this subject before and after the start of our project in 1998. Because of the assumed heterogeneity of interventions, settings, patient populations and reported outcomes in combination with differences in guidelines, it was decided not to statistically pool the results of the studies.

\section{Results}

The search identified 397 publications for review of their abstracts that met the inclusion criteria. Of 261 references, full articles were obtained, except for one reference unavailable in Dutch libraries. Based on the selection criteria, a final set of 38 articles was obtained, describing 35 different systems.

Review articles $(n=38)$, studies that contained only a system description $(n=46)$, papers that described electronic patient records or imaging systems $(n=153)$ and systems that only generated printed reminders or summaries $(n=41)$ were excluded. Also articles that described systems that: were not automated $(n=21)$, only generated advice to non-physicians (patients, nurses or pharmacists) $(n=9)$, or were developed for students and educational purposes only $(n=35)$ were excluded. Finally, we excluded duplicates $(n=3)$ and 13 studies for other reasons.

More than one article on a single system were included if the articles described distinct aspects of the evaluation. Flanagan et al. $(26,27)$ and Goldberg et al. (28, 29) published two different evaluation studies in different papers about the same system. Safran et al. $(30,31)$ published the same study results twice (once in the Medinfo proceedings) and therefore these papers are counted as one study. Two papers $(32,33)$ contained two studies (or trials) and therefore 39 studies were included. Table 1 lists the 39 selected studies with the design, data collection method and the different attributes assessed in each study.

\section{Types of system.}

Eleven $(31 \%)$ of the selected articles concerned reminder systems (26-29, 34-42), ten $(29 \%)$ concerned critiquing systems $(32,43-51)$, four systems concerned suggesting systems $(52-56)$, two of the systems provided alerts $(57,58)$ and two provided information messages $(59,60)$. Information messages display relevant 
information about the patient or about the patient's treatment. Two systems combined alerts and reminders $(30,31,61)$, another two combined critiquing and reminder messages $(33,62)$ and one system combined four types of messages (alerting, critiquing, reminding and information messages) (63). Two systems were put into the wrong category according to the classification of decision support systems mentioned in the introduction $(9,10)$. Koide et al. (46) classified their system as a reminder system and Halkin et al. (43) classified their system as an alerting system, while in both studies a critiquing system was described.

A variety of information is displayed by the different systems. Fifteen systems displayed treatment recommendations $(30-32,35,41,42,44,48,52-56,62,63)$. Other information displayed was screening advice ( 5 systems $(29,34,37,38,40)$ ), drug interactions and/or adverse drug events (5 systems $(33,43,47,49,50)$ ), inappropriate care provided ( 4 systems $(39,45,46,61))$, critical laboratory results (2 systems $(57,58)$ ), vaccination advice (2 systems $(26,27,36)$ ), post test probability $(51,59)$ and drug allergies (2 systems $(33,49))$. The following information was displayed in only one system: cost effectiveness information (63), patient education (38), contra-indications of drugs (47), presence of infections (61) and LOS (Length Of Stay) (60). Six systems displayed two different types of information in their system $(38,47,49,52,61,63)$ and one system combined four different types of information in their system (33). Most of the systems (89\%) were implemented in hospitals (inpatient clinic). One was implemented in an outpatient clinic (34) and one in a community based clinic (43).

\section{Study designs \& data collection methods.}

Table 2 shows that a controlled before-after (CBA) study design was applied most frequently, whereas the multiple case study was only applied in one study (28). In one of the randomised controlled trials (RCTs) a crossover design was applied (27). Three of the CBA studies were randomised studies $(29,56,58)$. The level of randomisation of these studies was the patient (58), the physician (56) and the team or practice (29). The level of randomisation for the RCTs varied also from patient $(34,45,51,57,60)$, physician $(27,32,50)$ and team or practice $(31,33,35,39,40)$.

Besides the level of randomisation also the unit of analysis is important. The patient is most often the unit of analysis $(15,26,29,34-38,53-55,58)$. One of these studies clustered the results on the patient's level per physician (54). When patient outcome was evaluated, analysing the results on the level of the patient was correct. This occurred in three studies $(38,58,63)$. The physician was used as the level of analysis in 13 studies $(27,30,31,39,41,43,46,49-52,56,61)$. One of these studies corrected for the team the physician was in using a multi level analysis (39). Reminders or orders were used as the unit of analysis in 10 studies $(32,33,44,45$, $47,48,57,59,62)$ and the team or practice in onlly two studies $(28,40)$. 
Table 1. Description of included studies.

\begin{tabular}{|c|c|c|c|c|c|c|}
\hline Authors & $\begin{array}{l}\text { Study } \\
\text { design }\end{array}$ & $\begin{array}{l}\text { Systom } \\
\text { typo }\end{array}$ & Displayed & $\begin{array}{l}\text { Setting } \\
\text { (Country) }\end{array}$ & $\begin{array}{l}\text { Intervention } \\
\text { i) intervention group } \\
\text { c) control group }\end{array}$ & $\begin{array}{l}\text { a) physicians (n) } \\
\text { b) patients (n) } \\
\text { c) practices, units } \\
\text { (n) }\end{array}$ \\
\hline $\begin{array}{l}\text { Rind git } \\
1994(58)\end{array}$ & $\mathrm{CBA}$ & Alarts & $\begin{array}{l}\text { Reing creatinine } \\
\text { lever }\end{array}$ & $\begin{array}{l}\text { Mosipital } \\
\text { (USA) }\end{array}$ & $\begin{array}{l}\text { Drug prescribing, hest } \\
\text { ordering } \\
\text { i) Computerised alents } \\
\text { c) No interverition }\end{array}$ & $\begin{array}{l}\text { a) } 648 \\
\text { b) } 14130 \\
\text { c) } 1\end{array}$ \\
\hline $\begin{array}{l}\text { Kupeman et } \\
\text { al } 1999(57)\end{array}$ & RCT & Allerts & Coftutal lab results & $\begin{array}{l}\text { Hospital } \\
\text { (USA) }\end{array}$ & $\begin{array}{l}\text { Test ordering } \\
\text { i.) Computenised alerts } \\
\text { c) No intenvention }\end{array}$ & $\begin{array}{l}\text { a) ? } \\
\text { b) } 1412 \text { patient } \\
\text { days } \\
\text { c) } 1\end{array}$ \\
\hline $\begin{array}{l}\text { Safram et al: } \\
1995(30,31)\end{array}$ & RCT & $\begin{array}{l}\text { Alerts } \\
\text { Reminders }\end{array}$ & $\begin{array}{l}\text { Appropriate care } \\
\text { management }\end{array}$ & $\begin{array}{l}\text { Primary } \\
\text { care. } \\
\text { Hospital } \\
\text { (USA) }\end{array}$ & $\begin{array}{l}\text { Vaccination, Screening, } \\
\text { Therapy } \\
\text { 1) EPR with alerts and } \\
\text { reminders } \\
\text { c) EPR }\end{array}$ & $\begin{array}{l}\text { a) } 126 \\
\text { b) } 349 \\
\text { c) } 5\end{array}$ \\
\hline $\begin{array}{l}\text { Rowha et al } \\
2001(61)\end{array}$ & CBA & $\begin{array}{l}\text { Alerts * } \\
\text { Reminders }\end{array}$ & $\begin{array}{l}\text { Presence and } \\
\text { management of } \\
\text { infections }\end{array}$ & $\begin{array}{l}\text { lintensive } \\
\text { care. } \\
\text { Pediatrics, } \\
\text { Hospital } \\
\text { (USA) }\end{array}$ & $\begin{array}{l}\text { Detection } \\
\text { i) Computerised alents and } \\
\text { reminders } \\
\text { c) No intervention }\end{array}$ & $\begin{array}{l}\text { a) } 27 \text { physicians } \\
\text { supported by } 84 \\
\text { nurses } \\
\text { b) ? } \\
\text { c) } 3\end{array}$ \\
\hline $\begin{array}{l}\text { Pestotrik et } \\
\text { al. } 1996 \text { (63) }\end{array}$ & TS & $\begin{array}{l}\text { Alerts * } \\
\text { Ferninders + } \\
\text { Ofillquing + } \\
\text { Information }\end{array}$ & $\begin{array}{l}\text { Presence of infec- } \\
\text { tion, incorrect } \\
\text { dose, route or } \\
\text { interval: need for } \\
\text { testing, cost effec- } \\
\text { tiveness or } \\
\text { probability }\end{array}$ & Hospital & $\begin{array}{l}\text { Drug prescribing } \\
\text { i) EPR + computerised } \\
\text { allerts, ete. } \\
\text { c) - }\end{array}$ & $\begin{array}{l}\text { a)? } \\
\text { b) } 63759 \\
\text { c)? }\end{array}$ \\
\hline $\begin{array}{l}\text { Tiermey at al. } \\
1988(51)\end{array}$ & $\mathrm{RCT}$ & Critiquing & $\begin{array}{l}\text { Probablity estima- } \\
\text { tion of test results }\end{array}$ & $\begin{array}{l}\text { Hospital } \\
\text { (USA) }\end{array}$ & $\begin{array}{l}\text { Test ordering } \\
\text { i) Comptiterized critique } \\
\text { c) No intervention }\end{array}$ & $\begin{array}{l}\text { a) } 112 \\
\text { b) } 9496 \\
\text { c) ? }\end{array}$ \\
\hline $\begin{array}{l}\text { Bates et at } \\
1995(46)\end{array}$ & RCt & Crilitioung & $\begin{array}{l}\text { Redundant te:sts } \\
\text { (thme interval) }\end{array}$ & $\begin{array}{l}\text { Hospital } \\
\text { (USA) }\end{array}$ & $\begin{array}{l}\text { Test ordering } \\
\text { i) POE + compulterised } \\
\text { reminders } \\
\text { CIPOE }\end{array}$ & $\begin{array}{l}\text { a) ? } \\
\text { b) ? } \\
\text { c) ? }\end{array}$ \\
\hline $\begin{array}{l}\text { Conryelly at al. } \\
1996(40)\end{array}$ & $\mathrm{D}$ & Critiquing & $\begin{array}{l}\text { Foedback on } \\
\text { appropmateness } \\
\text { order: }\end{array}$ & $\begin{array}{l}\text { Hosphal } \\
\text { (USA) }\end{array}$ & $\begin{array}{l}\text { Test ordering } \\
\text { i) - } \\
\text { c) - }\end{array}$ & $\begin{array}{l}\text { a)? } \\
\text { b) ? } \\
\text { c)? }\end{array}$ \\
\hline $\begin{array}{l}\text { Leo mt al. } \\
1990(49)\end{array}$ & $D$ & Critiquing: & $\begin{array}{l}\text { Allwgy checking, } \\
\text { ditug thiteractions }\end{array}$ & $\begin{array}{l}\text { Hospital } \\
\text { US.A. }\end{array}$ & $\begin{array}{l}\text { Drug prescribing } \\
\text { i) - } \\
\text { c) - }\end{array}$ & $\begin{array}{l}\text { a) } 112 \text { physictans } \\
\text { supported by } 93 \\
\text { nurses } \\
\text { b) ? } \\
\text { c)? }\end{array}$ \\
\hline $\begin{array}{l}\text { Rotman at al } \\
1906(50)\end{array}$ & $\mathrm{RCT}$ & Critiquing & $\begin{array}{l}\text { Drug costs, } \\
\text { prescription } \\
\text { polloy, adverse } \\
\text { drug events }\end{array}$ & $\begin{array}{l}\text { Hospittal } \\
\text { (USA) }\end{array}$ & $\begin{array}{l}\text { Drug prescription } \\
\text { 1) EPR + computerised } \\
\text { critique } \\
\text { c) EPR }\end{array}$ & $\begin{array}{l}\text { a) } 37 \\
\text { b) ? } \\
\text { c)? }\end{array}$ \\
\hline
\end{tabular}


Tablle 1. Continued.

\begin{tabular}{|c|c|c|c|c|}
\hline Authors & $\begin{array}{l}\text { Impact on Physiciami } \\
\text { (OCM") }\end{array}$ & Patient outcome $\left(\mathrm{BCH} \mathrm{C}^{\mathrm{N}}\right)$ & $\begin{array}{l}\text { Organisation } \\
\text { (DCM })\end{array}$ & Conclusion \\
\hline $\begin{array}{l}\text { Rind al al. } \\
1994(58)\end{array}$ & $\begin{array}{l}\text { Time interval } \\
\text { Acceptance allerts (Q) }\end{array}$ & $\begin{array}{l}\text { Creatinine level, mortality } \\
\text { patient (D) }\end{array}$ & Costs ( $)$ LOS (D) & 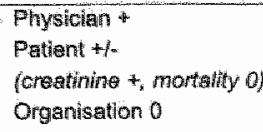 \\
\hline $\begin{array}{l}\text { Kuperman et al. } \\
1999(57)\end{array}$ & Time interval (CR) & $\begin{array}{l}\text { Frequency adverse } \\
\text { events (CRR) }\end{array}$ & & $\begin{array}{l}\text { Physician to } \\
\text { Patient o }\end{array}$ \\
\hline $\begin{array}{l}\text { Safran et al. } \\
1995(30,31)\end{array}$ & Response time (CR) & & $\begin{array}{l}\text { Hospltalisation rate } \\
\text { (CR) }\end{array}$ & $\begin{array}{l}\text { Physician * } \\
\text { Organisation * }\end{array}$ \\
\hline
\end{tabular}

Rocha at al. Advice followed (CR),

2001(61) Opinion (Q)

Pestotnik at al. Freq. Prescriptions

$1996(63) \quad(C R, D)$
ADE (antiblotics resistance), mortality $(C R, D)$

Casts [D]

Costs (D) 1996 (49) Satisfiaction (Q). quality documentation (D): changes in test ardering pattern (D)

Lee et al. Usage pattern (SR) Userulness (Q)

Rotman et al. Frequency use (D) $1996(50)$

Bates et al. Number of cancelled tests (CR)

Connelly et al. Number of orders (D) 1996 (40) 1995 (45) (D) Justiffication overrides

Tieney et al. Number of tests ordered $1988(51)$

(D)

interactions (D)

Frequency drug
interactions (D)

Costs (D)

Pryysician -

Patient 0

Organisation 0
Physician t.

Organisation *

Physician +

Physicien +

Organizatlon +

Physicitan +

(Satisfaction) 
Table 1. Continued.

\begin{tabular}{|c|c|c|c|c|c|c|}
\hline Author & $\begin{array}{l}\text { Shudy } \\
\text { disigh }\end{array}$ & $\begin{array}{l}\text { Siystem } \\
\text { lypo }\end{array}$ & Displayed & $\begin{array}{l}\text { Setting: } \\
\text { (Country) }\end{array}$ & $\begin{array}{l}\text { Interventitor } \\
\text { i) intervention group } \\
\text { c) conttroil group }\end{array}$ & $\begin{array}{l}\text { a) physicians (n) } \\
\text { b) patients (n) } \\
\text { c) practlces, units } \\
\text { (n) }\end{array}$ \\
\hline $\begin{array}{l}\text { Gothe of al } \\
1997(4) 5)\end{array}$ & $\mathrm{CBA}$ & Critiquing & $\begin{array}{l}\text { Treatment } \\
\text { advice }\end{array}$ & $\begin{array}{l}\text { Psychiatics } \\
\text { HIospillal } \\
\text { (USA) }\end{array}$ & $\begin{array}{l}\text { Drug presicribing test } \\
\text { ordering } \\
\text { b) Computerised critque } \\
\text { c) No intervention }\end{array}$ & $\begin{array}{l}\text { a) } 36 \\
\text { b) } 6077 \\
\text { c) } 1\end{array}$ \\
\hline $\begin{array}{l}\text { Harpole et } \\
\text { al. } 1907(32)\end{array}$ & $\mathrm{CBA}_{4}$ & Critiquing & $\begin{array}{l}\text { Appropriate } \\
\text { test order }\end{array}$ & $\begin{array}{l}\text { Maspifall } \\
\text { USAA) }\end{array}$ & $\begin{array}{l}\text { Test ordering } \\
\text { i) Computerised reminders } \\
\text { phase if } \\
\text { c) No intervention }\end{array}$ & $\begin{array}{l}\text { a) ? } \\
\text { b) } 681 \\
\text { c)? }\end{array}$ \\
\hline $\begin{array}{l}\text { Harpole ot } \\
\text { ail. } 1997(32)\end{array}$ & $\mathrm{RCT}$ & Critiquing & $\begin{array}{l}\text { Appropriate } \\
\text { teist order }\end{array}$ & $\begin{array}{l}\text { Howointal } \\
\text { UUSA) }\end{array}$ & $\begin{array}{l}\text { Test ordering } \\
\text { i) lmproved phase } 2 \\
\text { reminders } \\
\text { c) Computerised } \\
\text { reminders phase } 1\end{array}$ & $\begin{array}{l}\text { a)? } \\
\text { b) } 681 \\
\text { c) ? }\end{array}$ \\
\hline $\begin{array}{l}\text { Nightingale all } \\
\text { al. } 2000(47)\end{array}$ & D & Critiquing & $\begin{array}{l}\text { Drug-drug } \\
\text { Interiactions or } \\
\text { contuaindications: }\end{array}$ & $\begin{array}{l}\text { Hhospital } \\
\text { (UK) }\end{array}$ & $\begin{array}{l}\text { Drug presicribing } \\
\text { i) - } \\
\text { c) - }\end{array}$ & $\begin{array}{l}\text { a) } 18 \text { physicians } \\
\text { supported by } 34 \\
\text { nurses } \\
\text { b) } 1646 \\
\text { c) } 1\end{array}$ \\
\hline $\begin{array}{l}\text { Koide et al. } \\
2000(46)\end{array}$ & $\mathrm{CBA}$ & Criticuing & $\begin{array}{l}\text { Drug ardered willh. } \\
\text { oul normal AST/ } \\
\text { ALT test } \\
\text { result or AST/ALT } \\
\text { test ordered }\end{array}$ & $\begin{array}{l}\text { Hospital } \\
\text { (Japan) }\end{array}$ & $\begin{array}{l}\text { Test ondering } \\
\text { b) Computerised critique } \\
\text { c) No intervention }\end{array}$ & $\begin{array}{l}\text { a) } 21 \\
\text { b) ? } \\
\text { c) ? }\end{array}$ \\
\hline $\begin{array}{l}\text { a) Bates at al. } \\
1998(33)\end{array}$ & CBA & $\begin{array}{l}\text { Critiquing + } \\
\text { Reminders }\end{array}$ & $\begin{array}{l}\text { Drug-drug, drug- } \\
\text { allergy, drug-lab, } \\
\text { consequently lab } \\
\text { tests }\end{array}$ & $\begin{array}{l}\text { Hospital } \\
\text { (USA) }\end{array}$ & $\begin{array}{l}\text { Drug presicribing, test or- } \\
\text { dering } \\
\text { i) POE + team interwention } \\
\text { c) No intervention }\end{array}$ & $\begin{array}{l}\text { a)? } \\
\text { b)? } \\
\text { c) } 6\end{array}$ \\
\hline $\begin{array}{l}\text { 2) Bates ol al. } \\
1998(33)\end{array}$ & RCT & $\begin{array}{l}\text { Critiquing + } \\
\text { Remindiers }\end{array}$ & $\begin{array}{l}\text { Drug-drug, drug- } \\
\text { allergy, drug-lab, } \\
\text { consequently lab } \\
\text { tests }\end{array}$ & $\begin{array}{l}\text { Hospital } \\
\text { (USA) }\end{array}$ & $\begin{array}{l}\text { Drug prescribing test or- } \\
\text { dering } \\
\text { i) POE+team intervention } \\
\text { c) POE }\end{array}$ & $\begin{array}{l}\text { a) ? } \\
\text { b) ? } \\
\text { c) } 8\end{array}$ \\
\hline $\begin{array}{l}\text { Taloth al al. } \\
2000(62)\end{array}$ & Tis & $\begin{array}{l}\text { Critiouting th } \\
\text { Romindars }\end{array}$ & $\begin{array}{l}\text { Drug use guide- } \\
\text { lines, offering sug- } \\
\text { gestions hor ap- } \\
\text { propriate dosess } \\
\text { and frequencles }\end{array}$ & $\begin{array}{l}\text { Acmomic } \\
\text { hrospital } \\
\text { qUSA) }\end{array}$ & $\begin{array}{l}\text { Drug presicribing } \\
\text { ) CDSS added to a POE } \\
\text { c) - }\end{array}$ & $\begin{array}{l}\text { a)? } \\
\text { b)? } \\
\text { c)? }\end{array}$ \\
\hline $\begin{array}{l}\text { Halkn ot al. } \\
2001(43)\end{array}$ & CBA & Critiquing & Drug Interactions & $\begin{array}{l}\text { Communtly } \\
\text { based } \\
\text { practices } \\
\text { phrael }\end{array}$ & $\begin{array}{l}\text { Drug presicribing } \\
\text { i) critiquing tor } \\
\text { pharmacists , physicians } \\
\text { and pattients. } \\
\text { c) critiquing for } \\
\text { pharmacists }\end{array}$ & $\begin{array}{l}\text { a) } 5504 \\
\text { b) } 775186 \\
\text { c) ? }\end{array}$ \\
\hline $\begin{array}{l}\text { Shea et al. } \\
1996(60)\end{array}$ & ROT & Information & $\begin{array}{l}\text { Dilagnose rellated } \\
\text { awerage LOS and } \\
\text { actual LoS }\end{array}$ & $\begin{array}{l}\text { Hospital } \\
\text { (USA) }\end{array}$ & $\begin{array}{l}\text { LOS } \\
\text { i) Conputerised reminders } \\
\text { c) No interventian }\end{array}$ & $\begin{array}{l}\text { a) ? } \\
\text { b) } 14099 \\
\text { c)? }\end{array}$ \\
\hline $\begin{array}{l}\text { Sollonnon est } \\
\text { al. } 1999(59)\end{array}$ & CT & Information & $\begin{array}{l}\text { Post test } \\
\text { probability }\end{array}$ & $\begin{array}{l}\text { Hospital } \\
\text { qUSA }\end{array}$ & $\begin{array}{l}\text { Test ondering } \\
\text { i) Computer interwention } \\
\text { c) No intervention }\end{array}$ & $\begin{array}{l}\text { a) } 225 \\
\text { b) } 335 \\
\text { c)? }\end{array}$ \\
\hline
\end{tabular}


Table 1. Continued.

\begin{tabular}{llll}
\hline Authors & $\begin{array}{l}\text { Impact on Physician } \\
\left(\mathrm{OCM}^{*}\right)\end{array}$ & Patient outcome (DCM $)$ & Organisation \\
(DCWN) & Concluston
\end{tabular}

\section{Goethe et al. Number neminders (D)}

$1997(48)$

"Harpole et al. Charge rate (D),

$1997(32)$ cancellations (D)

3 Harpole et al. Change rate (D).

1997 (32) cancellatilians (D)

Potential impact of

cancelled films: positive tesil results (CR)

Nightingalo et Cancelled prescriptions

al. 2000 (47) (number of accepted

warnings) (D)

Satisfaction (Q)

Koide et al. Appropriate prescriptions, Abnomal test results (D) 2000 (46) Number of accepted

reminders (D)

2) Bates et al. Number of medication

$1998(33) \quad$ enrors (CR)

2) Bates el al. Number of medication

1998 (33) enrors (CR)

Teich ot al. Change in prescription

2000 (62) treatment (D)

Halkin et al. Number of drug

2004 (43) interactions (D).

Number of alents (D)

Shea ef al.

$1995(60)$

Solomon et al. Freq cancelled tests (D)

$1999(59)$

\author{
Physiciant \\ (Number of allents \\ decreased
}

Costs (?)

$?$

Phyeician th- pothinging

orders * cancelthy

ondars -

Pallent *

Organisation *

(6\% potentian savings )

Plrysicilan +

(Acoroptanco *)

Physicien +

Patient +

Phystolan +

Physician: 0

Pthystomete

Prinsician *

$\operatorname{LOS}(C R)$

Orgarisiation +

Physician * (small aftacl) 
Table 1. Continued.

\begin{tabular}{|c|c|c|c|c|c|c|}
\hline Authion & $\begin{array}{l}\text { Study } \\
\text { destign }\end{array}$ & $\begin{array}{l}\text { Syotem } \\
\text { typo }\end{array}$ & Displayed & $\begin{array}{l}\text { Setting } \\
\text { (Country) }\end{array}$ & $\begin{array}{l}\text { Intervention } \\
\text { 1) intervantion growp } \\
\text { c) control group }\end{array}$ & $\begin{array}{l}\text { a) physicians (n) } \\
\text { b) patients (n) } \\
\text { c) practices, units } \\
\text { (nj) }\end{array}$ \\
\hline 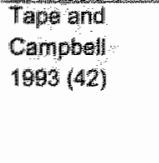 & $\mathrm{CT}$ & Reminders & $\begin{array}{l}\text { screenting and } \\
\text { wascination } \\
\text { rectimmendations }\end{array}$ & $\begin{array}{l}\text { lrttemal } \\
\text { medicine } \\
\text { Hospilal } \\
\text { (USA) }\end{array}$ & $\begin{array}{l}\text { Screening; Vacxination } \\
\text { i) EPR + computerised } \\
\text { reminders } \\
\text { c) Paper record + paper } \\
\text { Plow sheet }\end{array}$ & $\begin{array}{l}\text { a) } 49 \\
\text { b) } 1809 \\
\text { c) ? }\end{array}$ \\
\hline $\begin{array}{l}\text { Ornotein et at: } \\
1995(4) 1)\end{array}$ & CBA & Reminders & Treatment advice & $\begin{array}{l}\text { Hospital } \\
\text { (USA) }\end{array}$ & $\begin{array}{l}\text { Screening, Vacnination } \\
\text { i) EPR reminder system } \\
\text { c) No intervientiom }\end{array}$ & $\begin{array}{l}\text { a) } 23 \\
\text { b) } 822 \\
\text { c) } 1\end{array}$ \\
\hline $\begin{array}{l}\text { Dwathag ot } \\
1.1996(40)\end{array}$ & ROT & Reminders & $\begin{array}{l}\text { Preventive care } \\
\text { sugigested }\end{array}$ & $\begin{array}{l}\text { General } \\
\text { medicine, } \\
\text { Maspital } \\
\text { (USA) }\end{array}$ & $\begin{array}{l}\text { Vaccination, test ordering } \\
\text { Computerised reminders } \\
\text { c) No intenention }\end{array}$ & $\begin{array}{l}\text { a) } 78 \\
\text { b) } 1929 \\
24\end{array}$ \\
\hline $\begin{array}{l}\text { Owerhage } \\
\text { al. } 1997 \text { (39) }\end{array}$ & $\mathrm{RCT}$ & Reminders & Corollay orders & $\begin{array}{l}\text { General } \\
\text { medicine, } \\
\text { Hospital } \\
\text { (USA) }\end{array}$ & $\begin{array}{l}\text { Test ordering } \\
\text { i) Computeriged reminders } \\
\text { c) No interwention }\end{array}$ & $\begin{array}{l}\text { a) } 86 \\
\text { b) } 2181 \\
\text { c) ? }\end{array}$ \\
\hline $\begin{array}{l}\text { Curtinn at al. } \\
1998(38)\end{array}$ & $\mathrm{CBA}$ & Reminders & $\begin{array}{l}\text { Screening done? } \\
\text { (patten aducation) }\end{array}$ & $\begin{array}{l}\text { Haspital } \\
\text { (USA) }\end{array}$ & $\begin{array}{l}\text { Vaccination, education } \\
\text { i) Comptherised neminders } \\
\text { c) No intervention }\end{array}$ & \\
\hline $\begin{array}{l}\text { Morgan at al. } \\
1998(37)\end{array}$ & $C B A$ & Reminders & Sicreening done? & $\begin{array}{l}\text { Primary } \\
\text { cang, Hospi- } \\
\text { tal (USA) }\end{array}$ & $\begin{array}{l}\text { Screening, test ordering } \\
\text { i) Computerised reminders } \\
\text { c) No intervention }\end{array}$ & $\begin{array}{l}36 \\
\text { a) } 24200 \\
\text { c) ? }\end{array}$ \\
\hline $\begin{array}{l}\text { Flanagan et } \\
\text { al. } 1999(27)\end{array}$ & $\mathrm{RCT}$ & Reminders & $\begin{array}{l}\text { waccination } \\
\text { necessary }\end{array}$ & $\begin{array}{l}\text { Primary } \\
\text { carie clinic } \\
\text { (USA) }\end{array}$ & $\begin{array}{l}\text { Vaccination } \\
\text { 1) Computerised reminders } \\
\text { c) No intervention }\end{array}$ & $\begin{array}{l}\text { a) } 93 \\
\text { b) } 817 \\
\text { c) ? }\end{array}$ \\
\hline $\begin{array}{l}\text { Halanagan } \\
\text { and Walker } \\
1990(26)\end{array}$ & CBA & Reminders & $\begin{array}{l}\text { vaccination } \\
\text { nocessary }\end{array}$ & $\begin{array}{l}\text { Pitmary } \\
\text { ciare clinic } \\
\text { (US,A }\end{array}$ & $\begin{array}{l}\text { Vaccination } \\
\text { i) Compulerised reminders } \\
\text { c) No intervention }\end{array}$ & $\begin{array}{l}\text { a)? } \\
\text { b) ? } \\
\text { c)? }\end{array}$ \\
\hline 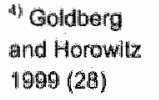 & MCS & Reminders & Serening done? & $\begin{array}{l}\text { Primary } \\
\text { care clinic } \\
\text { (USA) }\end{array}$ & $\begin{array}{l}\text { Screaning } \\
\text { l) - } \\
\text { c) - }\end{array}$ & $\begin{array}{l}\text { a)? } \\
\text { b)? } \\
\text { c) } 2 ?\end{array}$ \\
\hline $\begin{array}{l}\text { Tiang at al. } \\
\text { 1999 }(36)\end{array}$ & $\mathrm{CBA}$ & Reminders & $\begin{array}{l}\text { Vacionation } \\
\text { mocessary }\end{array}$ & $\begin{array}{l}\text { Internall } \\
\text { medicime } \\
\text { clinic (USA) }\end{array}$ & $\begin{array}{l}\text { Vaccination } \\
\text { i) EPR with computerised } \\
\text { reminders } \\
\text { c) Paper recond without } \\
\text { reminders. }\end{array}$ & $\begin{array}{l}\text { a) } 23 \\
\text { b) } 981 \\
\text { c) ? }\end{array}$ \\
\hline $\begin{array}{l}\text { Ganon and } \\
\text { Allan } 2000 \\
\text { (34) }\end{array}$ & $\mathrm{RCT}$ & Reminders & $\begin{array}{l}\text { Advice to screen } \\
\text { patient }\end{array}$ & $\begin{array}{l}\text { Outpatient } \\
\text { mential cinic: } \\
\text { (USA) }\end{array}$ & $\begin{array}{l}\text { Screening } \\
\text { 1) Computerised reminders } \\
\text { c) Manual reminders } \\
\text { (paper checiknist) }\end{array}$ & $\begin{array}{l}\text { a) } 4 \\
\text { b) } 78 \\
\text { c) } 1\end{array}$ \\
\hline $\begin{array}{l}\text { Demakis ot at. } \\
2000(35)\end{array}$ & $\mathrm{RCT}$ & Reminders & Appropriale care & $\begin{array}{l}\text { Ambulatory } \\
\text { care clinic } \\
\text { (USA) }\end{array}$ & $\begin{array}{l}\text { Screening, drug } \\
\text { prescribing, test ordering } \\
\text { i) Computierised reminders } \\
\text { c) no intervention }\end{array}$ & $\begin{array}{l}275 \\
\text { b) } 12989 \\
\text { c) } 12\end{array}$ \\
\hline
\end{tabular}


Table 1. Continued.

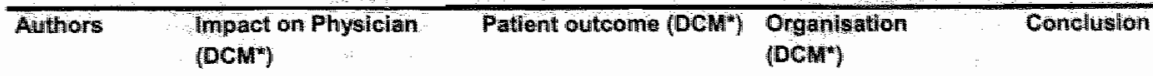

$\begin{array}{ll}\text { Tape and } & \text { Compliance to guldelines: } \\ \text { Campbell } & \text { screening, waccination } \\ 1993(42) & \text { done? (D) }\end{array}$

Ornstein et al. Adherence rate (D). 1995 (41) Usage (SR) User satisfaction (Q, $)$

Dverhage et al. Compliance to guidellines: $1996(40)$

$\%$ of prewentive care services carried out (D), opinion preventive ciare service (Q)

Overinage et al. Complance to guidelines: Creatinine !evel (D) 1997 (39) suggested tests ordered (D)

$1998(38)$

Morgan et al. Compliance to guidelines: $1998(37)$ screening carried out (D)

3) Flanagan et Frequency waccination (D): al. $1999(27)$

3) Flanagan

Frequency vaccination (D) and Walker

1999:(20)

4) Goldberg and Horowitz $1999(28)$

Tiang et al. 1999 (30)

User satisfaction $(0,1)$

Frecuency of vaccination

$\left(D_{1}, C R\right)$, altitude to

preventive health care (O)

Carnon and Screening rates (D),

Allen completeness of

$2000(34)$ documentation (CR, D)

Demakis et al. Adherence rate $(\mathrm{D}, \mathrm{CR})$

$2000(35) \quad$ Attitude to guidelines (Q)
Provided preventive senvices by physician (Q)

LOS. casts, inumber of pharmacist interwentions (D)

Quality of Life $(Q)$, patients's self management (CR)

Physicign *

(Complience better but far from perfect

Physician +

User satisfaction

Patient 0

Physician 0

Physictian +

Patient 0

Organsisiation $+\%$

rcosts 0, Los and phemima. cists intarvantions +)

Patient +

Organisiation + disease (Q)

Physician *

(for mosil guidelines)

Plysician +

Phys

Prodess $(0,1)$

Physiclian + (User siatigfaction +$)$ Organisation?

Physuldant

Physician +

Physiciar +

(ractine compliance over (trves) 
Table 1. Continued.

\begin{tabular}{|c|c|c|c|c|c|c|}
\hline Authiots & $\begin{array}{l}\text { Studiy } \\
\text { design }\end{array}$ & $\begin{array}{l}\text { Syrsiom } \\
\text { type }\end{array}$ & Dhsiplayed & $\begin{array}{l}\text { Settinig } \\
\text { (Country) }\end{array}$ & $\begin{array}{l}\text { Interwention } \\
\text { Dintenwention group } \\
\text { c) control group }\end{array}$ & $\begin{array}{l}\text { a) physicians (n) } \\
\text { b) patients (n) } \\
\text { c) practices, units } \\
\text { (n) }\end{array}$ \\
\hline $\begin{array}{l}\text { Goldoerg et } \\
\text { dil } 2000(29)\end{array}$ & CQA & Reminders & Screening done? & $\begin{array}{l}\text { Primary care } \\
\text { chinc (USA) }\end{array}$ & $\begin{array}{l}\text { Screienting } \\
\text { i) Printed and computier- } \\
\text { ised reminders } \\
\text { c) No intervention }\end{array}$ & $\begin{array}{l}\text { a) } 42 \\
\text { b) } 2655 \\
\text { c) } 2\end{array}$ \\
\hline $\begin{array}{l}\text { Day at } \\
1995(53)\end{array}$ & $\mathrm{CBA}$ & Suggesting & $\begin{array}{l}\text { Appropriate tests } \\
\text { and treatments }\end{array}$ & $\begin{array}{l}\text { Emergency } \\
\text { department, } \\
\text { Hospital } \\
\text { (USA) }\end{array}$ & $\begin{array}{l}\text { Drug prescribing, test or- } \\
\text { dering } \\
\text { if Computerised reminders } \\
\text { c) No intervention }\end{array}$ & $\begin{array}{l}\text { a)? } \\
\text { b)? } \\
\text { c)? }\end{array}$ \\
\hline $\begin{array}{l}\text { Shiffrnan et } \\
\text { at: } \\
1999(52)\end{array}$ & CBA & Suggesting & $\begin{array}{l}\text { Sewerity discase } \\
\text { and management } \\
\text { recommendations }\end{array}$ & $\begin{array}{l}\text { Podiatric } \\
\text { prinary care } \\
\text { clinic (USA) }\end{array}$ & $\begin{array}{l}\text { Drig prescribing } \\
\text { in Handheld computers with } \\
\text { guidelines aidwice } \\
\text { c) No intervention }\end{array}$ & $\begin{array}{l}\text { a) } 9 \\
\text { b) ? } \\
\text { c)? }\end{array}$ \\
\hline $\begin{array}{l}\text { Sichriger et al. } \\
2000(54)\end{array}$ & CBA & Suggesting & $\begin{array}{l}\text { Gulldeline recom } \\
\text { mendations }\end{array}$ & $\begin{array}{l}\text { Energency } \\
\text { department, } \\
\text { Hospital } \\
\text { (USA) }\end{array}$ & $\begin{array}{l}\text { Test ordering, therapy. } \\
\text { diagnoses } \\
\text { i) Computerised } \\
\text { suggestions } \\
\text { c) No intervention }\end{array}$ & $\begin{array}{l}\text { a) } 185 \\
\text { b) } 830 \\
\text { c) } 1\end{array}$ \\
\hline $\begin{array}{l}\text { Shiffmarn at } \\
\text { aㅏ. } 2000(56)\end{array}$ & CBA & Suggesting & $\begin{array}{l}\text { Guldeline reom- } \\
\text { mendatioms }\end{array}$ & $\begin{array}{l}\text { Pediatrics } \\
\text { Primany care } \\
\text { dinic (USA) }\end{array}$ & $\begin{array}{l}\text { Drug prescribing } \\
\text { 1) Computerised reminders } \\
\text { c) No intervention }\end{array}$ & $\begin{array}{l}\text { a) } 9 \\
\text { b) } 165 \\
\text { c)? }\end{array}$ \\
\hline $\begin{array}{l}\text { Bonaud el al. } \\
2001(55)\end{array}$ & CBA & Suggesting & $\begin{array}{l}\text { Treatment recom- } \\
\text { mendations }\end{array}$ & $\begin{array}{l}\text { Oncology } \\
\text { Hospiltal } \\
\text { (France) }\end{array}$ & $\begin{array}{l}\text { Therapy } \\
\text { i) Computerised } \\
\text { suggestions } \\
\text { c) No intervention }\end{array}$ & $\begin{array}{l}\text { a) } 13 \\
\text { b) } 127 \\
\text { c) }\end{array}$ \\
\hline
\end{tabular}

1) "2) "3) "St Studies that arre related are marthed with the same number. "and "2t are accounted as two studies arid ${ }^{35}$ and ${ }^{4)}$ are accounted as one system.

DCM $*$ Data collection method CDSS = Clinical docision support system, POE = Physician order entry, $\mathrm{EPR}=$ Electronic patlent record.

Design: RCT = Randomised controlled Irial, $\mathrm{CBA}=$ Controlled before after study, $\mathrm{TS}=$ time series, MCS $=$ Multiple case study, $\mathrm{D}=$ descriptive study, $\mathrm{CT}=$ Controlled trial. 
Table 1. Continued.

\begin{tabular}{|c|c|}
\hline Authors & $\begin{array}{l}\text { Impact on Physician } \\
\text { (DCMik) }\end{array}$ \\
\hline 4) Goldberg ef & Screening frequency (D) \\
\hline
\end{tabular}

al. $2000(29)$

Day et a Compliance to guidelines:

4995 (53) Appropriate tests/dugs

ordered, freq. tests/drugs

ordered, dociumentation

(CR, D)

Shiffman et al. Usage (SR), experience,

$1999(52) \quad$ satisfaction, frustration,

self assessed changes,

desirability of

functionalities (Q)

Schriger et al. Documentation quality. 2000 (54) approprate testing and treatment $(D, C R)$

Shiffman et al. Frequency of wisit, $2000(515)$ duration visit, measure ments done (adherence to guideline) (SR)

Number of diays absent from school mortality (Q)

\section{Costs (O)}

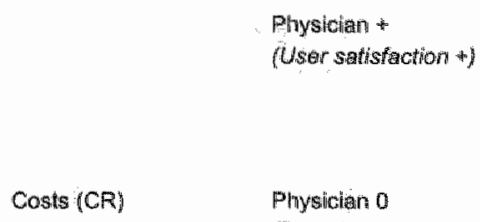

$$
\text { Costs (CR) }
$$

Paysictiatin w

User satisfaction in

Conelugion

(DCMIt)

Phyrigitian $4 \%$

(Diffarent w affects on whongt soreming procedures)

Physicion +

Organistation 0

Number of hospitai vis- Physician *

its, number of

Patient 0

re-visits to the praclice, Organilisation $+/$ -

costs (a) costs - of

Physician *

Bowaud et al. Compliance to guidelines: $2001(55)$ approprate decisions. Modification preseription (?)

intervention: $=$ not applicablle:? $=$ not reported.

Data collection method: $\mathrm{D}=$ Database, $\mathrm{CR}=$ Chart Review, $\mathrm{Q}=$ Questionnaire, $\mathrm{SR}=$ Selt Reported, I Interviews, $0=$ Observations.

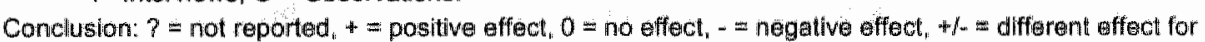
different outcome measures. 
Data collection methods varied by retrieval from querying databases, chart review, questionnaires, self reported usage, observations and open-end interviews (table 2). Data retrieval from querying databases and chart review are the most used data collection methods. Interviews and abservations are less often used. Overall, the impact of the system on the physician was evaluated in $95 \%$ of the studies (table 3 ). The absolute number of published studies increased when comparing the period 1988 to 1998 (a mean of 1.7 studies per year) with the period 1998 and afterwards (a mean of 5.5 studies per year). The percentage of studies evaluating the impact on the patient and the impact on the organisation decreased over the years when studies before and after 1998 are compared.

Table 2. Data collection method per study design.

\begin{tabular}{llllllll}
\hline & n & \multicolumn{7}{c}{ Data collection method } \\
\cline { 3 - 8 } & & D & CR & Q & SR & 1 & 0 \\
\hline CBA & 18 & 12 & 7 & 7 & 3 & 1 & \\
RCT & 13 & 11 & 8 & 3 & & & \\
Non randomised CT & 2 & 2 & & & & & \\
Descriptive & 3 & 2 & & 2 & 1 & & \\
Time series & 2 & 2 & 1 & & & & \\
Muiltiple case study & 1 & & & & & 1 & 1 \\
\hline Total & 39 & 29 & 16 & 12 & 4 & 2 & 1 \\
\hline
\end{tabular}

$D=$ Database,$C R=$ Chart Review, $Q=$ Questionnaire, $S R=$ Self Reported, $I=$ Interviews, $O=$ Observations

Table 3. Aspects measured before and after 1998. Number of trials and percentage of the total number of trials.

\begin{tabular}{llll}
\hline & \multicolumn{1}{l}{$1988-1998(n=17)$} & $\begin{array}{l}\text { 1998 and after- } \\
\text { wards }(n=22)\end{array}$ & $\begin{array}{l}\text { Overall } \\
(n=39)\end{array}$ \\
\cline { 2 - 4 } & $\%$ of total $(n)$ & $\%$ of total $(n)$ & $\%$ of total $(n)$ \\
\hline Impact on physician & $94 \%(16)$ & $95 \%(21)$ & $95 \%(37)$ \\
Impact on patient & $35 \%(6)$ & $18 \%(4)$ & $26 \%(10)$ \\
Impact on organisation & $54 \%(10)$ & $18 \%(4)$ & $36 \%(14)$ \\
\hline
\end{tabular}

Various data collection methods were used to obtain the data (table 4). In 9 studies different data collection methods were used to measure certain attributes of the impact on the physician $(18,35,36,40,41,47,49,61)$. Goldberg et al. used two data collection methods to measure one attribute of the impact on the physician (user satisfaction), namely interviews and observations (28). Database retrieval was the most frequently used data collection method for all three aspects. Questionnaires were mostly used to measure user satisfaction (6 studies (18, 40, $41,47,49,61)$ ). Table 5 shows that for all types of CDSSs the majority of the 
articles report positive effects on physicians' performance. Of the studies that measured physicians' performance, patient outcome and/or organisational aspects, the majority showed positive results for the aspect measured. An exception were systems that generate suggestions. The effects on patient care and organisation are ambiguous or even absent for these systems.

Table 4. Data collection method per aspect.

\begin{tabular}{lccccccc}
\hline & $\mathbf{n}$ & \multicolumn{7}{c}{ Data collection method } \\
\cline { 3 - 8 } & & $\mathrm{D}$ & $\mathrm{CR}$ & $\mathrm{Q}$ & $\mathrm{SR}$ & 1 & $\mathrm{O}$ \\
\hline Impact on physician & 37 & 24 & 11 & 10 & 4 & 2 & 1 \\
Impact on patient & 10 & 6 & 5 & 3 & 1 & & \\
Impact on organisation & 14 & 7 & 4 & 1 & 1 & 1 & 1 \\
\hline Total & & 33 & 20 & 13 & 6 & 3 & 2 \\
\hline
\end{tabular}

$D=$ Database, $C R=$ Chart Rewiew, $Q=$ Questionnaire, $S R=$ Self Reported, $1=$ Interviews, $O=$ Obserwations

Table 5. Number of studies with positive effects* (in the numerator) of the total number of studies that studied the aspect (in the denominator) per system type.

\begin{tabular}{lllll}
\hline System & n & Physician & Patient & Organisation \\
\hline Reminder & 19 & $16 / 18$ & $2 / 4$ & $4 / 5$ \\
Critiquing & 15 & $12 / 15$ & $3 / 4$ & $4 / 5$ \\
Alerting & 5 & $4 / 5$ & $2 / 3$ & $2 / 3$ \\
Suggesting & 5 & $4 / 5$ & $0 / 1$ & $1 / 3$ \\
Information & 3 & $2 / 2$ & $1 / 1$ & $2 / 2$ \\
\hline
\end{tabular}

" positive effect is defined as + or $+1 \%$ in table 1 and negative effect is defined as - in table 1

\section{Impact on the physician}

The impact on the physician was studied in 37 studies. The most frequently addressed topics were if advice of the system was accepted and if the advice resulted in the application of appropriate care (or a change in treatment of the patient). Eight studies investigated the physician's satisfaction with the system (18, $28,40,41,47,49,50,61)$, the attitude towards guidelines (35) or towards screening services (36) and the acceptance of the recommendations provided (47).

The majority of the studies showed a positive effect of the system on the performance of the physician ( 28 systems). Of those studies, six reported that users were satisfied about the system and/or the acceptance of the system was positive $(18,28,41,47,49,58)$. However, Rotman et al. (50) reported that when a critiquing system was coupled to an existing electronic patient record (EPR), the satisfaction of the users decreased with the combined system. Goethe et al. concluded that their system was effective and that the number of recommendations presented 
decreased over time indicating that the users learnt from the system (48). In contrast, Demakis et al. found that there was a decrease in compliance with the recommendations over time (35). They mentioned the competing demands on the physicians' time in a busy clinic and the lack of feedback concerning the performance of the physician (for instance the change in degree of adherence to the guidelines) Using the CDSS as two possible explanations. Two studies found mixed effects. Harpole et al. reported that their CBA study resulted in a positive effect on changing orders, but no decrease in unnecessary orders (32). Goldberg et al. reported different effects for different screening procedures (29). Finally, four studies found no effect on the behaviour of the physician $(33,40,54,61)$.

\section{Impact on the patient}

The impact on the patient was investigated in 10 studies. A variety of aspects were investigated. Apart from medical consequences such as mortality level, adverse events and creatinine level, other factors such as quality of life (38), patients" selfmanagement and the services provided by physicians as experienced by the patients (41) were measured. Five studies reported positive effects on patient outcome $(32,38,46,58,63)$ while five authors reported no effect $(39,41,50,56$, 57). Two authors studied abnormal test outcomes $(32,46)$. Harpole et al. (32) clearly demonstrated that cancellation of requested films that were discouraged by the system had no negative effects for the patients' disease management. Effects of using the system for monitoring the creatinine level, adverse events and mortality were ambiguous. One of the authors found a positive effect of an alerting system that reacts on rising creatinine levels in hospitalised patients receiving nephrotoxic or renally excreted medications (58) while other authors found no effect using a system that gives feedback about corollary orders $(39,50,57)$ or an alerting system on critical laboratory results $(39,50,57)$. One author observed a decrease in adverse events $(63)$ and two found no effect on adverse events $(39,50,57)$. Finally, two authors found no effect on patient mortality $(56,58)$ while Pestotnik et al. $(63)$ found a positive effect on patient mortality.

\section{Impact on the health care organisation}

Fourteen studies measured the impact on the health care organisation. Costs of the care provided were most frequently measured ( 8 studies $(32,39,44,50,51,53,54$, $56,58,63))$. Length of stay (LOS) in the hospital (4 studies $(39,58,60,63))$ and hospitalisation rate $(3$ studies $(30,31,38,56))$ were also frequently measured attributes. Shiffman et al. and Curtin et al. studied the hospitalisation rate for the management of asthma $(30,31,38,56)$ while Safran et al. studied the hospitalisation rate for the management of HIV infections. Other attributes, such as the number of pharmacist's interventions (39), number of visits or re-visits to the practice (56) and the process of providing patient care (28) were mentioned less 
frequently.

Only four authors found a reduction in costs as a result of the use of a CDSS (32, $44,51,63$ ). However, Harpole et al. (32) mentioned that only $6 \%$ of the potential savings were realised. Four other studies did not report any change in costs $(50,53$, 54,58 ) while Overhage et al. concluded that the charges per visit increased (39). Also, the reported effect on LOS was ambiguous. Three studies reported no effect on the LOS in the hospital $(39,58,63)$. In contrast, the system studied by Shea et al. (60) that displayed informative messages about the patients' LOS resulted in a significant reduction of the LOS. Finally, mixed effects of this type of CDSS on the hospitalisation rate of the patient were also reported. Shiffman et al. (56) reported no effect on the hospitalisation rate while Safran et al. $(30,31)$ and Curtin et al. (38) showed that the hospitalisation rate decreased.

\section{Discussion}

The review was performed to identify which aspects were investigated in studies concerning CDSSs and how they were obtained in terms of data collection methods and study designs. Most studies concerned reminder systems, which remind a physician to perform a task, or critiquing systems which evaluate the physicians' decision.

The impact on the physiclan of a CDSS was studied most often. Adherence to guidelines and change in behaviour were the most frequently measured variables in this respect. Only a few studies focused on user satisfaction with the CDSS, whille only one study focused on the user acceptance of and user satisfaction with the provided recommendations. Seven out of eight papers which described user satisfaction reported satisfied users and a positive effect on physicians' behaviour. One study reported that their users were not satisfied and therefore did not use the system frequently. These authors found no impact on physicians' behaviour (50). Only Bouaud et al. reported that although physicians agreed on $96 \%$ of the recommendations, they only followed $65 \%$ of them (55). The reasons for these discrepancies were not reported. None of the studies in this review focused on the reasons for non-adherence by physicians to the advice of the system. A review by Kaplan et al. also concluded that reasons why systems fail to be effective are missing (19). Knowledge of these reasons may lead to improvement of the comments and as a result may improve the acceptance of the advice of the system.

Most evaluations of CDSSs were before-after studies ( $46 \%$ ) but a substantial part of the studies were randomised controlled trial (33\%). However, in these trial designs, often the unit of allocation and the unit of analysis were applied incorrectly. When the intervention focused on influencing the behaviour of a physician's work within a practice (or team), randomisation and analysis at the level of the practice is the best option $(21,64-66)$. Only few studies randomised and analysed on practice level or 
corrected for the incorrect level of analysis. This may result in an over-estimation of the effect measured (64).

Overall, all types of recommendation systems had positive effects on the physicians' performance, patient outcome and organisation aspects. However, the number of alerting, suggesting and information systems used in daily practice is low and the effect on patient and organisation were too infrequently measured to draw generally valid conclusions.

Given the number of systems, interventions, displayed information, number of participants and the intervention period, this review highlights the heterogeneity of study designs, of data collection methods and attributes measured that determine the effectiveness of these CDSSs. Even when one outcome, such as adherence to guidelines, was assessed in several studies, a variety of different variables and data collection methods were used. Most of the studies were carried out in hospitals. No evaluation studies in primary care practices were found where the morbidity and problems of the patients are different from those in hospitals.

Despite our extensive literature search, we could have missed some studies. The designation of CDSSs is variable and many different terms are used, for example 'decision support systems', 'physician order entry systems (POE)' or "automated feedback systems'. A range of search terms were included, but we might have missed some studies that used a different description for their system. Even the use of MESH-terms does not completely rule out the possibility of studies missed. Furthermore, the apparent effectiveness of the aspects taken into account may have been overestimated due to the possibility of publication bias (67).

Previous reviews of CDSSs have focused on preventive care only, effects on physician only or on methodological issues (22-24). The impact on the patient and/ or the organisation were not reported in these papers. Nevertheless, their findings that CDSSs are effective in influencing the physician are consistent with this review. Four other reviews, which focused on more than one aspect, also concluded that measuring impact on patient care and organisation is under-evaluated in the studies they included $(13,14,18,24)$. None of these reviews compared the effectiveness for different types of decision support systems that generate recommendations to physicians.

The impact of critiquing and reminder systems on the performance of the physician in a hospital environment has been studied extensively over the past years. These studies clearly showed positive effects on physicians' performance. However, evaluations about systems that generate on screen recommendations in primary care practices, about systems that measure patient outcome and about the impact 
on the organisation are less frequently described in the literature. Furthermore, more emphasis should be put to the question why physicians do or do not accept the advice of the CDSS. Quantitative research techniques are not enough to study these aspects. Hence, we have to focus more on combining quantitative and qualitative research methods to understand the clinical use effectiveness and acceptance of these systems.

\section{References}

4. Davis DA, Taylor VA. Translating guidelines into practice. A systematic rewiew of theoretic concepts, practical experience and research evidence in the adoption of clinical practice guidelines. CMAJ 1997;157(4):408-16.

2. Davis $D A$, Thomson MA, Oxman $A D$, Haynes $R B$. Changing physician performance: $A$ systematic review of the effect of continuing medical education strategies. Journal of the American Medical Association 1995;274(9):700-705.

3. Grimsthaw JM, Russell IT. Effect of clinical guidelines on medical practice: a systematic peview of rigorous evaluations. Lancet 1993;342:1317-1322.

4. Woolf SH, Grol R, Hutchinson A, Eccles M, Grimsthaw J. Clinical guidelines: potential benefits, limitations, and harms of clinical guidelines. British Medical Journal 1999;318:527-530.

5. Grol R, Dalhuijsen J, Thomas $S$, Veld $C$, Rutten $G$, Mokkink $H$. Attributes of clinical guidelines that influence use of guidelines in general practice: observational study. British Medical Journal $1998 ; 317(7162): 858-61$.

6. Cabana MD, Rand CS, Powe NR, Wu AW, Wilson MH, Abboud PC, et al. Why don't physicians follow clinical practice guidelines?: A framework for improvement. Journal of the American Medical Association 1999,282:1458-1465.

7. Buntinx $F$, Winkens $R$, Grol $R$, Knottnerus $J A$. Influencing diagnostic and preventive performance in ambulatory care by feedback and reminders. A review. Family Practice 1993;10(2):219-228.

8. Wensing $M$, van der Weijden $T$, Grol R. Implementing guidelines and innovations in general practice: which interventions are effective? British Journal of General Practice 1998;48:991997.

9. Pryor TA. Development of decision support systems. International Journal of Clinical Monitoring and Computing 1990;7:137-146.

10. Randaiph $A G$, Haynes RB, Wyatt JC Cook DJ, Guyatt $G H$. Users' guides to the medical literature: XVIII. How to use an article evaluating the olinical impact of computer-based clinicall decision support system. JAMA 1999:282:67-74.

11. Friedman CP, Wyatt JC. Evaluation Methods in Medical Informatics. Now York: Springer* Verlag: 1997.

12. Langton KKB, Johnston ME, Haynes RB, Methieu A. A critical appraisal of the literature on the effects of computer-based clinical decision support systems on clinician performance and patient outcomes. Proceedings / AMIA Annual Fall Symposium 1992:626 630.

13. Johnston ME, Langton $\mathrm{KB}$, Haynes RB. Mathieu A. Effects of computer-based clinical decision support systems on clinician performance and patient outcome: A critical appraisal of research. Annals of Internal Medicine 1994:120:135-142.

14. Hunt DL, Haynes RB. Hanna SE, Smith K. Effects of computer-based clinical decision support systems on physician performance and patient outcomes: a systematic review. JAMA $1998 ; 280(15): 1339-1346$.

15. Payne TH. Computer decision support systems. Chest 2000;118(2 suppl):47S-52S.

16. Elson RB, Connely PD. Computerized decision support systemis in primary care. Primary Care 
$1995: 22(2) ; 365-384$

17. Elson RB. Connelly DT. Applications of computer-based clinical guidelines. Journal of the American Medical Association 1998;279 (13):989-989.

18. Shiffman $R N$, Liaw $Y$. Brandt $C A$, Corb $Q J$. Computer-based guideline implementation systems: A systematic review of functionality and effectiveness. JAMIA 1999;6(2):104-114.

19: Kaplan B. Evaluating informatics applications - clinical decision support systems fiterature review. International Journal of Medical Informatics 2001:64(1):15-37.

20. Reisman $Y$. Computer-based clinical decision aids. A review of methods and assessment of systems, Medical Informatics 1996;21(3):179-197

21. Chuang J, Hripcsak $G$, Jenders RA. Considering clustering: A methodological review of clinical deciston support system studies, In: Proceedings / AMIA Annual Fall Symposium; 2000: 2000. p. 146-150.

22. Austin $S M_{1}$ Balas $E A_{i}$ Mitchell $J A_{i}$ Ewingman $B G$. Effect of physician reminders on preventive care: Meta-analysis of randomized clinical trials. Proceedings of the Annual Symposium on Computer Applications in Medical Care 1994;18:121-124.

23. Shea $S$, DuMouchel $W$. Bahamonde $L$. A meta-analysis of 16 randomized controlled trials to evaluate computer-based clinical reminder systems for preventive care in the ambulatory setting. JAMIA 1996;3(6),399-409.

24. Balas EA, Weingarten $S$, Garb $C T$, Blumenthal D, Boren SA, Brown GD. Improving preventive care by prompting physicians. Archives of Internal Medicine 2000; 160(3):301-308.

25. Balas EA, Austin SM, Mitchell JA, Ewigman BG, Bopp KD, Brown GD. The clinical value of computerized information services. A review of 98 randomized clinical trials. Archives of Family Medicine $1996 ; 5(5): 271-8$.

26. Flanagan J-R, Waker K-P. Tracking vaccine compliance in a primary care setting: online thistory, reminders, order entry, and charting. Proc AMIA Symp 1999:760-4.

27. Flanagan J-R, Doebbeling BN, Dawson J, Beekmann $S$. Randomized study of online vaccine reminders in adult primary care. Proc AMIA Symp 1999:755-759.

28. Goldberg $H-I_{;}$Horowitz $C-R$. Musings on using evidence to guide CQl efforts toward success: the computerized firm system as primary care microunit. Jt Comm J Qual Improv 1999;25 (10):529-38.

29. Goldberg $H H_{i}$ Neighbor WE, Gheadle AD, Ramsey SD, Diehr $P$, Gore E. A controlled timeseries trial of clinical reminders: using computerized firm systems to make quality improvement research a routine part of mainstream practice. HeHealth Services Research 2000;34(7);15191534.

30. Safran C, Rind D-M, Davis R-B, Sands D-Z, Caraballo E, Rippel K, al A chinical trial of a knowledge-based medical record. Medinfo 1995;8:21076-80.

31. Safran $C$, Rind DM, Davis RB, Iwes D, Sands $D Z$, Currier $J$, al Guidelines for management of HV infection with computer-based patient's record. Lancet 1995:346(8971):341-346.

32. Harpole L-H, Khorasan $R$, Fiskio J, Kuperman G-J. Bates D.W. Automated evidence-based critiquing of orders for abdominal radiographs" impact an utilization and appropriateness. $J \mathrm{Am}$ Med Inform Assoc 1997:4(6),511-21.

33. Bates DW, Leape $L L$, Cutlen DJ, Laird N, Petersen $L A$, Teich $\mathrm{JM}_{3}$ et al. Effect of Computerized Physician Order Entry and a Team Intervention on Prevention of Serious Medication Errors. JAMA 1998;280(15):1311\%1316.

34. Cannon D-S, Allen S-N. A comparison of the effects of compuler and manual reminders on compllance with a mental health clinical practice guideline. I Am Med inform Assoc 2000;7 (2):196-203.

35. Demakis $\mathrm{J} G$, Beauchamp $C$, Cull $W-L$, Denwood $R$, Eisen $S-A$, Lofgren $R$, et al Improving residents' compliance with standards of ambulatory care: results from the VA Cooperative Study on Computerized Reminders dama 2000;284(11):1411-6. 
36. Tang P-C, LaRosa M-P, Newcomb $C$, Gorden S-M. Measuring the effects of reminders for outpatient influenza immunizations at the point of clinical opportunity. J Am Med Inform Assoc $1999 ; 6(2): 115-21$.

37. Morgan M-M. Goodson J, Barnett G-O. Long-term changes in compliance with clinical guidelines through computer-based reminders. Proc AMIA Symp 1998:493-7.

38. Curtin K, Hayes B-D, Holland $\mathrm{C}-\mathrm{L}$, Katz L-A. Computer-generated intervention for asthma population care management. Eff Clin Pract 1998;1(1):43-6.

39. Overthage J-M, Tierney W-M, Zhou X-H, McDonald $\mathrm{C}-\mathrm{J}$. A randomized trial of "corollary orders" to prevent errors of omission. J Am Med linform Assoc 1997,4(5):364-75.

40. Overhage $J-M$. Tiemey $W-M$. McDonald $C-J$. Computer reminders to implement preventive care guidelines for hospitalized patients. Arch Intern Med 1996;156(14):1551-6.

41. Ornstein S-M, Garr D-R, Jenkins R-G, Musham $C_{\text {, Hamadeh }}$, Lancaster C. Implementation and evaluation of a computer-based preventive services system. Fam Med 1995,27(4):260-6.

42. Tape $T-G$, Campbell J-R. Computerized medical records and preventive health care: success depends on many factors. Am J Med 1993;94(6):619-25.

43. Halkin $H$, Katzir I, Kurman 1 , Jan J, Malkin B-B. Preventing drug interactions by online prescription screening in community pharmacies and medical practices. Clin Pharmacol Ther $2001 ; 69(4): 260-5$.

44. Coninelly D-P, Sielaff B-H, Willard K-E. The clinical workstation as a means of improving llaboratory use. Clin Chim Acta 1996:248(1):51-64.

45. Bates DW, Kuperman GJ, Rittenberg $E$, Teich JM, Onderdonk $A$, Winkelman $J$, al. Reminders for redundant tests: results of a randomized controlled trial. Proceedings / The Annual Symposium on Computer Applications in Medical Care 1995;19:935.

46. Koide D, Ohe K, Ross-Degnan D, Kaihara $S$. Computerized reminders to monitor liver function to improve the use of etretinate. International Journal of Medical Informatics 2000;57:11-19.

47. Nightingale $P G$, Adu $D$, Richards NT, Peters M. Implementation of rules based computerised bedside prescribing and administration: intervention study. Britisch Medical Journal $2000,320: 750-753$.

48. Goethe $\mathrm{J}-\mathrm{W}_{*}$ Schwartz H-I, Szarek B-L. Physician compliance with practice guidelines. Conn Med 1997;61(9):553-8.

49. Lee $F$, Teich JM, Spurr CD, Bates DW. Implementation of physician order entry: user satisfaction and self-reported usage patterns. J Am Med Inform Assoc 1996;3(1):42-55.

50. Rotman BL, Sullivan AN, McDonald TW, Brown BW, DeSmedt $P$, Goodnature D, et al. A randomized controlled trial of a computer-based physician workstation in an outpatient setting: Implementation barriers to outcome evaluation. JAMIA 1996;3(5);340 348 .

51. Tiemey WM. MCDonald CJ, Hui SL, Martin DK. Computer predictions of abnormal test results: effects on outpatient testing. Journal of the American Medical Association 1988;259(8):1194 1198.

52. Shiffman R-N, Liaw $Y$, Navedo D-D. Freudigman K-A. User satisfaction and frustration with a handheld, pen-based guideline implementation system for asthma. Proc AMIA Symp 1999:940-4.

53. Day F, Hoang L-P, Ouk S, Nagda $S$, Schriger D-L. The impact of a guideline-driven computer charting system on the emergency care of patients with acute low back pain. Proc Annu Symp Comput Appl Med Care 1995:576-80.

54. Schriger $D L$, Baraff LJ, Buller $K$, Shendrikar MA, Nagda S, Lin Ed, al Implementation of Clinical Guidelines via a Computer Charting System: Effect on the Care of Febrile Children Less than Three YearsofAge. J. Am. Med. Inform. Assoc. 2000;7(2):186-195.

55. Bouaud J, Séroussi B. Antoine E-C. Zelek L. Spielmann M. A before-after study using OncoDoc, a guideline-based decision support-system on breast cancer management: Impact upon physician prescribing behaviour. In: Patel VL, Rogers R, Haux R, editors. Medinfo 2001; 
$20012-5$ September 2001; London: 10S Press: 2001. p. $420-424$.

56. Shiffinan $R N$, Freudigman $M$, Brandt $C_{*}$, Liaw $Y$, Navedo DD. A guideline implementation system using handheld computers for office management of asthma; effects on adherence and patient outcomes. Pediatrics 2000;105(4 Pt 1):767-773.

57. Kuperman G-J, Teich J-M, Tanasijevic M-J. Ma'Luf N, Rittenberg E, Jha A, et al. limproving response to critical laboratory results with automation: results of a randomized controlled trial. $\triangle$ Am Med Inform Assoc 1999;6(6):512-22.

58. Rind DM, Safran C, Phillips RS, Wang Q, Calkins DR, Delbanco TL, el al, Effect of computerbased alerts on the treatment and outcomes of hospitalized patients. Arch Intern Med $1994: 154(13): 1511-1517$.

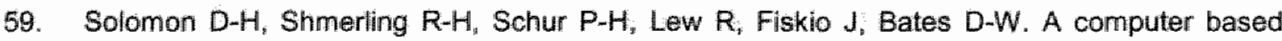
intervention to reduce unnecessary serologic testing. J Rheumatol 1999;26(12):2578-84.

60. Shea $S$, Sideli $R$, DuMouchel $W$, Pulver $G$; Arons $R$, Clayton $P$. Computer-generated informational messages directed to physicians: effect on length of hospital stay. J. Am. Med. Inform. Assoc. 1995;2(1):58-64.

61. Rocha BHSC, Christenson JC, Scott Evans R, Gardner RM. Clinicians" response to computerized detection of infections. JAMIA 2001:8(2):117-125.

62. Teich J-M, Merchia P-R, Schmiz J-L, Kuperman G-J, Spurr C-D, Bates D-W. Effects of computerized physician order entry on prescribing practices. Arch Intern Med 2000;160 (18):2741-7.

63. Pestotnik SL, Classen DC, Evans RS, Burke JP. Implementing antibiotic practice guidelines through computer-assisted decision support: clinical and financial outcomes. Annals of internal Medicine 1996; 124(10):884-890.

64. Kerry $\mathrm{SM}_{3}$ Bland JM. Analysis of a trial randomised in clusters. Britisch Medical Journal $1998 ; 316: 54$.

65. Campbell MK, Grimshaw JM. Cluster randomised trials: time for improvement. Britisch Medical Journal 1998;317:1171-1172.

66. Campbell MK, Mollison J, Steen N, Grimshaw JM, Eccles M. Analysis of chuster randomized trials in primary care: a practical approach. Family Practice $2000 ; 17(2): 192-196$.

67. Egger $M, S m i t h ~ G D$. Meta-analysis bias in location and selection of studies. BMJ 1998;316: $61-66$. 


\title{
Chapter 3
}

\author{
GRIF: A TEST ORDERING SYSTEM \\ WITH AUTOMATED FEEDBACK
}

Publlished as:

R. Bindels, P.A. de Clercq, R.A.G. Winkens, A. Hasman.

A lest ordering system with automated reminders for primary care based on practice guidelines,

International Journal of Medical informatics (2000) 58-59 pp 219-233. 


\section{Introduction}

The consumption of diagnostic tests has increased over the past 20 years and there is a growing awareness that a relatively large percentage of test requests in health care are inappropriate (1). To manage test consumption and to improve appropriateness of requests an automated reminder system was developed to change General Practitioners' (GP) test ordering behaviour.

In the past, various strategies have been used to change GPs' test ordering behaviour, like education (2), redesigning the request form $(3,4)$ and feedback on number, rationality (5) or costs (6) of the requested tests. Most review articles that compare different strategies to modify the test ordering patterns of clinicians (7-9) came to the conclusion that there is a wide range of interventions possible but that there are 'no magic bullets' as Oxman eloquently pointed out. However, several studies concluded that automated reminders, a form of decision support, are effective (10-15).

As for reminders, two main principles can be distinguished: pro-active and re-active systems. Pro-active systems give comments or suggestions before tests are chosen and re-active systems give comments after tests are chosen but before the test is ordered. Our real-time automated reminder system that will be described here is a re-active system and focuses entirely on primary care, covering a range of diagnostic tests. Compared to other existing reminder systems our reminder system focuses basically on the appropriateness of tests ordered.

To manage test consumption in the Maastricht region, the Transmural \& Diagnostic Centre (T\&DC) has given personal feedback in the form of written reports to GPs in the Maastricht region since 1985. Twice a year, each GP in the Mlaastricht region ( $\pm 85 \mathrm{GPS}$ ) receives a structured feedback report with critical comments on his/her test requests in a previous month. The individual biannual written feedback is based on a comparison of requests (including provided clinical data) with accepted national or regional guidelines.

The Department of Medical Informatics of the Maastricht University had already some experience with decision support systems to influence test ordering behaviour of GPs. Dupuits et al. (16) developed a prediction instrument that is able to determine TSH test adequacy on the basis of acquired diagnostic data as volunteered by patients themselves. Also, De Wilde et al. (17) studied - as part of the Openlabs project (18) - the effect of automated feedback on the rationality of TSH test requests and concluded that an automated reminder system could reduce inadequate test requests by 10 to $20 \%$.

Earlier studies showed that feedback on GPs' test ordering behaviour was highly effective and appreciated by the GPs $(5,19,20)$. However feedback remains a 
laborious method. Consequently, the T\&DC tried to develop a less laborious way to provide information on diagnostic tests to GPs and to give them insight into their own test ordering behaviour (17). The reminder system is developed against this background. The only difference between the re-active reminder system and the existing written feedback system in this context is that the GP can change his/her request immediately after a reminder is shown.

The main aim of this study is to develop an accurate and reliable reminder system to give immediate feedback about diagnostic test ordering of GPs. In the section methods the development of the reminder system and the method to validate the reminder systems' knowledge base are described. In the section results the description of the reminder system, the description of the knowledge base and the results of the first validation study are presented. Finally these results are discussed and some conclusions are drawn.

\section{Methods}

The reminder system integrates national and regional guidelines concerning test request behaviour into a tool that helps GPs to better adhere to the guidelines and therefore to a more rational test request behaviour.

\section{Design criteria}

In routine practice GPs in the Maastricht region indicate on a pre-printed request form which tests they want to order. They have to check off boxes on the paper form and may enter some relevant patient data. These data consist of: patient registration data such as name, address, gender and date of birth; medical data: working hypotheses, signs and complaints, existing problems, physical examination and medication; reason for test request.

The structured manual feedback reports contain several items: number of tests requested (compared to the previous analysis and compared to the average number of requests of their colleagues), rationality of the requests based on provided patient information, discussion of incorrect or redundant requests, a number of questions concerning the policy of the GP after receiving the results of the tests and a request to answer questions posed in the letter and to comment on the feedback. Our reminder system covers only a part of these items. It provides feedback concerning incorrect or redundant requests and indicates when insufficient patient information is given.

In daily practice the GP has about 8 to 10 minutes for the consultation of one patient. For this reason the reminder system's most important requirement is to work fast. The system must be easy to use and should not force GPs to enter data twice. Another important requirement is that the GP receives the feedback at the time the tests are requested. Finally, we wanted to limit the entry of free text (when entering the working hypotheses, existing problems and complaints) because a reminder 
system is better able to interpret standardised medical data.

\section{Development of the system}

The process to develop the reminder system can be divided into five steps:

1. formalisation of a set of guidelines

2. verification of the knowledge base

3. programming the reminder system

4. validation of the knowledge base

5. assessing usability, acceptance and satisfaction of the users

Verification refers to an internal static check on the system which can be performed without test cases and validation refers to tests performed to check the accuracy of the results given by the system; i.e. the performance of the system itself (21). In the following sections we describe the first four steps.

\section{Formalisation of a set of guidelines}

Before it is possible to implement the accepted guidelines into the reminder system, the guidelines, written in natural language, have to be translated into a formal language. After studying the national and regional guidelines it was concluded that IF-THEN rules could be used for knowledge representation.

Guidelines used by intelligent humans need not be fully consistent or complete. The human user, with his/her background knowledge, is usually able to resolve any ambiguities. The situation is completely different if a computer system uses practice guidelines (22). In this situation the guidelines need to be complete, free of contradictions and sufficiently detailed to avoid that only the most trivial reminders are given (23). We onlly translated the semi-formal rules that met the following criteria: clearly formulated rules with well-defined conditions.

The researcher (R.B.), a GP (R.W.) and an experienced internist performed the translation of the relevant parts of the practice guidelines into semi-formal IF-THEN rules (still in natural language). The regional guidelines are divided into the sections: goals, indications, remarks on indications, available tests, costs and interpretation of results. The relevant 21 guidelines were translated into IF-THEN rules (still in natural language). These regional guidelines represent all recommendations in the sections aims indications and remarks on indications. The national guidelines have a different structure depending on the described medical problem. However, 47 of the national guidelines contained a separate section on diagnostic tests. All the recommendations in these sections were transllated into IF-THEN rules (in natural language).

In total we found 280 IF-THEN rules in the practice guidelines. Table 1 indicates that only $92(33 \%)$ of all rules from the practice guidelines were used to build the computerised rules that are stored in the knowledge base. We chose to formallise the well-defined rules first. The rules that were not formalised lacked well-defined 
conditions such as 'the elderly', 'clear emotional problems' of 'atypical complaints'. These terms should be described in more detail before we can formalise them. In addition, in some of the not implemented rules other information was needed such as the duration of complaints, the nature of the consultation (first consult, second consult) or the findings on the physical examination.

Since a reminder text is only applicable in a certain situation, one IF-THEN rule can result in more than one computerised rule in the knowledge base. For example a rule from the practice guideline 'cultures for patients with diarrhoea' resulted in four different reminders, one reminder for each culture.

Table 1. The translation of written practice guidelines into computerised IF-THEN rules.

\begin{tabular}{lllll}
\hline Practice guidielines & \multicolumn{2}{c}{ Rules } & \multicolumn{2}{c}{ Computerised rules } \\
\cline { 1 - 4 } Institution & Number & All & Used & \\
\hline Regional & 21 & 98 & 37 & 85 \\
National & 47 & 182 & 55 & 69 \\
Total & 68 & 280 & $92(33 \%)$ & $154^{*}$ \\
\hline
\end{tabular}

* Our knowledge base contains 134 different rules, that means that 20 rules are mentioned both in the national and the regional guidelines.

The expressions of the IF-THEN rules consist of logical propositions combined with Boolean operators, such as AND, OR or NOT. In these rules the conclusion only contains the action to provide feedback. For example:

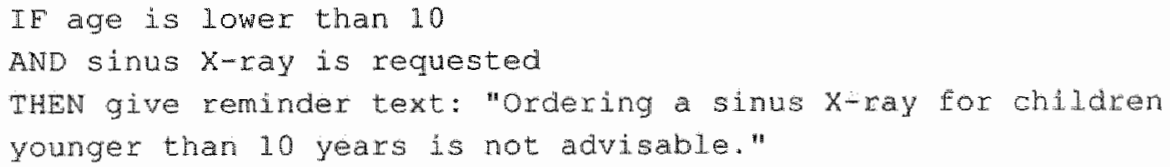

\section{Verification of the knowledge base}

Two clinicians and the researcher carried out a logical verification (detection of contradictions and conflicts). A structure verification (detection of duplication of rules, circular rules and redundancies) of the knowledge base (24) was also carried out using a rule compiler (25). As described earlier 92 of the 280 rules could be totally formalised. Since one IF-THEN rule can result in more than one reminder, as explained earlier, finally 134 reminders resulted.

\section{The prototype reminder system}

We developed a prototype reminder system in a web environment using HTML and the JAVASCRIPT programming language. Due to web technology we could build and rebuild the system quickly based on comments and advice of the GPS (26). 
After the structure, possibilities and shortcomings of the prototype reminder system were set, we built the final reminder system using DELPHI.

The prototype and the actual system were different in the way the data are presented on the screen. In the web-based reminder system all the tests are presented in one page, similar to the paper request form, while in the DELPHI based reminder system the tests are divided into several subcategories, each avaliable under a different tab. The latter was appreciated by the cooperating GPs. Contrary to the web-oriented programming language (JAVASCRIPT) with standard alert boxes to present the reminders to the GP, the DELPHI based version enabled a more flexible layout of the reminder window.

In addition, the DELPHI based reminder system can log all the actions of the GP, whereas this is more difficult to accomplish with the web-based version. Other additional advantages of the DELPHI based version of the reminder system are the easy way to create and maintain the reminders because of the combination of the system with a knowledge based editor (KBE) developed at the Eindhoven University of Technology (27), and the fact that the DELPHI based version is compatible with 386 or 486 systems and Windows 3.1 or 3.11 , the most commonly used configurations by Dutch GPs at the moment.

\section{First validation of the knowledge base}

For a first validation of the knowledge base of the reminder system we compared the reaction of the reminder system with the reaction of an expert. We used an iterative approach with a growing set of request forms and used the sets as training sets to correct errors and shortcomings of the knowledge base.

In three rounds, random selections of paper request forms, from the archives of the T\&DC, were taken and both a human expert and the reminder system assessed the appropriateness of the requested tests. We matched the comments of the expert with the reminders of the reminder system. Discrepancies occur when either the expert gives a comment and the system not or vice versa, or when the human expert and the reminder system give a different comment. Two independent reviewers judged these discrepancies. For each discrepancy, we established the reason. Comments of the expert outside the predefined domain of the program (not based on the guidelines) were labelled 'outside domain'. If both reviewers judged the comment of the program correct and the comment of the human expert was judged incorrect this case was labelled 'correct reaction system'. If the human expert was correct and the system not the case was classified as incorrect. A wrong translation from the written guidelines into the IF-THEN rules was labelled 'error in the formalisation process' and a reminder that was not in the knowledge base was labelled 'not implemented rules'. These 'not implemented rules' were present in the written guidelines, but because we focused on the implementation of the relatively simple rules in this phase of the development not all rulles were implemented. A less detailed reminder that was given in addition to a more detailed correct reminder and 
therefore should not be presented; was labelled 'redundant less detailed reminder". An error in programming the IF-THEN rules was labelled as "system error".

We calculated the overall percentage agreement between the comments of the expert and the reminder system. The kappa coefficient; used to calculate agreement beyond chance, could not be used because of low values in one of the cells of the two by two table (28). The 'shortcomings' of the reminder system include the discrepancies labelled as 'redundant less detailed reminder" "error in the formalisation process' and 'not implemented rules'. We calculated the percentage "shortcomings' by dividing the 'shortcomings' by the total number of requested tests. Discrepancies labelled 'outside domain' were not taken into account. This occurred in cases where no guideline was available. After each round was analysed, the reminders in the knowledge base were corrected for the errors that were found and if possible not implemented rules were implemented.

\section{Results}

\section{System description}

The reminder system consists of five parts: a knowledge base, an order entry system, a module that provides re-active support (il.e. the reminders), a module that provides passive support and a database (figure 1). In the following sections the five different parts of both systems are described.

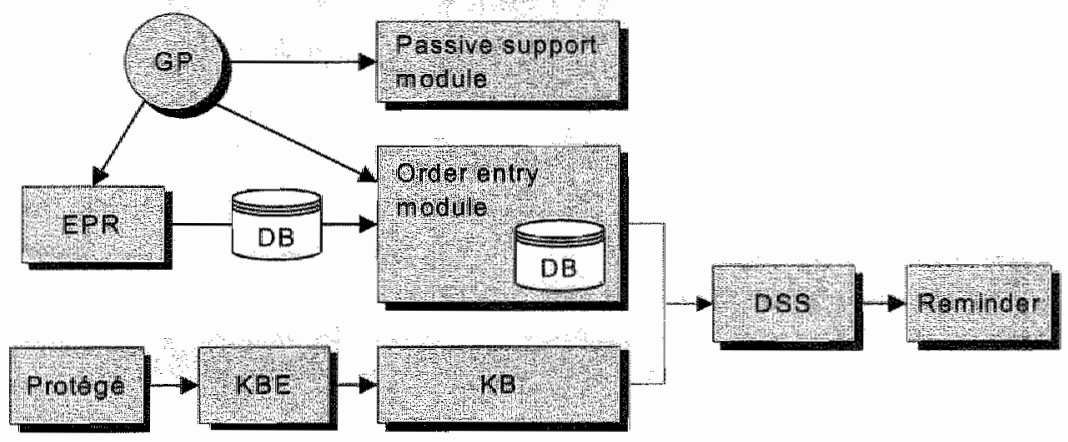

Figure 1. General structure of the reminder system. EPR is the Electronic Patient Record of the GP and $\mathrm{DB}$ represents a database.

\section{The knowledge base}

The guidelines are entered into a knowledge base using a Knowledge Base Editor (KBE), a graphical knowledge acquisition tool that enables us to formulate and structure domain knowledge. The knowledge is implemented as independent rules which, based on patient-specific data from the EPR, lead to a reminder if the corresponding guideline is not followed (10).

To allow reasoning about a medical domain an ontology was built (a formal description of the objects, the objects' properties and the relations among them 
(29)). We used Protege (30) to construct the ontology. The output of Protége is a file containing the ontology description using the CLIPS language. This file is read by the KBE and implemented as a class tree. In PROTEGE II the user can define classes, subclasses and the class members. At present the ontology consists of 153 objects divided into 11 classes. These objects are the diagnostic tests, patient information (age and gender), medical information (working hypotheses, existing problems and complaints) and the reasons for request.

Similar to the implementation of the terms in the ontology, the KBE represents guidelines by means of objects. Each guideline object encapsulates an IF-THEN rule (expression) and other properties such as name, reminder message and explanation (text, literature reference or hyperlink). The expression consists of instantiated objects from the ontology class tree. To implement an AND-operator objects have to be selected from the ontology tree and dragged to the right window. Propositions on different lines are ANDed. Propositions that are dragged atop an existing proposition are ORed. Finally, to implement a NOT operator objects have to be dragged to the lower right window. Figure 2 shows the user interface of the KBE.

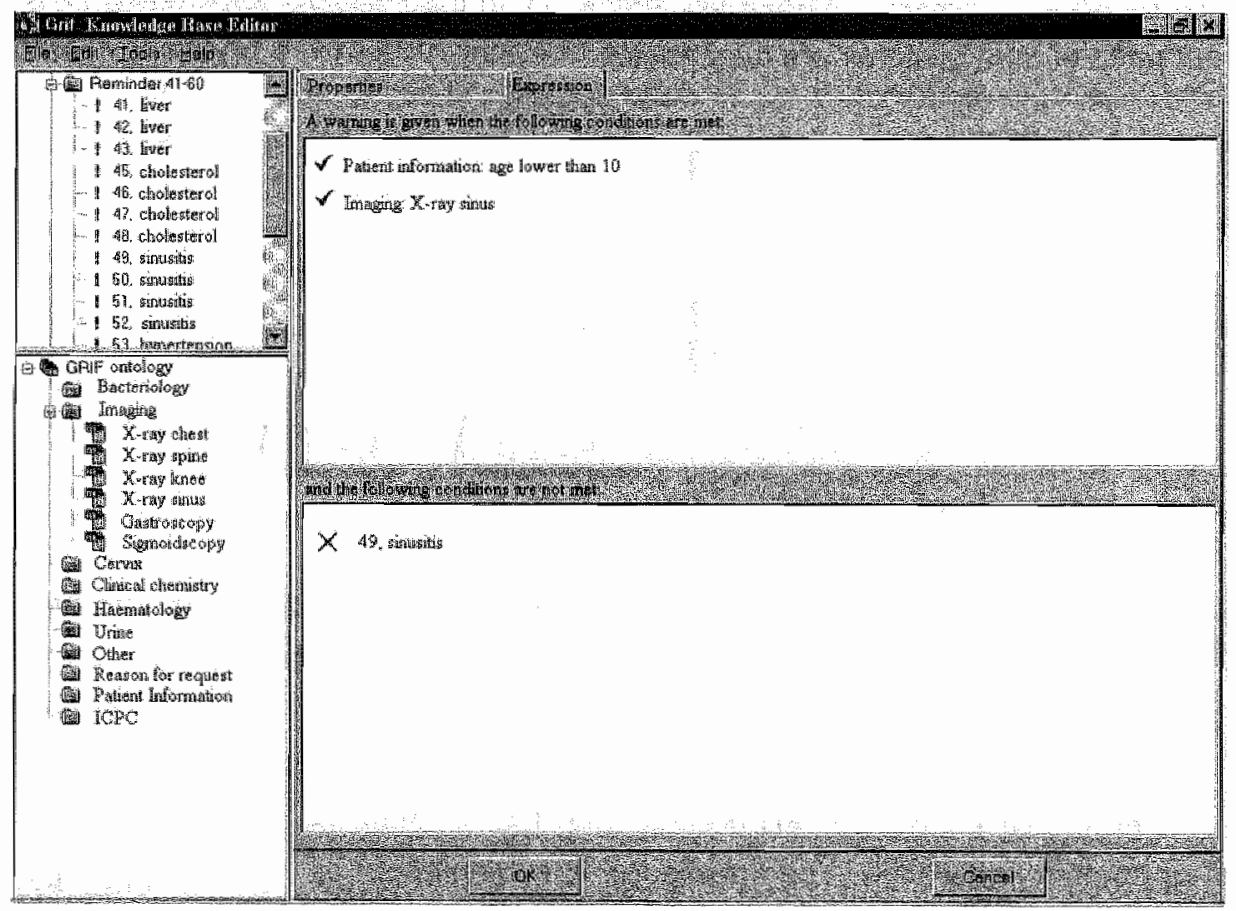

Flgure 2. The user interface of the Knowledge Base Editor (KBE). The upper left window presents the knowledge base with all currently implemented guidelines. The lower left window shows the ontology class tree. The right window presents the guideline's expression and contains an AND operator in the upper part and a NOT operator in the lower part of the right window. 
In this figure the "expression' page of a guideline is presented. This particular expression evaluates to true if a sinus $X$-ray is requested. the age of the patient is lower than 10 years and a more detailed reminder about sinusitis indicated in figure 2 as ' 49 , sinusitis' has not been presented to the GP earlier during this request. As a result, the reminder will be issued. Finally "the designer is able to export the guidelines of the KBE into a DLL-file that can be used by the reminder system.

\section{The order entry system}

The GP will have to enter the data that (s)he thinks are sufficient to support the test request in the DELPHI based order entry system. The order entry system is not yet fully integrated with the Electronic Patient Record (EPR) of the GPs but has an online connection with the EPR via an intermediate database. At the moment the GP wants to request diagnostic tests, (s)he can switch from the EPR to the reminder system and the necessary patient related data (name, address, date of birth, gender, medication and existing problems) will be transferred from the EPR database to an intermediate database. At the time the GP starts the order entry system the data are transferred automatically from the intermediate database into the corresponding fields of the order entry system. Request specific data are entered directly into the system. These data consist of: 1) medical data: working hypotheses, signs and complaints and physical examination; 2) reason for test request.

Test clusters such as haematology and bacteriology are separated by tabs (figure 3). Finally we added a facility that allows the GP to use his own terminology. The facility uses a file containing the medical terms for complaints and diagnoses from a list, containing all International Classification of Primary Care (ICPC) terms (31) and their synonyms. After the GP has entered a search term, a list of corresponding ICPC terms is presented and the GP has to choose the term that matches his/her description. The chosen term will be translated into the corresponding ICPC code. In this way we standardise the medical data the GP enters and therefore our IF-THEN rules can now be based on ICPC codes only.

\section{Active support module}

The KBE stores the rules into a knowledge base and compiles the knowledge base into a DLL-file that is used by the reminder system (27) to provide the active support, i.e. to generate the actual reminders. This part of the system, indicated as 'DSS' (Decision Support System) in figure 1, reads the patient data and checks whether any of the IF-THEN rules will fire. An example is the potassium rule from the hypertension guideline. This rule will lead to a reminder whenever a potassium test is requested for a check up of the patient's hypertension when the patient is not on diuretics. The reminder, as shown in figure 3 , contains critical comments about the requested tests. In addition to the reminder text, the pop-up window contains 
three buttons. The GP presses "accept' to indicate that (s)he accepts the reminder and 'reject' to indicate that (s)he does not agree. In both cases it is still possible for the GP to make changes in the request form after ( $s$ )he has seen the reminder. Moreover the reminder window contains a button to request more information. If this button is chosen the reminder window will expand and may contain hyperlinks to the appropriate guidelines and/or references to the literature.

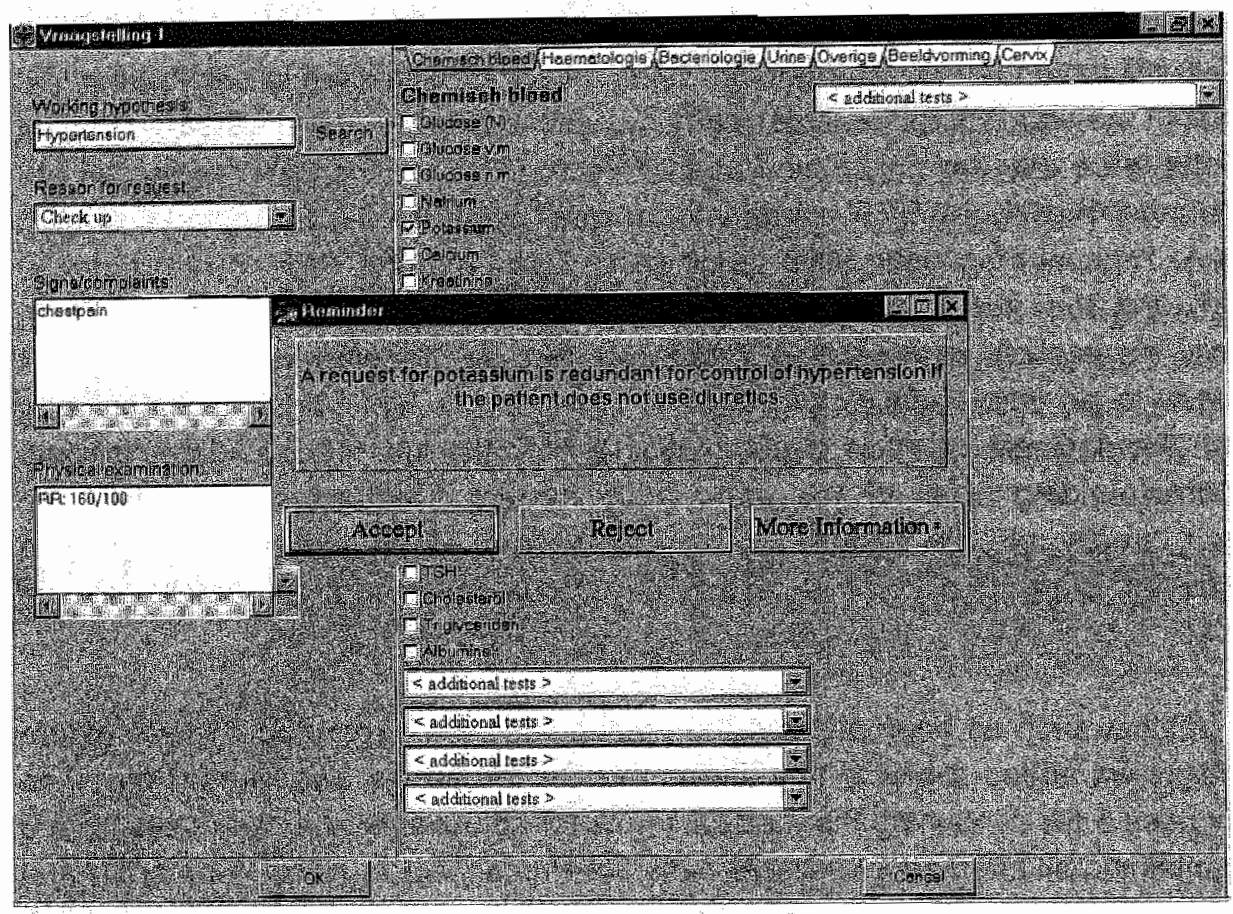

Figure 3 . If a request is not according the guidelines, the reminder system generates and displays a reminder that overlays the normal user interface of the request form. Only the relevant words in the figure were translated from Dutch into English.

One of the earlier mentioned requirements is that the reminder system must operate in real time. To that end, we used a rule evaluator developed with the SYMPLEXIS toolbox (25).

\section{Passive support module}

Another option in the reminder system allows the GP to ask for additional background information about the guidelines, indicated as passive support module in figure 1. With this option textbook information about the regional and national guidelines is presented in a web-based environment by means of an internal web browser. In figure 4 an example is shown. In this example the content of the regional guideline about allergy is presented in the right part of the window. The hyperlinks in the left part of the window refer to different chapters of the regional guidelines. 
Information about the national guidelines and patient education material are presented under tabs in the upper part of the window.

With the web-based environment the user can browse quickly through the available information.

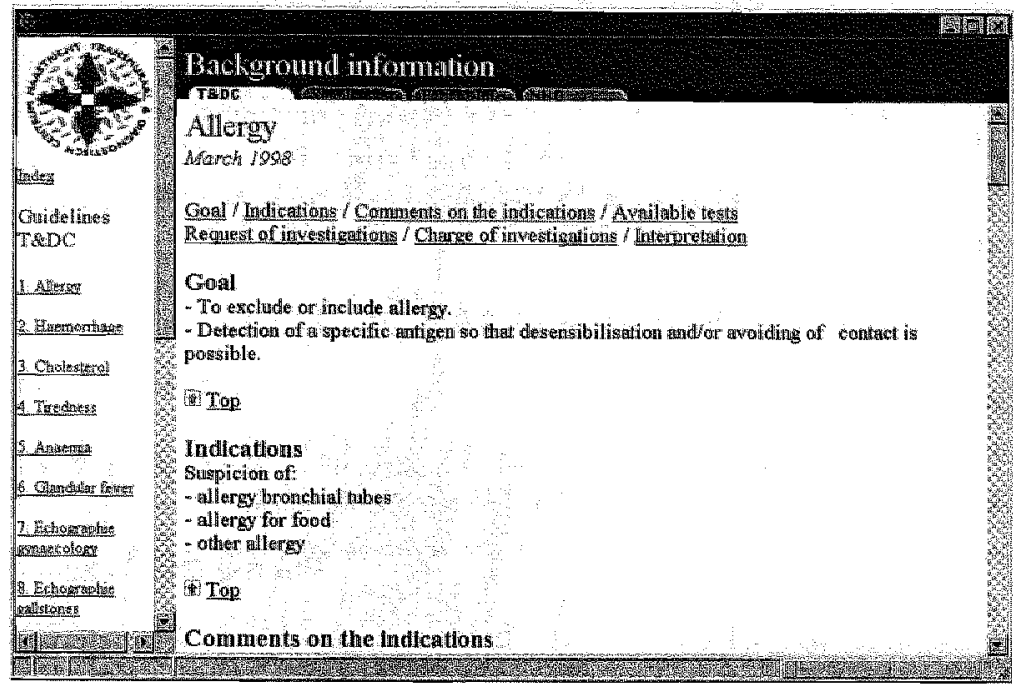

Figure 4. An example of the provision of passive support. The content of the regional guideline about allergy is presented in the right part of the window. The hyperlinks in the left part of the window refer to different chapters of the regional guidelines. Information about the national gulidelines and patient education material are presented under tabs in the upper part of the window.

Context sensitive background information is presented if the GP clicks on one of the tests of the electronic order entry form. Furthermore, a help-function, also using web technology, is added to assist the GP in solving problems concerning the reminder system.

\section{Data storage and output}

We use a dBase database to store the information filled in on the request form, the given reminders, the reaction of the GP on the reminders (acceptance or rejection) and the other information the GP used (help or passive support). These data will be further analysed. Finally, the request form is printed using the same layout as the conventional paper form. Electronic submission of the form is also possible.

\section{Content of the knowledge base}

The development strategy used shows that web-based techniques can easily be used to quickly develop a prototype reminder system that gives the users a good impression of the eventuall system. The first reactions of the GPs on the actual reminder system - in a development environment - were positive.

At the start of the validation, the actual reminder system contained 134 reminders 
concerning various medical problems as shown in table 2 .

The 78 tests that are dealt with by the reminder system cover about $75 \%$ of the total amount of the requested tests and most of the frequently requested tests are covered by the rules.

Table 2. Number of reminders per medical problem

\begin{tabular}{ll}
\hline Medical problem & Reminders \\
\hline Musculoskeletal & 21 \\
Allergy & 13 \\
Glandular fever & 13 \\
Liver & 9 \\
Infections & 7 \\
Diarrhea & 6 \\
Thyroid gland & 6 \\
Urine complaints & 5 \\
Rheumatism & 5 \\
Sinusitis & 4 \\
Cholesterol & 4 \\
Hypertension & 4 \\
Gal-bladder & 3 \\
Goul & 3 \\
Other & 31 \\
\hline Tolal & 134 \\
\hline
\end{tabular}

Since the reminder concerns information about the inadequate request of a test the conditional part of the IF-THEN rule usually contains the requested test. The conditions of the IF-THEN rules may also contain medical patient information, personal information (age and gender) or a combination of these types of information (table 3). In case the condition only contains the requested test the reminder concerns an obsolete test or a general remark about the requested test. If the condition contains the names of two tests (indicated as test-test in table 2) these tests should not be requested together.

The imajority of the conditions of the IF-THEN rules $(75 \%)$, as shown in table 3 , contain a test in combination with medical information about the patient. For example:

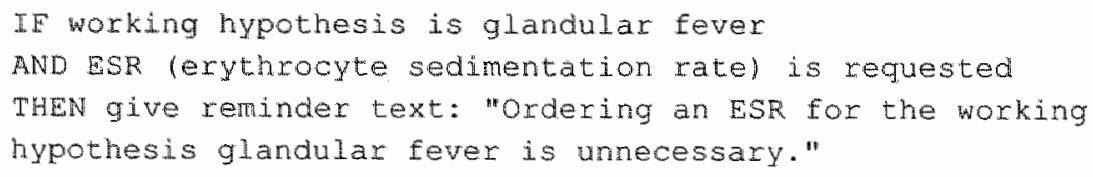


When the condition contains personal information it concerns tests that are contraindicated because of age and/or gender. Also combinations of three different types of information is possible (personal patient information, medical information and a diagnostic test). An example of a rule of which the condition is only based on medical information is the guideline on 'Migraine':

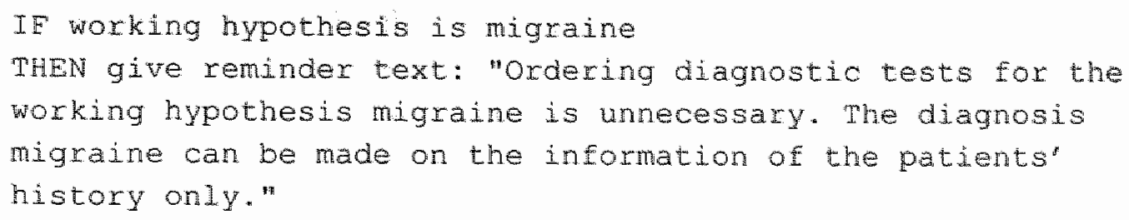

In this case, all tests the GP may request for the working hypothesis migraine are unnecessary.

Table 3. Distribution of the used conditions (or a combinations of conditions) of the IF-THEN rules applled in the reminder system.

\begin{tabular}{ll}
\hline Condition IF-THEN rulle & \\
\hline Test & 5 \\
Test - test & 6 \\
Test - medical information & 102 \\
Test - personal information & 6 \\
Test - personal - medical information & 14 \\
Medical information & 1 \\
\hline Total & 134 \\
\hline
\end{tabular}

\section{Validation}

Three validation rounds were carried out. In table 4 the overall results are presented. In total 26 test requests were examined in the first round, 55 tests in the second round and 119 tests in the third round. We use the term test in a restricted sense to indicate a request for which only one reminder can be given if the test is requested unnecessary. The reminder system and the expert gave more or less the same number of comments in all rounds. However, the overall agreement between the comments of the expert and the reminder system is $46 \%$ (12 out of 26 ) in the first round $60 \%$ (33 out of 55 ) in the second round and $69 \%$ ( 82 out of 119 ) in the third round.

Not implemented rules and errors in the formalisation process constitute a substantial part of the discrepancies and only one system error was found in all three validation rounds (table 5). We calculated the percentage "shortcomings' of the reminder system. This percentage decreased over the subsequent validation rounds (respectively $26 \%, 17 \%$ and $11 \%$ ). After the errors of the three validation rounds were adjusted, the knowledge base contained 149 reminders. 
Table 4, Results of the validation study, a comparison between the comments of a human expert and the reminder system.

\begin{tabular}{lllll}
\hline & & Round 1 & Round 2 & Round 3 \\
\hline Total number of requested tests & 26 & 55 & 119 \\
Comments & - expert & 18 & 34 & 79 \\
& - reminder system & 16 & 34 & 78 \\
No comments & - expert & 8 & 21 & 40 \\
& - reminder system & 10 & 21 & 41 \\
Agreement & 12 & 33 & 82 \\
- both same comment & 10 & 23 & 60 \\
- both no comment & 2 & 10 & 22 \\
\hline
\end{tabular}

Table 5. Reasons of discrepancies between the comments of the reminder system and the human expert.

\begin{tabular}{llll}
\hline & Round 1 & Round 2 & Round 3 \\
\hline Discrepancies (system - expert) & 14 & 22 & 37 \\
- correct reactions reminder system & 5 & 10 & 19 \\
- incorrect reactions reminder system & 9 & 12 & 18 \\
- redundant less detailed reminder & 1 & 1 & 0 \\
- error formalization process & 3 & 1 & 6 \\
- system error & 0 & 0 & 1 \\
- comment outside domain & 3 & 3 & 5 \\
- not implemented rule & 2 & 7 & 6 \\
\hline
\end{tabular}

\section{Discussion}

In this paper we presented a real-time automated reminder system that monitors the diagnostic test ordering behaviour of GPs. The knowledge base of the reminder system, the most important part, contains rules about various medical problems. Because, up till now, not all medical problems a GP deals with are described in practice guidelines, the knowledge base cannot be complete. In addition the knowledge base only contains $33 \%$ of the semi-formalised rules from these practice guidelines. However, rules about the most frequently requested tests are stored in the knowledge base. These rules cover about $75 \%$ of the total volume of requested tests. The GP knows that de knowledge base is not complete yet and (s)he also knows that (s)he cannot blindly rely on the reminder system. Due to the complex nature of the situations under which diagnostic tests are requested and the fact that not all situations are well described in the practice guidelines, it is still necessary to rely on the GP's human expertise. In the end, the GP remains responsible for the test request. The current reminder system merely focuses on diagnostic tests that 
are unnecessary, whereas situations where tests are incorrectly not requested may also be non-rational. In the future these situations should be included into the reminder system. But then, full integration with the EPR system is necessary.

Although the knowledge base is not complete we still can accomplish the goal to develop an accurate and reliable system. As the results of the first validation study show, the percentage agreement increased over the subsequent validation rounds and the percentage 'shortcomings' of the reminder system decreased. We still have a relatively large number of "not implemented' rules. This is caused by the fact that we chose to start to formalise the relatively simple rules. As mentioned in the section 'Verification of the knowledge base' the practice guidelines sometimes contain some vague and therefore difficult to formalise terms.

The majority of the discrepancies labelled as 'not implemented rule' ( 8 out of 15) concerned comments of the expert where he pointed out that there was no medical information mentioned on the request form that could justify the requested test. These comments are not explicitly mentioned in the practice guidelines and therefore they were not formalised in the first place. Some discrepancies were not corrected in the knowledge base. For example there were discrepancies in comments about the request of ESR. Because an ESR is a frequently requested test and this test can be requested in relation to several diagnoses, adjusting the rules to prevent these discrepancies would imply too many false positive reminders. The system error that was found in the third validation round could not be corrected, because it concerned a deficiency in the ICPC coding. In this situation two $x$-rays ( $x$ hip and $x$-knee) were requested. The $x$-ray of the hip was appropriate because the GP wanted to exclude a tumour. However the $x$-ray for the knee was inappropriate. Using ICPC coding it is not possible to indicate the location of a tumour in the musculoskeletal system. Due to the use of the general ICPC code for a tumour in the musculoskeletal system and the fact that the rule about $x$-knee has this code in the NOT statement, the system did not generate the appropriate reminder. In situations where only one $x$-ray is requested the reminder system reacts correctly. In some cases the human expert not only gave concrete feedback based on guidelines but also discussed test ordering in general and asked the GP the pre-test probability of a certain test or test combination given the medical data. Tierney et al. (12) and Dupuits et al. (16) already used information about pre-test probability in their systems. When these types of comments of the expert are given often, we have to consider if and how these remarks can be implemented into the reminder system.

The results of the validation study should be interpreted with some caution because of the limited numbers of requested tests and the absence of an objective gold standard. In the near future, a large study to validate the knowledge base will be carried out. 
The effectiveness of the reminder system depends on the satisfaction of the users and on the quality of the presented reminders. Acceptance and satisfaction with the reminder system itself is important for the implementation and use of the system in daily practice. Although we have tried to make the system easy to use and fast, it will never be as fast as filling in the conventional paper request form (32). We still have to evaluate whether this may influence acceptance by users.

Also the need to code the medical data (coding in this context means choosing a term belonging to the $I C P C$ list that represents a particularly medical term) in the electronic order entry form, could be a disadvantage of the reminder system compared to the conventional written feedback. The main problem is that the ICPC codes are not specific enough to code all medical problems in dailly practice.

The quality of the presented reminders depends upon the maintenance of the reminders in the knowledge base on the one hand and on the completeness of the medical data provided by the GPs on the other. It is important that the medical knowledge will be kept up-to-date. The use of the KBE makes it easy to enter or madify the rules so that the system can also be used in regions where perhaps other guidelines are used. During the trial the researcher maintains the knowledge base. In the future a professional body of GPs has to be responsible for the maintenance of the system.

As mentioned in the introduction, more systems have been developed to assist the GP in ordering diagnostic tests. Some of these decision support systems resemble the reminder system described here. The reminder system developed by Tierney et al. (12) is also based on detailed medical data entered by a physician. Other comparable systems only take into account the main medical problem of the patient $(11,14,15)$. The system of van Wijk et al. (15) is not a critiquing but a pro-active system. Their system suggests certain tests to the GP according to a given protocol. Our system, on the other hand, mainly focuses on appropriateness, leaves the decision to the GP and only reacts if the request is not in accordance with the guidelines. It therefore doesn't overload the GP with suggestions that (s)he most of the time probably already knows. Why bother a GP with suggestions if (s)he is doing his/her job well? Moreover, by offering a number of test alternatives a GP may be inclined to request more tests than necessary. GPs in the Maastricht region are used to order the tests and receive feedback only if the request is non-rational. The sole difference with the new method is that the GP receives the feedback at the moment (s)he orders the tests. The reminder system developed in this study does not replace the GP's decision making. It will assess and critique if necessary the GP's choice of diagnostic tests, based on national and regional guidelines, after the GP has come up with a possible diagnosis. 


\section{Conclusion}

As we noted in the introduction we had already some experience with reminder systems covering only a small number of tests. It was concluded that these systems were effective. Therefore it was decided to develop a real-time automated reminder system. The system was prototyped using web-based technology. The system appears to be fast, is able to produce 134 different reminders and provides the guidelines in text format if the GP wants to know more about the rationale of the guideline. The number of correct reactions of the reminder system is almost as high as the number of correct reactions of the human expert. A large validation study of the medical knowledge in the reminder system will be carried out to draw further conclusions about the functionality of the reminder system. A planned future investigation in daily practice will reveal whether the use of this system is as efficient as the current feedback system.

\section{Acknowledgements}

We acknowledge the assistance of Marieke Vissers in the development of the prototype reminder system in JAVASCRIPT and Sjef Roos for the development of the ICPC search program and the print module. Furthermore we acknowledge Peter Pop for giving feedback about the requested tests for the validation study.

\section{References}

1. Kassirer JP. Our stubborn quest for diagnostic certainty. New England Journal of Medicine 1989;320:1489-1491.

2. Eisenberg JM. An educational program to modify laboratory usie by house staff. Journal of Medical Education 1977;52:578-581.

3. Wong ET, Lincoin TL. Ready! Fire! ... Aim! Journal of the American Medical Association $1983 ; 250(18): 2510-2513$.

4. Zaat JO, van Eijk JT, Bonte HA. Laboratory tesil form design influences test ordering by general practitioners in The Netherlands. Medical Care 1992;30(3):189-98.

5. Winkens RAG, Pop P. Bugter-Maessen AMA, Grol RPTM, Kester ADM, Beusmanis GHMI, al. Randomised controlled trial of routine individual feedback to improve rationality and reduce numbers of test request. The Lancet 1995;345:498-502.

6. Tierney $W_{M}$ Miller ME, MCDonald CJ. The effect on test ordering of informing physicians of the charges for outpatient diagnostic tests. New England Journal of Medicine 1990,322 (21):1499-1504.

7. Oxman $\mathrm{AD}$, Thomson MA, Davis DA, Haynes RB. No magic bullets: A systematic review of 102 trials of interventions to improve professional practice. Canadian Medical Association Journal $1995 ; 153(10): 1423-1431$.

8. Fraser CG, Woodiord FP. Strategies to modify the test-requesting patterns of clinicians. Annals of Clinical Biochemistry 1987;24(Pt 3):223-31.

9. Axt-Adam $P_{n}$ van der Wouden JC. Influencing behavior of physicians ordering laboratory tests; A literature study. Medical Care 1993/31(9):784-794.

10. MCDonald CJ, Hui SL, Smith DM. Tierney WM, Cohen SJ, Weinberger M, et al. Reminders to physicians from an introspective computer medical record. A two-year randomised triall. Annalls 
of Internal Medicine 1984;100:130-138.

11. Nightingale PG, Peters M, Mutimer D, Neuberger JM. Effects of a computerised protocol management system on ordering of clinical tests. Quality in Health Care 1994:3:23-28.

12. Tierney WM; McDonald CJ ${ }_{1}$ Hui SL, Martin DK. Computer predictions of abnomal test results: effects on outpatient testing. Joumal of the American Medical Association 1988:259(8):11941198.

13. Bates DW Kuperman GJ, Rittenberg E, Teich JM, Onderdonk $A$, Winkelman $J$, et al. Reminders for redundant tests: results of a randomized controlled trial. Proceedings / The Annual Symposium on Computer Applications in Medical Care 1995; 19:935.

14. Harpole $\mathrm{LH}_{3}$, Khorasani R, Fiskio J, Kuperman GJ, Bates DW. Automated evidence-based critiquing of orders for abdominal radiographs: impact on utilization and appropriateness. Joumal of the American Medical Informatics Association 1997;4(6):511-521.

15. van Wijk $M_{3}$ Mosseveld $M_{4}$ van der Lei $j$. The impact of guideline-based decision support on general practitioners' testordering: A randomized controlled trial. In: Moorman PW, van der Lei J. Musen MA, editors. Preceedings of IMIA Working group 17; 1998; Rotterdam: IMIA; 1998.

16. Dupuits FMHM, Pop $P$. Hasinan $A$, Schouten HJA. A rational request behawior: The development of prediction instruments regarding thyroid function tests in primary care. Methods of linformation in Medicine 1999;38(1):31-36.

17. de Wilde EJL, Pop P. Hasman A, Blom JA. OpenLabs services for ordering laboratory investigations. Computer Methods and Programs in Biomedicine 1996;50:135-141.

18. O'Moore R, Groth T, Grimson W, Boran G. The OpenLabs Project. Computer Methods and Programs in Biomedicine 1996;50(2),85-6.

19. Pop P, Winkens RAG. A diagnostic centre for general practitioners; results of individual feedback on diagnositic actions. Journal of Royal College of General Practitioners 1989;39:507-508.

20. Winkens RAG, Pop P, Grol RPTM, Bugter-Maessen AMA, Kester ADM, Beusmans GHMl, et al. Effects of routine individual feedback over nine years on general practitioners' requests for tests: British Medical Journal 1996;312:490.

21. Engelbrecht $R$, Rector A, Moser W. Verification and validation. In: van Gennip E, Talmon J, editors. Assessment and evaluation of information technologies in medicine. Amsterdam: IOS Press; 1995. p. 51-66.

22. Shiffman RN, Brandt CA, Llaw $Y$, Corb G.J. A design model for computer-based guideline implementation based an information management services. Journal of the American Medical Informatics Association 1999;6(2);99-103.

23. Tierney $W M_{1}$, Overhage $J M_{1}$, Takesue BY, Harris $L E$, Murray $M D$, Vargo $D L$, at al. Computerizing guidelines to improve care and patient outcomes: The example of heart failure. Joumal of the American Medical Informatics Association 1995;2(5):316-322.

24. Fleschi M. Towards validation of expert systems as medical decision aids. International Journal of Blo-Medical Computing 1990;26:93-108.

25. Blom JA. Temporal logics and real time expert systems . Computer Methods and Programs in Biomedicine 1996;51:35-49.

26. Hasman $A$, Tange $H_{1}$ Vissers $M$. Combining a scientific approach and prototyping in the design of EHCR systems. IEEE Transactions on Information Technology in Biomedicine 1998;2 (3):117-123.

27. de Clercq PA, Blom $J A$, Hasman A, Korsten HHM. A strategy for developing practice guidelines for the $\| \mathrm{CU}$ using automated knowledge acquisition techniques. International Journal of Clinical Monitoring and Computing 1999;15:109-117.

28. Donker DK, Hasman A, van Geijn HP. Interpretation of low kappa values. International Journal of Bio-Medical Computing 1993;33(1):55-64.

29. Gruber TR. A translation approach to portable ontologies. Knowledge Acquisition 1993:5 
(2):199-220.

30. Musen MA, Tu SW, Eriksson H, Gennari JH, Puerta AR. PROTEGE-ll: An Environment for Reusable Problem-Solving Methods and Domain Ontologies, in: International Joint Conference on Artificial Intelligence; 1993; Chambery, Savoie, France; 1993.

31. Lamberts $H$, Wood $M$. International Classification of Primary Care. 3rd ed. Oxford: Oxford University Press; 1987.

32. Bates DW, Boyle DL, Teich JM. Impact of computerized physician order entry on physician time. Proceedings / The Annual Symposium on Computer Applications in Medical Care $1994 ; 18: 996$. 
$m$

तथ

- 


\section{CHAPTER 4}

THE RELIABILITY OF ASSESSING THE APPROPRIATENESS OF REQUESTED DIAGNOSTIC TESTS 


\section{Introduction}

Various methods such as peer review and audit are used to assess the approprateness of health care activities such as ordering diagnostic tests, prescribing medications, etc (1-7). Peer review is described as a method for implementing quality improvement of patient care with continuous, systematic, and critical reflections by a number of colleagues regarding their own and others' performance (8). Individual feedback on gaps in the physician's performance and audit are examples of peer review. The approach is often based on practice guidelines that are used and interpreted by human reviewers. The validity and reliability of peer review of medical practice is considered doubtful (9-11). Reliability is the degree to which a measurement is consistent or reproducible. Validity is the degree to which the results of the measurement reflect the true value of the variable you want to measure. Correctness and accuracy are terms associated with validity (12).

Smith et al. stated that the reasons for the lack of reliability and validity of the peerreview process are systematic bias of individual reviewers and systematic bias related to the professional training of reviewers (10). In the peer-review process physician reviewers often use implicit criteria to evaluate the appropriateness of care (11). In addition, there are limits to the capabilities of humans as information processors, which lead to random and systematic errors in their activities (13). These systematic errors may lead to inappropriate health care activities and are not detected if reviewers are subject to the same biases. Other reasons for variation in assessments of appropriateness of health care activities may include competing guidelines (leading to contradictory conclusions), inadequate guidelines (that do not apply to all patients), and inadequate documentation by the clinician.

As suggested by other researchers, the reliability of the review process can be improved by enhancing the agreement among raters for example by training them (14). An alternative is to increase the number of reviewers with consensus meetings between independent reviewers or peer review committees (15). Including multiple independent reviewers is responsible for the problem of low interrater agreement as mentioned above. The results of a discussion between physicians when reviewing medical information depends on the composition of the group and does not automatically improve the overall reliability of the judgment of physicians who take part in different panels (16).

Over the past thinty years, there has been an increase in ordering diagnostic tests. Diagnostic test ordering is a complex action, and it is not aways easy to reduce this growing consumption. There is a "stubborn quest for diagnostic certainty" as Kassirer eloquently pointed out (17). Studies have been published about normative appropriateness of diagnostic testing (18) and how such decisions may be biased by incentives (19). This literature identifies that there are two kinds of test ordering 
errors: ordering tests that are not warranted and not ordering tests that are warranted. In this chapter only the first error will be addressed.

In Maastricht, the Netherlands, the Diagnostic Centre of the Transmural Care Unit of the University Hospital has been giving personal feedback via written reports to the 90 General Practitioners (GPs) in its region since 1985. Twice a year, each GP receives a feedback report with critical comments on his or her test requests in an earlier month. The feedback focuses predominantly on the rationality of requested tests and is based on a comparison of information on the request forms (including medical patient data) with accepted national and regional practice guidelines on rational diagnostic testing. We consider a test rational if it is requested in accordance with accepted practice guidelines. Previous studies showed that this kind of feedback was effective in reducing numbers of ordered tests, improving rationality and reducing costs $(2,20-22)$. Notwithstanding the success of this feedback, it was not known how reliable the feedback actually was.

We studied the individual variability in the assessment of appropriate test ordering, the appropriateness of tests ordered, and assessed how this influences the work-up and depth of expert peer review. Although other researchers have already addressed the poor performance of expert peer review (9), it is necessary to quantify its reliability and to determine on what level expert peer review is advisable. We calculated Cohen's Kappa, measuring intrarater and interrater agreement, plus the joint reliability coefficient. By using this measure, we also tried to verify if feedback on test ordering based on expert peer review is suitable for case-by-case assessments of appropriateness. Furthermore, we compared the value of the joint reliability with similar data obtained in similar studies in other fields. In addition, reporting on the value of the joint reliability coefficient allows other evaluators to estimate the number of experts needed to create a reliable reference standard for their studies $(23,24)$.

\section{Methods}

\section{Setting and subjects}

Over the period May until October 1999, a random selection of 253 request forms was obtained from the archives of the Diagnostic Centre. In the Maastricht region, GPs are used to request diagnostic tests using a specially developed request form (see appendix 1). The GPs know that the information they provide on the request form will be used for the individual feedback process.

\section{Request forms}

The request form contains administrative and medical patient data plus the requested tests (Appendix I). The medical patient data include the following 6 items: possible diagnosis, working hypotheses, signs and complaints, medical history, 
physical examination, medication and the reason for the requests. The GP uses his or her own terms or descriptions to reflect the medical status of the patient. The GP is free to decide how much medical information is provided. The tests on the request form concern clinical chemistry tests, faeces tests and imaging techniques such as Xrays and Magnetic Resonance Imaging (MR)I.

\section{The review}

Three experts were asked to review the request forms. Reviewer 1 is a clinical chemist who has 25 years of experience in clinical chemistry and is regularly consulted by GPs regarding diagnostic testing. Reviewer 2 is an experienced General Practitioner with 17 years of experience and has been associated with the Diagnostic Centre for 15 years. Reviewer 3 is a general internist who has been working as an internist for 27 years and has provided the structured feedback for 16 years. The three reviewers judged the appropriateness of each test independently an the basis of their knowledge of the accepted national and regional practice guidelines on rational diagnostic testing. All reviewers are familiar with the guidelines; reviewer 1 had additional training in how to use the guidelines. The reviewers" assessments were based on a comparison of the combination of clinical patient data and the tests ordered with their recollection of the guidelines. Unclear handwriting on the request form was corrected so that all reviewers had the same information. A random selection of 50 forms (out of the total set of 253 forms) with a total of 238 diagnostic tests on it were reviewed for a second time after two months to measure the intrarater agreement.

\section{Analysis}

Intrarater and interrater agreement were calculated using the percentage of agreement and Cohen's kappa. The percentage agreement is calculated by dividing the number of agreed cases by the total number of cases.

Cohen's kappa calculates the agreement beyond chance of observers assessing the same objects. Values below 0.4 are usually interpreted as a "poor agreement beyond chance", values between 0.4 and 0.75 are interpreted as a fair to good agreement', and values larger than 0.75 may be interpreted to present 'excellent agreement" (25).

The joint reliability coefficient is calculated to assess the consistency in assessment between all observers $(12,14)$. We used equation 3 from the paper of Hripcsak et al. (14) (our equation 1). In this equation $\sigma^{2}$ abjecis is the true variance for objects (or cases), $\sigma^{2}$ resid the residual variance and $n$ is the number of observers. $\sigma^{2}$ resid is computed by subtracting $\sigma^{2}$ objects and $\sigma^{2}$ observations (variance for raters) from $\sigma_{\text {total }}^{2}$ (total variance). The reliability coefficient $(p)$ measures the proportion of the total variance in the data that is explained by the true variance between objects. 
(1)

$$
\rho_{n}=\frac{\sigma_{\text {abjects }}^{2}}{\sigma_{\text {abjects }}^{2}+\left(\sigma_{\text {resid }}^{2} / n\right)}
$$

With the help of equation 1 , both the per-rater reliability and the joint reliability can be obtained. When the $\mathrm{n}$ in this equation is set to 1 , the per-rater reliability is obtained. For all higher values, the joint reliability is acquired.

Reliability equalls 1 if all observers agree for all objects. If the overall performance of the observers has to be estimated, a joint reliability of 0.7 is probably sufficient. However, if the reference is used to draw conclusions about individual cases, a joint reliability of 0.95 has been suggested as necessary. Measurements with a joint reliability of 0.5 or less are rarely adequate (14).

To calculate the number of observers $(n)$ that are necessary to reach a certain value of the joint reliability coefficient, the same equation (equation 1) can be used (14). The reliability coefficient we used as a reference was $0.95\left(p_{n}\right)$.

Two factors could affect our findings, namely, the type of test (clinical chemistry and faeces tests versus imaging techniques) and the amount and quality of the information on the request form. Therefore, we calculated the percentage of agreement and the kappa values stratified by test type (laboratory test or imaging techniques) and the amount of information (too little or enough information). A request form was defined to contain "enough information" when the possible diagnosis and the reason for request were present and, in addition, 3 or more items (of a total of 6 information items) were filled in. Other request forms are lacking information'.

\section{Results}

In total, 253 request forms were included. These request forms contained 1215 requested tests. The request forms came from 88 different GPs with on average 2.9 forms per GP. The agreement among reviewers is shown in table 1 and the percentage agreement and kappa values in table 2. The differences in the total number of diagnostic tests in table 1 are due to missing values in the assessment of appropriateness by different reviewers. Only $0.2 \%$ of the assessments were missing for reviewer $1,2.3 \%$ for reviewer 2 , and $0.7 \%$ for reviewer 3 . Lowest agreement is measured between reviewer 1 and reviewer 3, whereas agreement between reviewers 2 and 3 was highest. All kappa values are relatively low, ranging from 0.33 to 0.42 . The agreement between reviewer 2 and reviewer 3 can be interpreted as 'fair to good agreement' and agreement of the other two comparisons as 'poor agreement'. As shown in table 3 , the intrarater agreement of the reviewers varied from 73 to $85 \%$ (kappa value of 0.48 to 0.68 ). 
Table 1. Agrement between the reviewers for the assessment of the appropriateness of diagnostic tests

\begin{tabular}{|c|c|c|c|c|}
\hline & & Reviewer & & \\
\hline & & Appropriate & linappropriate & Total \\
\hline \multirow[t]{5}{*}{ Revlewer 2} & Appropriate & 302 & 105 & 407 \\
\hline & Inappropriate & 257 & 526 & 783 \\
\hline & Total & 559 & 631 & 1190 \\
\hline & & Reviewer 1 & & \\
\hline & & Appropriate & Inappropriate & Total \\
\hline \multirow[t]{5}{*}{ Reviewer 3} & Approprialle & 276 & 104 & 380 \\
\hline & Inappropriate & 286 & 529 & 815 \\
\hline & Total & 562 & 633 & 1195 \\
\hline & & Reviewer 2 & & \\
\hline & & Approprilate & Inappropriate & Total \\
\hline \multirow[t]{3}{*}{ Reviewer 3} & Appropriate & 246 & 150 & 396 \\
\hline & Inappropriate & 161 & 657 & 818 \\
\hline & Total & 407 & 807 & 1214 \\
\hline
\end{tabular}

Table 2. Percentage agreement and kappa values for interrater agreement

\begin{tabular}{llll}
\hline & $\mathbb{R 1 - R 2}$ & $\mathbf{R 1 - R 3}$ & $\mathbf{R 2 - R 3}$ \\
\hline \% Agreement & $70 \%$ & $67 \%$ & $74 \%$ \\
Cohen's kappa & 0.38 & 0.33 & 0.42 \\
\hline
\end{tabular}

Notie: R1 areviewer 1, R2=reviewer 2 and $\mathrm{R} 3=$ reviewer 3

Table 3. Percentage agreement and kappa values for intrarater agreement

\begin{tabular}{llll}
\hline & R1 & R2 & R3 \\
\hline \% Agreement & $73 \%$ & $85 \%$ & $85 \%$ \\
Cohen's kappa & 0.48 & 0.66 & 0.68 \\
\hline
\end{tabular}

Note: R1 srevlewer $1, R 2=$ reviewer 2 and $R 3=$ reviewer 3

The information about complaints was present in $96 \%$ of the forms, the possible diagnosis in $87 \%$, the medical history in $28 \%$, results about physical examination in $61 \%$, medication in $48 \%$ and reason for request in $83 \%$. On $53 \%$ of the forms there was 'enough' information present. All 6 items were filled in in $12 \%$ of the request forms. The requested tests were laboratory tests: clinical chemistry tests $(86 \%)$ and faeces tests $(5 \%)$. Imaging techniques such as X-rays and MRI were requested in $9 \%$ of the cases. The results of the stratified analysis for test type and amount of 
information are presented in table 4 . In this table, two kappa values are very low and not reliable because one of the variables has a low prevalence (26).

Table 4. Percentage agreement and kappa values for interrater agreement stratified by type of test and amount of information presented on the request form by the GP

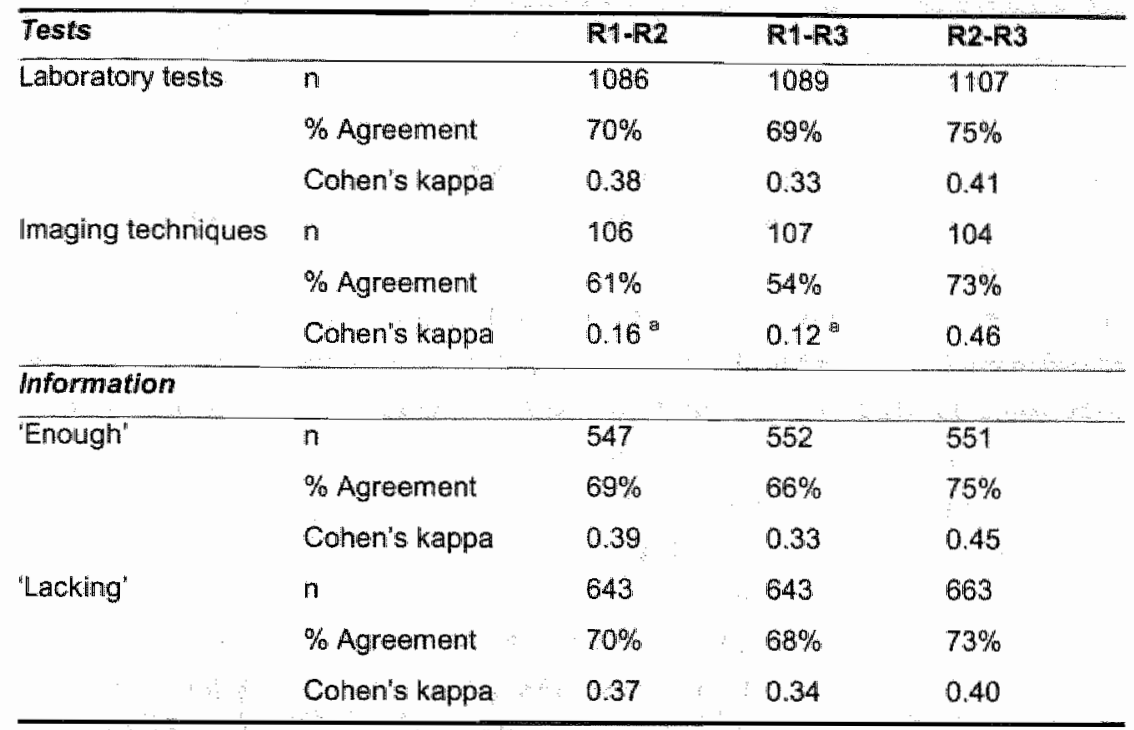

Note: R1=rewewer 1, R2=revilewer 2, R3=reviewer 3 and $n=$ number of tests

"Kappa values are not reliable because one of the varlables has a low prevalence.

In general, no differences were found between the overall agreement (table 2) and the agreement stratified on the amount of information (table 4). Two of three comparisons for imaging techniques (indicated in table 4) show a relatively large decrease in percentage of agreement when the overall agreement is compared to the stratified analysis. However, these results must be interpreted with some caution because the calculation of the kappa value was not reliable due to low prevalence of one of the variables, namely, the assessment of inappropriate test requests by reviewer 1 .

The joint reliability coefficient based on the assessment of all three reviewers is 0.66 . We calculated that we would need 16 reviewers to achieve a joint reliability of 0.95 , necessary to create a reliable assessment allowing conclusions on individual cases (14). This result was generated by solving equation 1 for $n$ and setting the desired reliability to 0.95 .

\section{Discussion}

Based on the interpretation of the cut-off points mentioned earlier (25) the intrarater and interrater agreement are poor to fair at best. The high level of experience for these reviewers suggests that the observed reliabilities may be greater than those 
for less experienced judges. This assumption can be stressed by the fact that the interrater reliabilities involving reviewer 1 , who needed an additional training as a result of less experience in applying the practice guidelines, are lower than that between the other two reviewers.

There are four possible explanations for the observed variation in assessment between the reviewers in our study. Sometimes, it may be difficult for the reviewers to use the guidelines to assess the appropriateness of the requested tests. A major reason is that the practice guidelines are not explicit enough and regularly leave room for differences in interpretation (27). Unspecific terms like 'obvious emotional problems' or 'atypical complaints' are used in the practice guidelines. These terms should be made more explicit.

Second, the reviewers may have interpreted the medical patient information on the request form differently. Occasionally, they indicated that there was a lack of medical patient data or that the information was ambiguous. An example is a request form on which the GP does not mention a clear possible diagnosis but merely indicates to request the diagnostic tests to exclude 'any pathology'. Such situations lead to different assessment of the appropriateness. In addition, for the GPs, it is difficult to write down all thoughts.

The reviewers indicated that they had to review a lot of patient information per request form. In addition, the reviewers based their assessment of the appropriateness of test requests on their recollection of the practice guidelines, which was usual for the feedback procedure used in the Maastricht region. Modern information tools exceeding the human capacity are needed to recall and process large amounts of relevant information under pressure of time. Easily accessible knowledge coupling (matching patient-specific data with general medical insights) could be one of the solutions (28).

Finally, another important reason for the low reliability is the fact that reviewers may use different decision thresholds for classifying tests as appropriate or inappropriate (18). The percentage of cases labelled appropriate ranged from 32 to $47 \%$. Because we do not know the true appropriateness of a requested test, it was not possible to compare the reviewers using ROC (Receiver Operating Characteristics) curves.

The stratified analyses showed that - apparently - more information does not lead to higher agreement. The agreement about the appropriateness of requesting imaging techniques seems to be different from the overall agreement. However, because of the low number of requested imaging tests (109 in total), we should be cautious in drawing conclusions. Possible explanations for this difference in agreement could be that the indications for imaging techniques are less well described in the guidelines and are requested in more complex situations compared to laboratory tests.

A methodological discussion point is the fact that multiple tests can be ordered on one request form. This means that the tests may not be independent of each other. 
We calculated the intraclass correlation coefficient (ICC) for dichotomous variables using the method as described in Snijders and Bosker (29). The ICC ranges from 0 to 1 . We calculated the $I C C$ for each reviewer and found values of $0.037,0.040$, and 0.071 for reviewer 1,2 and 3 , respectively. This indicates that on average $4.9 \%$ of the variance in the outcome variable (appropriateness of requested test) is explained by differences between the request forms. The ICC can also be interpreted as an estimation of the correlation within a request form. Based on the relatively low values of the ICCs, we may conclude that there is hardly any dependence between the judgments of the tests requested on one form.

Other researchers have reported similar moderate kappa values in other medical fields; a meta-analysis by Goldman et al. reported a weighted mean kappa value for interrater agreement of 0.3 based on a peer assessment of 21 independent findings from 13 studies (9).

The average of the individual reliability coefficients we found in our study is comparable to that calculated by Friedman et al. (12), who used the results of the study by van der Lei et al. (30) mentioned earlier. In this study, 8 reviewers were asked to judge 298 comments on the care of patients with hypertension as 'correct' or 'incorrect' by reviewing medical records. Friedman calculated a joint reliability coefficient of 0.65 based on assessments of 8 reviewers. In contrast, a reliability study of 24 experts interpreting chest radiographic reports found a joint reliability of 0.80 . On average, 6 experts were necessary to create a reference standard with a reliability of 0.95 . A single expert was sufficiently reliable to pass the 0.70 criterion for estimating overall performance (14). Hasman et al. (31) have reported an individual reliability coefficient for 6 different sets of pathology reports that varied form 0.80 to 0.89 in a study where the content of these pathology reports were judged by pathologists.

The joint reliability of 0.66 , we found in the present study, is not sufficiently; certainly not sufficient for the purpose we want to use the assessments for. We want to draw conclusions about individual cases, i.e., to give individual feedback on the appropriateness of diagnostic tests. On this case, the reliability should be in the order of 0.95 . We calculated that at least 16 reviewers are necessary to reach a reliability coefficient of 0.95 , but finding 16 reviewers willing to assess the appropriateness of many cases is virtually impossible. It is very unlikely that a personal judgment by an expert peer reviewer is reliable enough for a case-by-case assessment of the appropriateness of tests ordered. Perhaps audit systems should be restricted to an overall assessment over a series of request forms from which the reviewers selects (frequently appearing) examples of irrational requesting behaviour of the GPs. 
Peer review can also be improved by providing guidelines and standards or by using computerised decision support (15). In contrast with methods such as implicit and explicit review mentioned above, the physician is stimulated to follow the distributed practice guidelines on appropriate health care. Next a reviewer or the decision support system checks whether the individual GP adheres to the guidelines and produces feedback if necessary. Guidelines can be seen as important instruments to achieve a higher quality of care (32). Nevertheless, their implementation and use in daily practice are still a problem (33). Unawareness of or disagreement with the guidelines plus working under time constraints are important reasons physicians do not work according to the practice guidelines (34). The use of computers could potentially improve physicians' compliance with predefined care protocols (35). Computer-based decision support systems can be a way to deal with an overload of information and the knowledge coupling mentioned earlier could be a solution ( 28 , $36)$, for example to support relatively straightforward tasks of physicians.

Based on the findings presented in this chapter we conclude that the reliability of the assessment of appropriateness is relatively low and that this feedback method is not reliable enough to make a case-by-case assessment.

\section{References}

1. Studnicki J, Bradham DD, Marshburn J Foulis PR, Straumfjord JV. A feedback system for reducing excessilve laboratory tests. Arch Path Lab Med 1993;117:35-9.

2. Pop P. Winkens RAG. A diagnostic centre for general practitioners: results of individual feedback on diagnostic actions. J R Coll Gen Pract 1989:39:507-8.

3. O'Connell DL, Henry D, Tomlins R. Randomised controlled triall of effect of feedback on general practitioners' prescribing in Australia. BMJ 1999;318:507-11.

4. Mugford M, Banfield P, O'Hanion M. Effects of feedback of information on clinical practice: a review. BMJ 1991;303:398-402.

5. Mitchell MW, Fowkes FGR. Audit reviewed: Does feedback on performance change clinical behaviour? J R Coll Physicians Lond 1985;19(4):251-4.

6. Jorde R, Nordoy A. Improvement in cllinical work through feedback: intervention study. BMJ $1999,318: 1738-9$.

7. Buntinx $F$, Knottnerus JA, Crebolder HF, Seegers T, Essed GG, Schouten H. Does feedback improve the quality of cervical smears? A randomized controlled trial. $\mathrm{Br} J$ Gen Pract 1993;43 (370): 194-8.

8. Grol $R$, Lawrence $M$, van Beurden W. Quality improvement by peer rewiew: Oxford University Press: 1995.

9. Goldman RL. The reliability of peer assessments. A meta-analysis. Eval Health Prof $1994 ; 17$ (1).321.

10. Smith MA, Atherly AJ. Kane RL, Pacala JT. Peer review of the quality of care. Reliability and sources of variability for outcome and process assessments. JAMA 1997;278(19):1573-8,

11. Hayward RA, McMahon LF, Bernard AM. Evaluating the care of general medicine inpatients: how good is implicit review? Ann Intern Mead 1993:118(7):550-6.

12. Friedman CP. Wyatt JC. Evaluation Methods in Medical Informatics. New York: SpringerVerlag; 1997.

13. Kahneman D, Twersky A. On the reality of cognitive illusions. Psychol Rev 1996;103(3):582-91.

14. Hripicsak $G$, Kuperman $G J$, Friedman $C$, Heitjan DF. A reliability study for evaluation extraction 
from radiology reports. JAMIA 1999;6(2):143-50.

15. Goldman RL, Chesco E. Improwing peer review: Alternatiwes to unstructured judgements by a single reviewer. Jt Comm J Qual Improv 1996;22(11):762-9.

16. Hofer TP, Bernstein $S J$, DeMoniner $S$, Hayward RA. Discussion between reviewers does not improve reliability of peer review of hospital quality. Med Care $2000,38(2), 152-61$.

17. Kassirer JP. Our stubborn quest for diagnostic certainty. N Engl J Med 1989;320:1489-91.

18. Pauker $S G$, Kassirer JP. The threshold approach to clinical decision making. N Engl J Med $1980 ; 302(20): 1109-17$.

19. DeKay ML, Asch DA, is the defensive use of diagnostic tests good for patients, or bad? Med Decis Making 1998;18(1):19-8.

20. Winkens RAG, Pop P, Bugter-Maessen AMA, elt al. Randomised controlled trial of routime individual feedback to improve rationality and reduce numbers of test request. Lancet: 1995;345:498-502.

21. Winkens RAG, Pop P, Grol RPTM, et al. Effects of routine individual feedbeck over nine years on general practitioners' requests for tests. BMJ 1996; $312: 490$.

22. Winkens $\mathbb{R A G}$, Ament $A J$, Pop P, Reniers PH, Grol RP, Knottnerus JA. Routine individual feedback on requests for diagnostic tests: an economic evaluation. Med Decis Making 1996;16 (4):309-14.

23. Hripcsak G, Wilcox A. Reference standards, judges, and comparison subjects: Roles for experts in evaluating system performance. JAMIA 2002;9(1):1-15.

24. Friedman C. Towards a measured approach to medical informatics. JAMIA 1999;6(2):176-7.

25. Landis JR, Koch GG. The measurement of observer agreement for categorical data. Biometrics 1979;33:159-74.

26. Donker DK, Hasman $A_{x}$ van Geijn HP. Interpretation of low kappa values. Int J Biomed Compul $1993 ; 33(1): 55-64$.

27. Owens DK. Use of medical informatics to implement and develop clinical practice guidelines. West J Med 1998;168 (3):166-75.

28. Weed LL. Clinical judgement revisited. Methods Inf Med 1999;38:279-86.

29. Snijders TAB, Bosker RJ. Multilevel analysis. An introduction to basic and advanced multilevel modeling. In. Wiltshire: SAGE Publications; 1999. p. 19, 240.

30. vain der Lei J, Musen MA, van der Does E, Man in 't Veld AJ, van Bemmel JH. Comparison of computer-aided and human review of general practitioners' management of hypertension. Lancet $1991,338: 1504-8$.

31. Hasman $A$, Bruijn $4 M$, Arends JW. Evaluation of a method that supports the coding of pathology reports. Methods Inf Med 2001;40:293-7.

32. Woolf $\mathrm{SH}$, Grol $\mathrm{R}$, Hutchinson $\mathrm{A}$, Eccles $\mathrm{M}$, Grimshaw J. Clinical guildelines: potential benefits, limitations, and harms of clinical guldelines. BMJ 1999;318:527-30.

33. Grol $R$, Eccles $M$, Maisonmeuve $H$, Woolf $S$. Developing clinical practice guidelines: The European experience. Dis Manage Health Outcomes 1998;4(5):255-66.

34. Cabana MD, Rand $C S$, Powe $N R$, et al. Why don't physicians follow clinical practice guidelines?: A framework for improvement. JAMA 1999;282:1458-65.

35. MCDonald CJ. Protocol-based computer reminders, the quality of care and the nonperfectability of man. N Engl J Med 1976;295:1351-5.

36. Vissers MC, Biert J, wan der Linden C.J Hasman A. Effects of a supportive protocol processing system (PratoVIEW) on clinical behaviour of residents in the accident and emergency department. Comput Methods Programs Biomed 1996;49(2):177-84. 
$+3$

3

: :

$\therefore$

$\therefore$

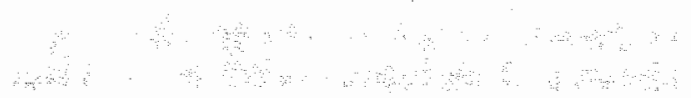

$\because \quad \because \quad:$

a

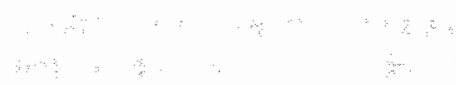

$\therefore:$ 


\section{CHAPTER 5}

VALIDATION OF GRIF

Published as:

R. Bindels, R.A.G. Winkens, P. Pop, J.W.J. van Wersch, A. Hasman

Validation of a knowledge based reminder system for diagnostic test ordering in general practice. International Joumal of Medical informatics (2001) 64 pp 341.354 . 


\section{Introduction}

The validity and reliability of peer review of medical practice is known to be questionable due to the variability in assessment of the peer reviewers $(1,2)$. Usually, there is one reviewer. Peer review can be expanded for example by using multiple reviewers in the process, or by guidelines and standards or computerised decision support (3).

The use of knowledge based decision support systems is becoming more and more popular in medicine (4-8). These systems are developed to assist physicians in making medical decisions to provide better care. To manage the quest for diagnostic certainty (9) and to improve appropriateness of diagnostic test requests, the GRIF automated reminder system was developed (10). The system should be instrumental in changing General Practitioners' (GP) test ardering behaviour. GRIF is a Dutch abbreviation of automated reminders as interactive feedback. At the moment the GP requests a diagnostic test that is not in line with accepted guidelines, the system generates a critical comment about the rationality of the test request. Several studies concluded that automated reminder systems for diagnostic test ordering are effective (11-16). As for reminders, two main approaches can be distinguished: pro-active and re-active reminders. Pro-active reminders suggest tests after patient data requested by the system have been entered, whereas reactive reminders give comments after tests are chosen but before they are ordered. Our real-time automated reminder system is a re-active system focusing on a range of diagnostic tests in use in primary care.

Before implementing GRIF for broad routine use, it should be evaluated in daily practice. The evaluation process can be divided into the following phases: verification, validation and testing. The validation of the knowledge base is a fundamental step and refers to checks concerning the accuracy of the reminders given by the reminder system (17), or to an investigation of the expected performance of the reminder system in realistic clinical circumstances (18). Other factors such as the usefulness of the reminder system, its user interface and its user's satisfaction are not taken into account during the validation process. In the validation process, problems may concern the precise definition of the systems' objectives as well as the subjective judgments of human evaluators (19). In our situation, an abjective 'gold standard' is lacking since practice guidelines, from which the rules in the knowledge base are derived, can be interpreted differently by each physician.

\section{Background}

Different methods are used to assess the appropriateness of healthcare services such as diagnostic test ordering, prescribing medications, etc. In the Maastricht region, the Transmural \& Diagnostic Centre (T\&DC) has been providing feedback (a form of peer review) in the form of written reports to GPs in the Maastricht region 
since 1985 (20-26). Twice a year, each GP receives a feedback report with critical comments on his or her test requests in a previous month. The individual written feedback is based on a comparison of requests with accepted valid guidelines using provided clinical data. Previous studies showed that this feedback on GPs" test ordering behaviour was highly effective and was appreciated by the GPS $(21,27$. 28 ). Since this type of feedback is rather time consuming, the need arose to automate the procedure.

This chapter describes the development process and the validation of GRIF's knowledge base. We compared the adequacy of test requests using GRIF with the assessment of three expert physicians in a realistic situation.

\section{Development of the knowledge base}

\section{Selection of guidelines}

We used national and regional guidelines that are in use for several years in the participating general practices. The national guidelines, named standards, were developed by the Dutch Royal College of General Practitioners (NHG) and were published in the Dutch scientific journal for General Practice (Huisarts en Wetenschap) since 1988. These standards are meant to reflect the 'state of the art' practice for managing certain diseases and symptoms in Dutch general practices and are used for medical audit, quality assurance, evaluation in vocational training and continuing education. Up till now, 70 national standards have been published. A number of these standards provide limited advice on diagnostic tests ordering. The regional guidelines, developed by the T\&DC in Maastricht, focus entirely on indications for diagnostic tests. GPs in the Maastricht region know these guidelines because they are used in continuing education and the guidelines are referred to in the conventional feedback reports that the GPs receive every half-year (27).

\section{Formalisation of the guidelines}

To build the knowledge base, practice guidelines about ordering diagnostic tests have to be translated into a formal language $(29,30)$. After studying the guidelines, it was concluded that IF-THEN rules could be used for knowledge representation. In these rules the conclusion only contains the order to print a reminder text. The researcher (discipline medical informatics), a general practitioner and an experienced internist translated the guidelines into IF-THEN rules (using natural language).

The regional guidelines are divided into the sections: goals, indications, remarks on indications, available tests, costs and interpretation of results. Recommendations are found in the sections aims, indications and remarks on indications. In total, 21 guidelines were translated into IF-THEN rules (in natural language). The national standards have a different structure depending on the described medical problem. However, 47 of the standards contained a separate section on diagnostic tests (see table 1). All the recommendations in these sections were translated into natural 
language IF-THEN rules (see column 2, table 1).

Table 1. Translation from written practice guidelines into computerised IF-THEN rules.

\begin{tabular}{lllll}
\hline Practice guidelines & \multicolumn{2}{l}{ IF-THEN rules } & Computerised rules \\
\hline Instifution & Number & Available & Used & \\
\hline T\&DC (regional) & 21 & 98 & 37 & 85 \\
NHG (national) & 47 & 182 & 55 & 69 \\
\hline Total & 68 & 280 & $92(33 \%)$ & 154 \\
\hline
\end{tabular}

The rules were then formalised into computerised rules. The expressions of these rules consist of logical propositions combined with Boolean operators, such as AND, OR or NOT. For example:

TE age is lower than 10

AND sinus $x$-ray is requested

THEN give reminder text: 'Ordering a sinus $x$-ray for children younger than 10 years is not advisable.'

The conditions of the rules can contain a requested test, medical patient information, personal information (age and gender) or a combination of these types of information.

Column 3 in table 1 shows that not all rules derived from the practice guidelines were used to build the computerised rules. We chose to formalise the well-defined rules first. Only $33 \%$ of the rules could be easily formalised and, subsequently, be stored in the knowledge base. The rules that were not computerised lacked welldefined conditions such as 'the elderly', 'clear emotional problems' or 'atypical complaints'. These terms should be described in more detail before they can be formalised. In addition, in some of the rules other information was needed such as the duration of complaints; the nature of the consultation (first consult, second consult) or the findings of the physical examination, which were not readily available to us.

One IF-THEN rule can result in more than one computerised rule. For example, a rule from the guideline "cultures for patients with diarrhoea" resulted in 4 different computerised rules, one for each culture. Since 5 rules are mentioned both in the national and the regional guidelines, the knowledge base contains 149 rules and not 154 as could be expected from table 1.

\section{Methods}

\section{The GRIF automated reminder system}

The GRIF automated reminder system "described elsewhere in more detail (31), is coupled to a GP information system when used in daily practice. First, the GP 
enters the diagnostic tests he wants to order and additional relevant medical patient information into the request form of the reminder system. These medical data consist of working hypotheses, signs and complaints, physical examination results and the reason for the test request. The medical terms have to be entered using ICPC (International Classification of Primary Care (32)) codes. A search program assists the user in the selection of the appropriate terms that are associated with an ICPC code. Due to this standardisation of terminology, the computerised rules are based on ICPC codes only. Next, the reminder system reads the patient data and checks whether any of the rules in the knowledge base will fire. If a rule fires, the corresponding reminder is generated immediately and presented by means of a pop-up window, overlaying the interface of the request form (figure 1). The reminder window contains critical comments about the requested tests as well as a link to the text of the practice guideline for more explanation.

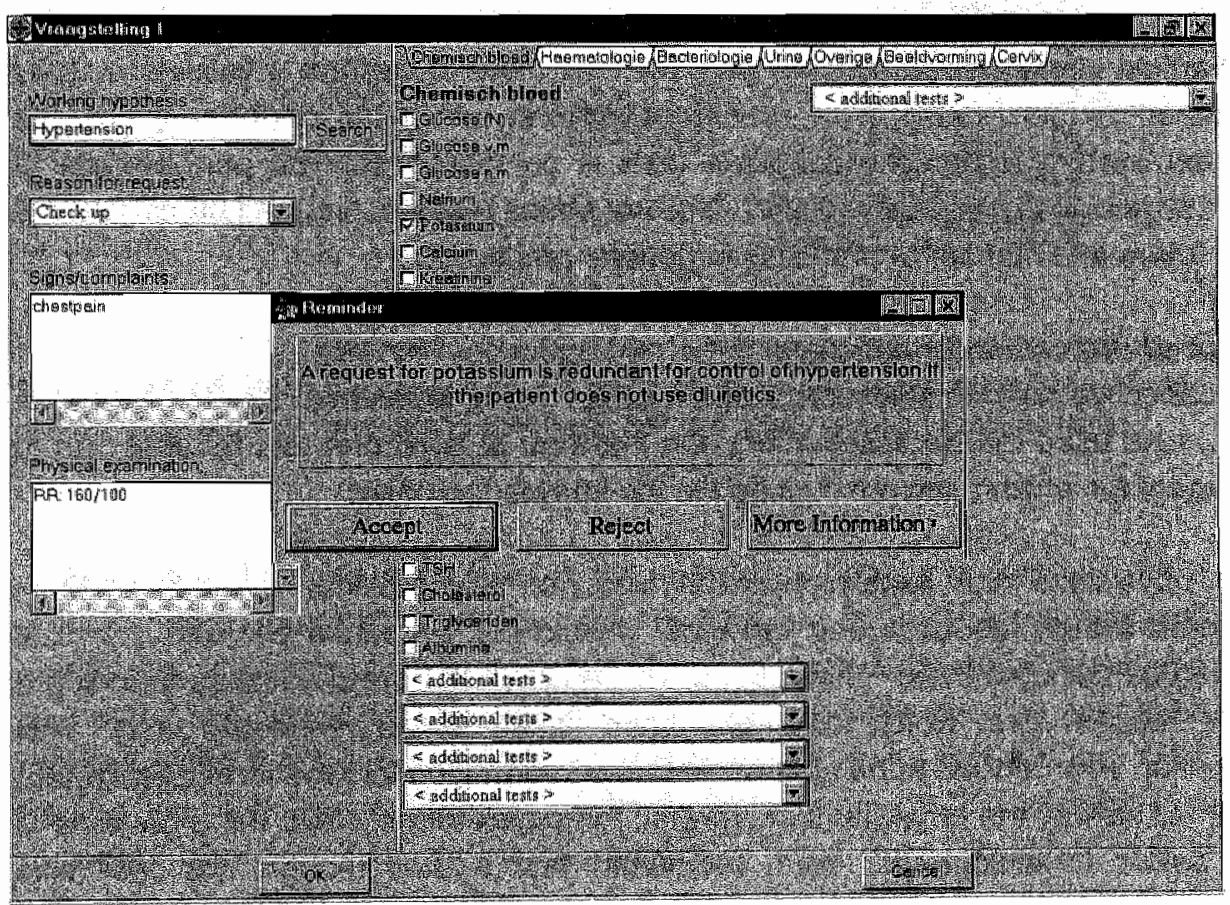

Figure 1. If a request is not according to the guidelines, the reminder system displays a reminder that overlays the normal user interface of the request form. Only the relevant words in the figure were translated from Dutch into English.

\section{Evaluation strategy}

The system was first verified and then validated. Verification refers to an internal static check on the system that can be performed without test cases, and validation refers to tests performed to check the accuracy of the results given by the system, 
Le., the performance of the system itself (17).

The method that was used to evaluate the knowledge base of the GRIF reminder system resembles the strategy of Molino and Molino (33). First, two clinicians and the researcher carried out an error analysis, a logical verification to detect contradictions and conflicts in the knowledge base (face validity): The updated version was used for verification. A crude indication of the agreement between an expert and the system using subsequent training sets was obtained (results are published elsewhere (31)). A structure verification (detection of duplication of rules, circular rules and redundancies) of the knowledge base (34) was also carried out using a rule compiler (35), and the domain coverage was estimated. The actual reminder system contains 149 reminders concerning various medical problems. The 78 tests that are dealt with by the reminder system cover most of the frequently requested tests, accounting for $75 \%$ of the total amount of the requested tests approximately.

The verified version of the knowledge base was used to perform a validation study (described in more detall in the section below) in which the performance of the reminder system to detect inadequate tests is compared with the performance of expert physicians (construct validity). The last phase (field-testing) will be carried out in the future in a number of practices in general practice.

\section{Design of the validation study}

A retrospective random selection of 253 request forms, taken from the archive of the T\&DC, was used for the assessment. On the form at least one test request had to be present for which rules are included in the knowledge base.

Three physicians (the expert physician who normally provides the conventional structured written feedback and two other physicians, an expert GP and a clinical chemist) participated in our study. First, we asked one of the physicians to indicate on the request form which diagnoses were linked to the requested tests. This information was needed to be able to enter the information into the reminder system similar to the way the physicians interpreted the paper forms. Next, the 3 physicians were asked to indicate for each requested test if they thought the test was appropriately requested or not. Finally, the medical patient information was translated into ICPC codes using the GRIF ICPC search module (31) and the information on the request forms was entered into the reminder system. The reminders were collected per form and, as shown in figure 2, the reminders can cover one test or a group of related tests. If one reminder covers more than one test this is translated on test request level into comments on the individual requested tests. 


\section{Type of feedback}

In addition, we asked the expert physician to indicate what kind of feedback he would give if the test request was not appropriate. Remarks could be sconed in three categories: 1) feedback on the basis of the guidelines, 2) remarks about insufficient patient information on the request form or 3) other kinds of feedback. In free text he could indicate the content of this 'other kind of feedback'.

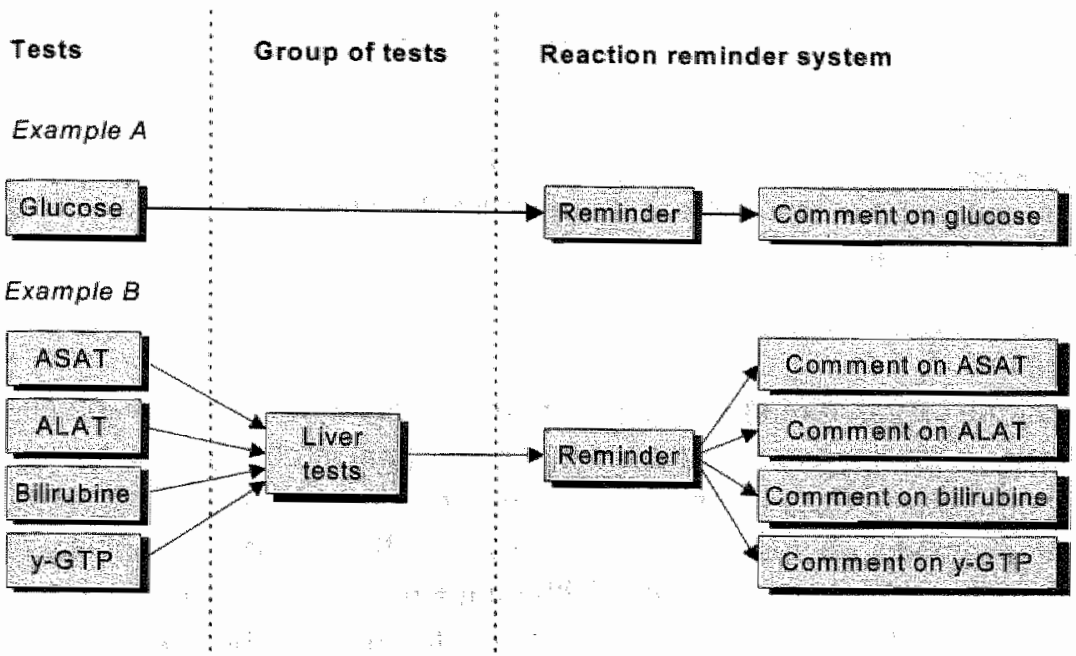

Figure 2. Relationship between the individual tests, reminders and comments. In certain cases (example B) reminders are given about a combination of related tests (e.g. liver tests). In this case one reminder is given, consisting of comments that specifically focus on separate tests.

\section{Detailed analyses}

The best way to validate the rules in the knowledge base is to compare them with a gold standard. In our situation the gold standard are the written practice guidelines. The humans, expert physicians in our situation, assess the appropriateness of the requested test based on their interpretation of the guidelines. The best standard is created when the experts consult the guidelines for every test request they judge. As this was too labour-intensive for the 1217 tests on the 253 request forms, the majority assessment of the three assessors was used. In case this majority assessment agreed with the judgment of the reminder system, it was assumed that the reminder system reacted correctly. A random sample of 50 request forms was further investigated to check this assumption. Differences between the majority assessment and the reminder system were analysed in more detall by inspection of the written guidelines. Finally, the reason why the reminder system did not react appropriately was studied in co-operation with the researcher who had insight into the way the computerised rules were constructed. 


\section{Results}

On the 253 forms in total 1217 diagnostic tests were requested. On average, the form contained 4.8 tests per form with a maximum of 17 tests. For 15 requested tests $(1 \%)$ the majority assessment of the physicians could not be determined because the assessments of one or more of the reviewers were missing. The reminder system produced 442 reminders, a mean of 1.75 per request form. No reminders were given for $29 \%$ of the forms, $27 \%$ of the forms received one reminder, $16 \%$ two reminders, $12 \%$ three reminders, $6 \%$ four reminders and $10 \%$ more than four reminders with a maximum of 8 reminders per form. Of a total of 149 rules in the knowledge base, 61 different rules fired. On average, each rule fires 7 times. The non-performance of each rule (number of times that a rule fires incorrectly) is listed in the appendix. II.

\section{Type of feedback}

Thirty-seven percent of the remarks of the expert physician were based on the practice guidelines, in $7 \%$ the expert indicated that insufficient information was given on the request form and in $56 \%$ the would give another kind of feedback. In most cases, these latter remarks contain questions concerning the pre-test probability of the working hypothesis or questions to the GP about his or her expectations what to do with the results of the requested test(s). Less frequently, the expert asks questions about risk factors of the patient or gives remarks about vague signs and complaints of the patient in relation to the requested tests.

\section{Detailed analyses}

The reminder system produced comments on 100 requested tests where the majority assessment of the physicians indicated no comments (table 2). These requests were further analysed using the written practice guidelines. It could be concluded that the system gave 41 incorrect comments on the requested tests (table 3). 29 Comments were given because the reminder system could not take into account relevant information. This relevant information concerned medications (14 out of 29) or results of prior diagnostic tests ( 3 out of 29), items that are not yet considered by the reminder system. Twelve comments (out of 29) were given because the reminder system couldn't take into account relevant information due to the absence of a suitable ICPC code. For example 'working in the food industry' or 'has recently been to the tropics' could not be coded using ICPC. Seven comments were given incorrectly because no working hypothesis was indicated on the request form while the physicians could infer this hypothesis based on the complaints and/or medication of the patient. For the other five given comments the ICPC codes in the IF-THEN rule should be modified to get a correct reaction of the reminder system. 
Although the system did not produce an advice, comments on 240 requested tests should have been given according to the majority assessment of the physicians. Consulting the written guidelines, it appeared that the reminder system correctly did not comment on 122 requested of these tests. The other 118 requested tests were judged as incorrect (table 3) and should have resuited in 92 reminders, 31 different rules.

Table 2. Agreement between the majority assesisment of the physicians and the reminder system.

\begin{tabular}{lllll}
\hline & & \multicolumn{3}{l}{$\begin{array}{l}\text { Appropriate tests } \\
\text { according to physicians }\end{array}$} \\
\cline { 3 - 5 } & & Yes & No & Total \\
\cline { 3 - 5 } $\begin{array}{l}\text { Appropriate tests } \\
\text { according to }\end{array}$ & Yes & 326 & 240 & 566 \\
reminder system & No & 100 & 522 & 622 \\
& Total & 426 & 762 & 1188 \\
\hline
\end{tabular}

Table 3. Reasons why a test was judged incorrectly as appropriate (a comment was given) or was incorrectly judged appropriate (a comment was not given).

\begin{tabular}{lll}
\hline Reason & $\begin{array}{l}\text { Incorrectly } \\
\text { not appropriate }\end{array}$ & $\begin{array}{l}\text { Incorrectly } \\
\text { appropriate }\end{array}$ \\
\hline No reminder in KB & - & 72 \\
System couldn"t check & 29 & 10 \\
- Medication & 14 & 5 \\
- No ICPC-code available & 12 & 3 \\
- Prior diagnostic tests & 3 & 1 \\
- Physical examination & - & 1 \\
No working hypothesis & 7 & - \\
Error IF-THEN rule & 5 & 25 \\
No information & & 11 \\
\hline Total & 41 & 118 \\
\hline
\end{tabular}

For 72 of these incorrect judgments there was no rule in the current knowledge base. Among them, comments about HbA1C (10 times) and sodium (13 times) are most frequently missed. Moreover, $21 \%$ (25 cases) of the incorrect comments were not given because some rules in the knowledge base contained an error. For example, the reminder system made no distinction between cholesterol, HDLcholesterol and triglycerides while the physicians did. Eight percent (10 cases) of the missing comments were due to the fact that the reminder system could not take into account medication, prior results of diagnostic tests and results of physical examination or the information could not be coded using ICPC codes. Finally, $9 \%$ (11 cases) of the comments were not given because there was no information on 
the request form.

In total, in $13 \%$ of the requested tests the reminder system did not react correctly $(41+118$ out of 1188$)$. Because one reminder can deal with more than one test (figure 2), 32 reminders were responsible for comments on 41 requested tests where the reminder system produced an incorrect reaction. This indicates that 32 of the 442 given reminders (7\%) were given incorrectly (false positive reminders).

\section{Discussion}

In this chapter the design and validation of a knowledge based reminder system that monitors and critiques the diagnostic test ordering behaviour of GPS was presented. The validation of the current knowledge base is not complete yet. The comments of the reminder system were tested with real cases, which resulted in the validation of only a part of the knowledge base. As was stated in the section Results, 61 different computerised rules of a total of 149 rules fired. The other 88 rules did not fire because a corresponding inappropriate test request was not on the request forms. We are sure that 25 of those rules are so obvious that no validation is needed. These rules concern checks on the presence of information (working hypothesis and reason for request), remarks about obsolete tests or simple checks such as ordering a mammography for a man. The other 63 rules that never generated a reminder will be validated by tracking their behaviour on future cases.

\section{Type of feedback}

The expert gives a relatively large percentage of remarks $(56 \%)$ that are not based on the practice guidelines nor related to the given medical unformation. These remarks of the expert often concern questions to the GP about his or her expectations what to do with the results of the requested test(s) or questions concerning the pre-test probability. Tierney et al. (13) and Dupuits et al. (36) used information about pre-test probability in their automated systems. The GRIF reminder system, on the other hand, does not take these probabilities into account.

\section{Detailed analyses}

The differences between the majority assessment of the physicians and the reminder system were further analysed using the written guidelines. In total 32 reminders were given incorrectly (table 3). Twenty-one of these reminders can be classifled as a 'soft' reminder, indicating that the reminder contains an advice or overall remark and only has an informative character. Eleven reminders that firmly reject a certain test request can be classified as "hard' (see also appendix 1ll). It is our goall to minimize the incorrect presentation of these "hard" reminders.

The fact that rules did not react correctly $100 \%$ was caused mainly by the fact that the rule could not be formulated correctly, because one condition could not be stated in ICPC terms. Since this condition does not occur frequently, it was 
accepted that sometimes a rule could fire incorrectly or not fire at all. By defining extra codes these errors can be solved in the future.

More comments (118 in total) should have been given by the reminder system. The most important reason why a reminder was not given was that a corresponding rule in the knowledge base was absent. As mentioned earlier, we focused on well formalisable rules based on data that could easily be collected. Rules that would need information that is more difficult to obtain in a consistent, automatic way, e.g. whether a test is performed in the last 3 months, have not yet been implemented. This situation will change in the future when we will add more rules to the knowledge base.

Compared with the guidelines, the accuracy of the reminder system was $87 \%$ (in 13 $\%$ of the requested tests the reminder system did not react correct). It was assumed that for the cases in which the reminder system agreed with the majority of the reviewers, the reminder system reacted properly. To assess the validity of this assumption, we took a random sample of 50 forms and checked these requests with the written practice guidelines for which the majority assessment and the reminder system agreed ( 88 requested test). In 4 of these 88 requested tests $(4.5 \%)$, the majority judgment of the reviewers appeared to be incorrect. If this error estimation is representative for the whole population, the reminder system has an accuracy of $82.5 \%$.

\section{Number of reminders}

A relatively large number of reminders per request form ( 5 reminders or more) were given in relation to $25(10 \%)$ request forms. This large number of reminders per form might result in irritation of the users fowards the reminder system. The main cause for this problem is the fact that no clear working hypotheses were recorded on the request forms. Fourteen request forms deal with a-specific vague terms such as 'pathology?', "abnormality?' or 'check up'. Further, on 5 request forms the working hypotheses fatigue and/or total malaise are indicated. GPs request a lot of tests in these situations, whereas the rationality of these tests is often doubtful. In order to reduce the number of reminders windows, the reminder system has been changed in such a way that the system will present only one window containing the various reminders instead of the presentation of one reminder after the other, as indicated in figure 1.

\section{Use in daily practice}

In real practice, the GRIF reminder system functions slightly different than the way it was validated. The reminder system notifies the GP that e.g. the working hypothesis or the reason for request is not entered. The GP may enter these missing data after being notified. Due to the retrospective nature of the validation study, interaction between GP and reminder system was not possible and as a result some 
information that could be relevant for the reminder system to react properly was missing. We think that by stimulating the GP to fill in these data, the reminder system can react more adequately.

The fact that the knowledge base is not complete (not all the advice from the written guidelines are translated into rules) could be a problem in daily practice. Therefore we notify future users that the knowledge base is not complete and that they are always responsible for their actions. Due to the complex nature of the situations under which diagnostic tests are requested, it is still necessary to rely on the GP's human expertise. The reminder system we developed does not replace the GP's decision making. The current reminder system merely focuses on diagnostic tests that are unnecessary, whereas situations where tests are incorrectly not requested may also be non-rational. In the future these situations should be included into the reminder system. The reminder system could indicate which tests need to be requested in case of a certain working hypothesis and given patient data. For this to be possible the GP must enter the necessary data into the EPR, so that the reminder system can retrieve them. The amount of information and the detail (the specificity of the terms) in which the GP describes the patients' medical status are crucial for the reminder system to react correctly.

The agreement between reminder system and the physicians is acceptable and also the percentage incorrectly given reminders is satisfactorily low. Therefore, we will start, after some adjustments of the rules in the knowledge base, an investigation of the impact of the reminder system in daily practice. This investigation will reveal whether the use of this system is effective and appreciated by the GPs.

\section{References}

1. Goldrnan RL. The reliability of peer assessments of quality of care. JAMA 1992;267(7):958960.

2. Smith MA, Atherly AJ, Kane RL, Pacala JT. Peer review of the quallity of care. Reliability and sources of variability for outcome and process assessments. JAMA 1997;278(19):1573-1578.

3. Goldman RL, Chesco E. Improwing peer review: Alternatives to unstructured judgements by a single reviewer. Joint Commission Journal on Quality Improvement 1996;22(11):762-769.

4. Bates DW, Pappius $E_{k}$ Kuperman $G_{1}$, Sittig D, Burstin $H_{n}$ Fairchild $D$, et al. Using information systems to measure and improve quality. International Journal Of Medical informatics 1999;53:115-124.

5. Young AJ, Beswick KBJ. Decision support in the United Kingdom for general practice: Past, present and future. In: Greenes $R$, Peterson $H_{1}$ Protti $D_{1}$ editors, Medinfo; 1995; Vancouver, Britisch Colombla, Canada: IMIA; 1995. p. 1025-1029

6. Johnston ME, Langton KB, Haynes RB, Mathieu A. Effects of computer-based clinical decision support systems on clinician performance and patient outcome: A critical appraisal of research. Annals of Internal Medicine 1994:120:135-142.

7. Balas EA, Austin SM, Mitchell JA, Ewigman BG, Bopp KD, Brown GD. The clinical value of computerized information services. A review of 98 randomized clinical trials. Archives of Family Medicine 1996;5(5):271-8.

8. Shea S, DuMouchel W, Bahamonde L. A meta-analysis of 16 randomized controlled trials to evaluate computer-based clinical reminder systems for preventive care in the ambulatory 
setting. Journal of the American Medical Informatics Association 1996;3(6);399-409.

9. Kassirer JP. Our stubborn quest for dilagnostic certainty. New England Jlournal of Medicine $1989 ; 320: 1489-1491$.

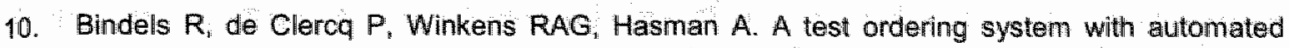
reminders for primary care based on practice guidelines. International Journal of Medical Informatics 2000;58-59:219-233.

11. McDonald $C J$, Hui SL, Smith DM, Tierney WM, Cohen SJ, Weinberger M, et al. Reminders to physicians from an introspective computer medical record. A two-year randiomizedi trial. Annals of Internal Medicine 1984; $100: 130-138$.

12. Nightingale $P G$, Peters $M$, Mutimer $D$, Neuberger JM. Effects of a computerised protocol management system on ordering of clinical tests. Quality in Health Care 1994;3:23-28.

13. Tierney WM, McDonald CJ, Hui SL, Martin DK. Computer predictions of abnormal test results: effects on outpatient testing. Journal of the American Medical Association 1988;259(8):11941198.

14. Bates DW, Kuperman GJ, Rittenberg E, Telich JM, Onderdionk A, Winkelman J, et al. Reminders for redundant tests: results of a randomized controlled trial. Proceedings / The Annual Symposium on Computer Applications in Medical Care 1995:19:935.

15. Harpole LH, Khorasani R, Fiskio J, Kuperman GJ, Bates DW. Automated evidence-based critiquing of orders for abdominal radiographs: impact on utilization and appropriateness. Journal of the American Medical Informatics Association 1997;4(6):511-521.

16. van Wijk MAW, Mosseveld $M_{1}$ van der Lei J. Design of a decision support system fot the test ordering in general practice: choices and decision to make. Methods of Information in Medicine 1999;38(4-5):355-361.

17. Engelbrecht $R$, Rector A, Moser W. Verification and validation. In: van Gennip E, Talmon J, editors. Assessment and evaluation of information technologies in medicine. Amsterdam: $10 \mathrm{~S}$ Press; 1995. p. 51-66.

18. Talmon J, Smeets R. Case acquisition for Knowledge-Based Decision Support System validation. In: van Gennip $E$, Talmon J, editors. Assessment and evaluation of information technologies in medicine. Amsterdam: IOS Press; 1995. p. 67-74.

19. Ohayon MM. Validation of expert systems: examples and considerations. In: Greenes $R$, Peterson H. Protti D, editors. Medinfo; 1995; Vancouver, Britisch Colombia, Canada: IMIA; 1995. p. $1071-1075$.

20. Studnicki J, Bracham DD, Marshburin ل, Foulis PR, Straumfjord JV. A feedback system for reducing excessive laboratory tests. Archives of Pathology and Laboratory Medicine 1993;117:35-39.

21. Pop $P$, Winkens RAG. A diagnostic centre for general practitioners: results of individual feedback on diagnostic actions. Journal of Royal College of General Practitioners 1989;39:507-508.

22. O'Connell DL, Henry $D$, Tomlins R. Randomised controlled trial of effect of feedback on general practitioners' prescribing in Australia. Britisch Medical Journal 1999;318:507-511.

23. Mugford M. Banfield $P, O^{\prime}$ Hanlon M. Effects of feedback of information on clinical practice: a review. British Medical Journal 1991;303:398-402.

24. Mitchell MW. Fowkes FGR. Audit reviewed: Does feedback on performance change clinical behaviour? Journal of the Royal College of Physicians of London 1985;19(4):251-254.

25. Jorde R, Nordoy A. Improvement in clinical work through feedback: intervention study. Britisch Medical Journal 1999;318:1738-1739.

26. Buntinx $F$, Knottnerus $J A$, Crebolder $H F$, Seegers $T$, Essed $G G$, Schouten $H$. Does feedback improve the quality of cervical smears? A randomized controlled trial. British Journal of General Practice 1993;43(370):194-8.

27. Winkens RAG, Pop P, Bugter-Maessen AMA, Grol RPTM, Kester ADM, Beusmans GHMI, et 
al. Randomised controlled trial of routine individual feedback to improve tationality and reduce numbers of test request. The Lancet 1995;345:498-502.

28. Winkens RAG, Pop P, Grol RPTM, Bugter-Maessen AlMA, Kester ADM, Beusmans GHMI, et at. Effects of routine individual feedback over nine years on general practitioners' requests for tests. British Medical Journal 1996,312:490.

29. Shifman RN. Representation of elinical practice guidelines in conventional and augmented decision tables. Joumal of the American Medical Informatics Association 1997;4(5):382-393.

30. Tlemey WM, Overhage JM, Takesue BY, Harris $L E_{\text {; }}$ Murray $M D$, Vargo $D L$, et al. Computerizing quidelines to improve care and patient outcomes: The example of heart failure. Joumal of the American Medical Informatics Association 1995;2(5):316-322.

31. Bindels $R$, Hasman $A$ Winkens $R$. Dewelopment of a reminder system for General Practitioners: In Kokol P, Zupan B, Stare J, Premik $M$; Engelbracht $R$, editors. Medical Informatics Europe 99 Conference; 1998; Ljubljana: IOS Press; 1999. p. 745-748.

32. Lamberts $H_{\text {. Wood } M}$. International Classification of Primary Care. 3rd ed. Oxford: Oxford University Press; 1987.

33. Molino G, Molino F. Assessment and evaluation of knowledge-based expert systems for medical diagnosis. In: van Gennip EMSJ, Talmon JL, editors. Assessment and evaluation of information technologies in medicine. Amsterdam: IOS Press; 1995. p. 151-166.

34. Fieschi M. Towards validation of expert systems as medical decision aids. International لournal of Bio-Medical Computing 1990;26:93-108.

35. Blom JA. Temporal logics and real time expert systems. Computer Methods and Programs in Biomedicine 1996;51:35-49.

36. Dupults FMHM, Pop P, Hasman A, Schouten HJA. A rational request behavior: The development of prediction instruments regarding thyroid function tests in primary care. Methods of Information in Medicine 1999;38(1):31-36. 
PART II

EVALUATION 


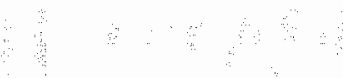




\section{CHAPTER 6}

EVALUATION OF GRIF IN A LABORATORY SETTING

Submitted as:

R. Bindels, A. Hasman, A. Kester, J.W.d. van Wersch,

J. Talmon, P.A. de Clercq, R.A.G. Winkens

The efficacy of an automated feedback system for General Practitioners. 


\section{Introduction}

Over the past 20 years, the number of requested diagnostic tests has increased both in primary and secondary health care which results in an increased pressure on clinical laboratories (1). Part of the increase in test consumption is understandable and can be explained by the ageing of the patient population and the growth in the number of preventive tasks in the practice of the physician. On the other hand, the increase is also caused by the care demand of the patients and the increased availability of new diagnostic tests $(2,3)$ for which the appropriateness of test use is not always clear (4).

Guidelines, such as guidelines on appropriate test ordering, are developed to improve the quality of care and reduce unnecessary diagnostic test consumption, but their implementation and use in daily practice are a problem $(5,6)$. Therefore, it is important to develop tools that improve physicians' adherence to guidelines. Decision support systems have gained popularity as an implementation strategy over the past 10 years (7-9). These systems have the potential to change physicians' behaviour, test ordering in particular (10). The advice of the system (a recommendation) describes the discrepancies between the physicians" actions and the guidelines, offering recommendations for improvement.

An automated feedback system named GRIF $^{1}$ was developed (11) and validated (12). GRIF is meant to stimulate the adherence to accepted practice guidelines on diagnostic tests. This system was developed to support or even replace the written feedback provided by the Transmural Care Unit (TCU) of the Maastricht University Hospital since 1985 (13).

To use the GRIF system in daily practice the general practitioner (GP) must enter relevant medical patient data (signs, symptoms, working hypotheses and the reason for request) and the tests to be ordered into an electronic order entry form. The knowledge base in which the recommendations are stored, now contains 150 rules (recommendations) derived from guidelines about various medical problems (11). A recommendation shows up whenever a request for diagnostic tests is not in accordance with the practice guidelines. The GP then decides to accept or reject the recommendation.

The objective of the experiment described in this chapter is to assess the efficacy of an automated feedback system. To obtain a gold standard, effects should be determined in an optimal situation, without the influence of practice conditions and the demanding patient. This may show the efficacy of the system and the magnitude of effects when such an intervention is used in daily practice.

1 GRIF is the Dutch acronym for "Geautomatiseerde Reminders als Interactieve Feedback' (Automated Reminders as Interactive Feedback). 


\section{Methods}

Thity from the approximately 90 GPs in the Mastricht region were randonily selected to participate in this study. Twenty-four GPs (80\%) agreed to participate. For each GP, a random sample of request forms he or she had submitted to the Transmural Care Unit in the preceding year was taken. Patient information (gender, age and medical information such as working hypothesis, complaints and medical history) was entered into the electronic order entry form of the GRIF program and International Classification of Primary Care (ICPC) codes were added to the medical patient data. The request forms were made anonymous so that knowledge of test results would not influence the GPs" juidgements.

In a laboratory setting, the GPs were confronted with the advice of the GRIF system on their earlier ordered diagnostic tests. The intervention took place at the Maastricht University in five group sessions. To ensure that GPs still approved their own test requests, we allowed them to remove or add tests. Then, the system was activated. The GP could accept or ignore the presented recommendations. The GPs had to work through the 30 cases one-by-one within limited time period ( 45 minutes) to simulate time pressure during real patient consultation. An overview of the different steps in the experiment and the items measured is presented in figure 1.

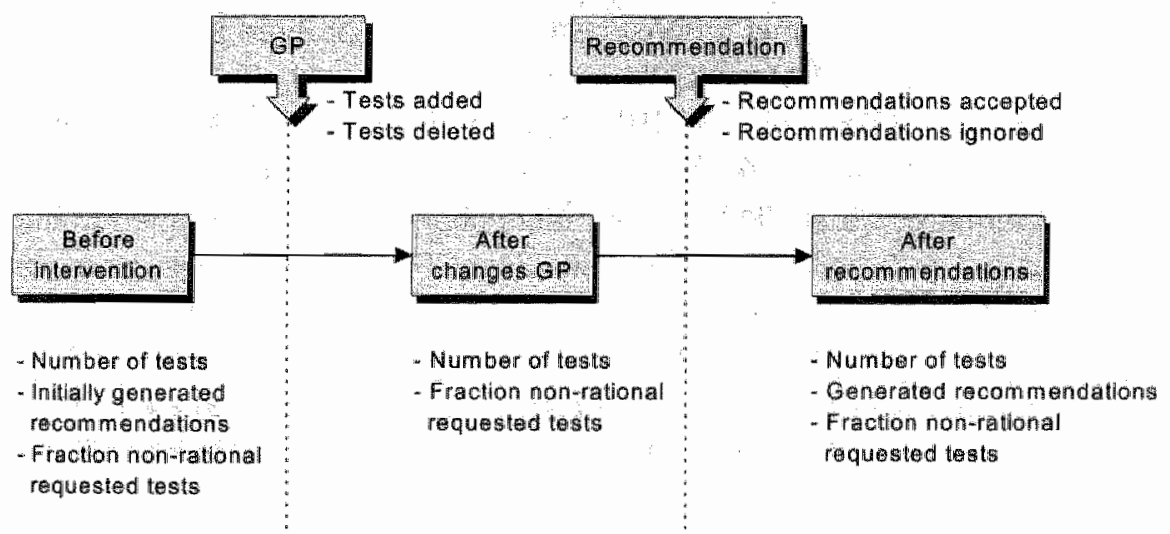

Figure 1. Description of the different steps of the intervention.

Following this laboratory experiment, also a field trial was planned using a balanced block design. In the field trial the recommendations in the knowledge base were divided into two clusters (A and $B$ ). Half of the GPS will receive recommendations on cluster $A_{3}$ the other half on cluster $B$. The GPs will be blinded to the remaining recommendations. Thus, the learning effect can be investigated during the field trial. To make the results of the laboratory experiment comparable to the results of the 
field trial, the same design was used.

The recommendations were clustered in such a way that both clusters led to approximately the same number of recommendations (based on results from the validation study (12)), and that the severity of the diagnoses (linked to the test requests) is about equal in both clusters. The diagnoses for test-cluster $A$ and $B$ are listed in table 1. The GPs were randomly assigned to receive either recommendations on test-cluster A or on test-cluster B.

Table 1. Dlagnoses for cluster A and B.

\begin{tabular}{ll}
\hline Cluster A & Cluster B \\
\hline Anemia & Allergy \\
Diabetes mellitus & Diarrhea \\
Glandular fever & Gal-bladder \\
Hypercholesterolaemie & Gout \\
Hypertension & lnfections \\
Liver problems & Physical problems \\
Urine complaints & Rheumatlsm \\
& Sinusitis \\
& Thyroid gland \\
\hline
\end{tabular}

Per GP the average number of test requests was measured at three points in time: on the original request form, after the GP's reconsiderations and after accepting or ignoring the recommendations of the GRIF system. Also determined the mean number of accepted and rejected recommendations per request form per GP was determined. Furthermore, we studied whether tests changed by the GPs led to the disappearance of one or more recommendations. Per GP, the percentage decrease in test numbers and the decrease in percentage of tests not in accordance with the practice guidelines was calculated at the earlier mentioned three points in time. Tests not in accordance with the practice guidelines were expressed as the number of not accepted recommendations divided by the total number of tests ordered. For each group the absolute change in tests not in accordance with the practice guidelines was determined: cluster A tests for GP group 1 and cluster B tests for GP group 2. First, a mean value per GP was calculated, next, the averages per group. Additionally, we studied the behaviour of the GPs in more detail and investigated correlations between cases in which changes were made by the GPs themselves and changes resulting from suggestions by the GRIF system.

Since most recommendations suggest the removal of one or more tests, the direction of the effect is one-sided. Hence significance testing against ' $H_{0}=$ there is no effect' does not make sense. Therefore, the mean values and the $95 \%$ confidence intervals $(\mathrm{Cl})$ of the effects were presented. 


\section{Results}

With respect to age, experience and gender, the $24 \mathrm{GPs}$ were comparable to the whole group of GPs in the Maastricht region. One case of one GP was missing due to a technical problem during one of the group sessions. Table 2 shows that the mean number of test requests decreased as a result of both the changes of the GPS and the suggestions of the GRIF system. The mean percentage decrease over the two GP groups is $30 \%$ ( $95 \% \mathrm{Cl}: 23$ to $37 \%$ ). Table 3 shows a strong decrease in the fraction tests not in accordance with the practice guidelines ( $43 \%$ over the two GP groups ( $95 \% \mathrm{Cl}: 32$ to $54 \%)$ for the total intervention).

Table 2. Mean number of test requests with corresponding standard deviation (SD) per request form per GP.

\begin{tabular}{lllll}
\hline & \multicolumn{2}{c}{ GP Group 1 } & \multicolumn{2}{c}{ GP Group 2 } \\
& Mean & SD & Mean & SD \\
\hline Before intervention & 3.75 & 0.90 & 1.62 & 0.44 \\
After changes GP & 3.32 & 1.28 & 1.42 & 0.47 \\
After recommendations & 2.67 & 0.95 & 1.09 & 0.25 \\
\hline
\end{tabular}

Table 3. Mean fraction of requested tests per request form per GP that were not in accordance with the practice guidelines and corresponding standard deviation (SD).

\begin{tabular}{lllll}
\hline & \multicolumn{2}{c}{ GP Group 1 } & \multicolumn{2}{c}{ GP Group 2 } \\
& Mean & SD & Mean & SD \\
\hline Before intervention & 0.45 & 0.06 & 0.46 & 0.15 \\
After changes GP & 0.41 & 0.06 & 0.44 & 0.16 \\
After recommendations & 0.25 & 0.12 & 0.29 & 0.16 \\
\hline
\end{tabular}

The 24 GPs ordered 4196 tests (mean 5.6 tests per patient) on the original request forms. Due to reconsideration, GPs removed 545 tests (of which ESR 39 times, creatinine 36 times and leukocyte count 36 times) and added 80 tests (of which fasting glucose 16 times and MCV 13 times). On average, there was a mean decrease of requested tests over the two groups of $12 \%(95 \% \mathrm{Cl}: 5$ to $20 \%$ ).

Of the removed 545 tests, 361 tests $(66 \%)$ would have generated a recommendation. Since more than one test request on one form may be related to the same recommendation, this would have resulted in a reduction of 255 recommendations. The other $184(34 \%)$ removed tests would not have generated a recommendation. Of these, 101 should not have been removed because they were in accordance with practice guidelines. Most tests were commonly requested and general tests such as glucose, creatinine, cholesterol and TSH, ordered for elderly people (age above 70 ) and were requested in accordance with the practice 
guidelines. For 83 requested tests no guideline existed.

After the GP changed the request form, 3731 test requests remained on the request form. Due to comments of the GRIF system, 457 tests were removed (leucocyte count 66 times, PCV 39 times and differential count 34 times) and 46 tests were added (fasting glucose 29 times and ALAT 10 times). The comments of the GRIF system resulted in a mean decrease in the number of tests ordered of $17 \%(95 \% \mathrm{Cl}$ : 12 to $22 \%$ ).

The system generated 1420 recommendations for the 720 cases of which 729 $(51 \%)$ were presented and $691(49 \%)$ stayed hidden to the GP because of the application of the block design. Of the 729 presented recommendations, 362 (50\%) were accepted and $367(50 \%)$ were ignored. The comments of the system resulted in a mean decrease in the fraction tests not in accordance with guidelines of $39 \%$ (95\% Cl: 28 to $51 \%)$.

We found four different behaviour patterns among the participating GPS. Four GPs didn't change anything on the request forms in 21 or more of the 30 cases (no changes by the GP and no recommendations accepted). Nine GPs mainly changed the request forms themselves but did not follow the advice of the GRIF system. Eight GPs did not change the request form but followed the advice of the system. Finally, three GPs both changed the request form and followed the advice of the system (not necessarily in the same case).

\section{Discussion}

We described the potential effects of an automated feedback system for test ordering by GPs. Both the number of tests ordered and the fraction of tests not in accordance with guidelines decreased.

Paper cases can be used to measure the competence of a cliniclan (14), but performance is what a physician actually does in daily practice (15). Although competence scores are usually higher than performance scores, competence is a good predictor for performance (16). Other researchers used simulated cases to assess the potential effect of decision support systems. They compared different forms of decision support for prescribing and for the management of breast and ovarian cancer and found they were potentially effective $(17,18)$. Walton et al. found that $35 \%$ of the recommendations of their decision support system were ignored (18). In our study, $50 \%$ of the recommendations were ignored. A possible explanation is that GPS in the Maastricht region have been receiving feedback on their test ordering behaviour since 1985. Their test ordering behaviour is already largely in line with the practice guidelines (13). 
Of the randomly selected 30 cases, some (on average wo to three) cases were almost similar. This might have resulted in a learning effect during the session. The data set was too small to detect such an effect. Nevertheless, some of the GPS indicated in group discussions held afterwards that they were more likely to accept a recommendation when it was presented repeatedly.

A disadvantage of an experiment in a laboratory setting is that the respondents may tend to give socially desired answers and act as they think the researchers want them to act. We tried to avoid this by convincing the GPs that the aim of the study was to measure the user satisfaction with the system instead of measuring the competence of the GPs.

The GPs themselves deleted a relatively large percentage of the initial test requests from the request form. The majority of the tests were correctly removed (tests were not in accordance with the guidelines). Besides a second critical look at one's own test requests, the influence of the Hawthorne effect, socially desired behaviour and the absence of the patient in the laboratory setting could have played a important role in this reduction (19).

The 4 behaviour patterns which were found were about equally distributed over the different group sessions, indicating that they were not due to information bias. Only 3 GPs changed the request form themselves and followed the recommendations, a strategy that we expected for most GPs. This implies that individual GPs need different approaches to change their diagnostic test ordering behaviour.

Remarkably, we found that in cases where GPs actively changed their own request form before the system advised them, the number of tests ordered not according to the practice guidelines seems to be lower than for GPs that did not actively change their request forms. It seems as if GPs that actively changed their request form know quite well which tests are appropriate or not. However, this latter finding needs to be interpreted with some caution because the analyses were performed on case level instead of on GP level.

This study clearly shows the potentials of computer recommendations to achieve a behaviour more according to guidelines in medical practice. The effects found are likely to be the maximum effect that can be reached in daily practice.

\section{References}

1. van Merode GG, Hasman A, Derks J, Schoenmaker B, Goldschmidt $H$ HM. Advanced management facilities for clinical laboratories. Computer Methods and Programs in Biomedicine 1996;50(2):195-205.

2. Kassirer JP. Our stubborn quest for diagnostic certainty. New England Journal of Medicine 1989;320:1489-1491.

3. Mandell HN. Technological imperative. Or, when your tool is a hammer, everything looks like a nail. Postgraduate Medicine 1983;74(2):24-26.

4. Wong ET, Lincoln TL. Ready! Fire! ... Aim! Journal of the Aimerican Medical Aissociation 
$1983,250(18): 2510-2513$

5. Grol $R$, Eccles $M$, Maisonneuve $H$, Woolf $S$. Developing clinical practice guidelines: The European experience. Disease Management and Health Outcomes 1998;4(5):255-266.

6. Woolf $3 H$, Grol $R_{i}$ Hutchinson $A_{4}$ Eccles $M$, Grimshaw J. Clinical guidelines: potential benefits, limitations, and harms of clinical guidelines, British Medical Journal 1999;318:527-530.

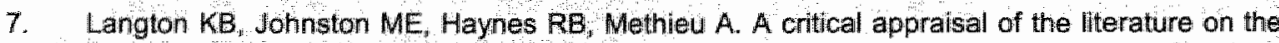
effects of computer-based clinical decision support systems on clinician performance and patient outcomes. Proceedings / AMIA Annual Fall Symposium 1992:626-630.

8. Shea $S$, DuMouchel $W$, Bahamonde $L$. A meta-anallysis of 16 randomized controiled trials to evaluate computer-based clinical reminder systems for preventive care in the ambulatory setting. Journal of the American Medical Informatics Association 1996;3(6):399-409.

9. Shiffman $\mathrm{RN}$, Llaw $\mathrm{Y}$, Brandt $\mathrm{CA}$, Corb GJ. Computer-based guideline implementation systems: A systemetic review of functionality and effectiveness. Journal of the American Medical Informatics Association 1999;6(2):104-114.

10. van der Weijden $T$, Grol $R$, Winkens $R$, Buntinx $F$, ter Riet $G$, Klazinga $N$. Interventions aimed at influencing the use of diagnostic tesis. The relevance of attention for contextual factors. The Cochrane Library 2001.

11. Bindels R, de Clercq P, Winkens RAG, Hasman A. A test ordering system with automated reminders for primary care based on practice guidelines. International dournal of Medical Informatics 2000;58-59:219-233.

12. Bindels R, Winkens RAG, Pop P, Wersch JW, Talmon J. Hasman A. Validation of a knowledge based reminder system for diagnostic test ordering in general practice. International Journal of Medicall Informatics 2001;64(2-4);341-354,

13. Winkens RAG, Pop P, Bugter-Maessen AMA, Grol RPTM, Kester ADM, Beusmans GHMI, et al. Randomised controlled trial of routine individual feedback to improve rationality and reduce numbers of test request. The Lancet 1995;345:498-502.

14. Neufeld WR. Assessing clinical competence. New York: Springer; 1985.

15. Norman GR, Neufeld GR, Walsch A, Woodward CA, McConvey G. Measuring physicians' performances by using simulated patients. Journal of Medical Education 1985;60;925-934.

16. Rethans JJ, van Leeuwen $Y$, Drop R, van der Vleuten $C$, Sturmans F. Competence and performance: two different concepts in the assessment of quality of medical care. Family Practice $1990 ; 7(3): 168-74$.

17. Emery J, Walton R, Coulson A, Glasspool D, Ziebland S, Fox J. Computer support for recording and interpreting family histories of breast and ovarian cancer in primary care (RAGs): qualitive evaluation with simulated patients. British Medical Journal 2000;321:28-32.

48. Walton $R T$, Gierl $C_{\text {; }}$ Yudkin $P$. Mistry $H_{4}$ Vessey MP. Fox J. Evaluation of computer support for prescribing (CAPSULE) using simulated cases. British Medical Journal 1997;315:791-795.

19. Deyo RA. A key medical decision maker: the patient. British Medical Journal 2001:323:466467. 


\section{CHAPTER 7}

EVALUATION OF GRIF IN DAILY PRACTICE 


\section{Introduction}

There is a growing number of practice guidelines for primary care. These guidelines include advice on the diagnostic process and the treatment. Part of the advice is directed towards ordering the most appropriate tests for diagnostic reasons or for monitoring the effects of treatment. The implementation and the use of practice guidelines in daily practice, however, are still problematic $(1,2)$. With respect to test ordering various strategies have been used to implement guidelines and to modify GPs' test ordering behaviour, like education (3), redesigning the request form $(4,5)$ and feedback on number, rationality (6) or costs (7) of the requested tests.

To manage appropriate test ordering in the Maastricht region, the Transmural Care Unit (TCU) has been giving personal written feedback to GPS in the Maastricht region since 1985. Twice a year, each of the approximately 90 GPs in the Maastricht region receives a feedback report with critical recommendations on his or her diagnostic tests requested in a randomly selected previous month. This feedback method is based on a comparison of request forms (including diagnostic tests and provided clinical patient data) with accepted national or regional guidelines.

Studies showed that this feedback procedure changed GPs' test ordering behaviour and was appreciated by the GPs in the Maastricht region $(6,8,9)$. However, the written feedback was given retrospectively and the TCU was looking for a more direct and less time-consuming intervention method to influence the GPs during the test ordering process.

Several studies showed that clinical decision support systems (CDSSs) could be effective (10-14). Three review articles have been published about systems that generate patient-specific advice such as reminder and critiquing systems (15-17). The authors concluded that reminder systems - systems that notify clinicians of important tasks that need to be done before an event occurs (18) - are effective and improve preventive care by physicians. The reviews focused entirely on preventive care in a hospital setting and do not take into account systems that influence diagnostic or therapeutic decisions. We developed (19) and validated (20) an automated feedback system (named GRIF ${ }^{1}$ ) that focuses on GPs working in a primary care setting outside the hospital. The system aims to improve adherence to accepted practice guidelines on diagnostic tests and moreover was developed to support and eventually replace the written feedback method (6).

Rigorous evaluation of CDSSs is important for two reasons: 1) to provide more information on the use and effectiveness of these systems and 2) to investigate whether such CDSSs have unexpected limitations (21). Thus, it is essential to

1 GRIF is the Dutch acronym for "Geautomatiseerde Reminders als Interactieve

Feedback' (Automated Reminders as Interactive Feedback). 
demonstrate that a CDSS actually changes physicians' performance.

The objective of this study was to evaluate the GRIF automated feedback system: The study focuses on the use of the GRIF system in daily practice and on the impact of the system on GPs' test ordering behaviour. The aim of the GRIF system is to improve test ordering behaviour such that more test requests are in line with existing practice guidelines and physicians refrain from test requests that are not in line with these practice guidelines. We translated the objective of the present study into the following research questions:

- Is the time it takes to use the GRIF system acceptable in daily practice?

- Which percentage of the recommendations was followed?

- Are GPS overloaded with information by the number of presented recommendations?

\section{Methods}

\section{Setting}

A trial was performed in two regions in the Netherlands (the regions Maastricht and Heerlen) from August 2000 to July 2001. In the Maastricht region GPs were used to receive written feedback while GPS in the Heerlen region were not used to receive any form of feedback. The GRIF automated feedback system was introduced in 21 practices ( $32 \%$ of those eligible) in which 23 GPs were working; 16 GPs from the Maastricht region and 7 GPs from the Heerlen region. Eleven GPs participated in the study for one year or more. Twelve GPs dropped out of the field trial. In an early stage $8 \mathrm{GPs}$ dropped out of the trial because of technical problems (mainly caused by an unexpected revision of the GPs' information system by the vendor), 3 dropped out because they could not (or did not want to) integrate the system into their busy daily practice routine and one GP had a protracted illness during the intervention period.

\section{The GRIF system}

To use the GRIF system, described in more detail elsewhere (19)" in daily practice the GP had to enter relevant medical patient data (working hypotheses, signs and symptoms and the reason for the test request) and the desired diagnostic tests into an electronic order entry form. The knowledge base in which the recommendations are stored contains 150 rules (recommendations) derived from regional and national practice guidelines about various medical problems (19). A recommendation or advice is presented whenever a test request is not in accordance with the guidelines. The GP can indicate if he or she wants to follow or ignore the recommendation. When needed, the system is able to provide additional contextspecific background information about the guidelines when a recommendation is presented. 
The knowledge base of the GRIF system contains roughly five types of recommendations:

- Advice not to request a test for a specified working hypothesis and/or complaint $(n=67)$;

- Advice that checks for the presence of a particular working hypothesis and/or complaint when a certain test is requested and critiques the request when that (coded) working hypothesis and/or complaint is not present $(n=36)$;

- Advice to remove a test because another - more appropriate or efficient - test was also requested $(n=25)$;

- Advice not to request a test because of the characteristics of the patient such as age and/or gender $(n=12)$;

- Advice to order a - more appropriate or efficient - test instead of the planned test $(n=10)$.

\section{The intervention}

The GRIF system was implemented on the workstations at the offices of the participating GPs. Each GP was instructed how to use the GRIF system and was familiarised with the system. In addition "an online help function and a paper manual were provided. The GPs were encouraged, but not forced, to use GRIF during patient consultation instead of completing the paper request forms. At the start of the study it was not possible for the TCU to receive the request forms electronically. Therefore, the completed GRIF request form was printed out. With this request form the patient visits the TCU.

Table 1. Diagnoses for cluster $A$ and $B$.

\begin{tabular}{ll}
\hline Cluster A & Cluster B \\
\hline Anemia & Allergy \\
Díabetes mellitus & Diarrhea \\
Glandular fever & Gal-bladder \\
Hypercholesterolaemile & Gout \\
Hypertension & Infections \\
Liver problems & Physical problems \\
Urine complaints & Rheumatism \\
& Sinusitis \\
& Thyroid gland \\
\hline
\end{tabular}

\section{Study design}

A randomised controlled trial using a balanced block design was conducted. Therefore, the recommendations in the knowledge base were divided into two clusters ( $A$ and $B$ ). Half of the GPs received recommendations on cluster $A$ and the 
other half on cluster B. The GPs were blinded to the remaining recommendations that were used to investigate the learning effect. The recommendations were clustered in such a way that both clusters led to approximately the same number of recommendations (based on results of the validation study (20)) and that the severity of the diagnoses (linked to the test requests) was about equal in both clusters. The diagnoses in test-clusters A and $B$ are listed in table 1. GP practices were randomly assigned to receive either recommendations on test-cluster $A$ or on test-cluster $B$.

\section{Data analysis}

Because half of the GPs dropped out of the field trial only 2 of the 11 participating GPs were in cluster 2, and the described RCT with a block design could not be used in the analysis. Therefore, the analysis focused on the GPs in cluster A. The first month the GP used the GRIF system was excluded from the analysis, because this month was used to get accustomed to the GRIF system. Two GPs started in August 2000, four in September 2000 and three in October 2000.

The use of the system was measured by different attributes: the frequency of use of functions of the GRIF system, whether the medical terms were classified using International Classification of Primary Care (ICPC) codes and the mean time spent to complete the request form. For each GP (unit of analysis), the total number of recommendations presented and the response of the GPS (follow or ignore a recommendation) were measured. The percentage of recommendations followed per type of recommendation were analysed. Furthermore, the trends in mean number of tests per request form, mean number of recommendations per request form and the percentage of followed recommendations over the trial period were investigated.

\section{Results}

GPs who participated in the trial for less than 5 months were considered as drop out. The characteristics of the study subjects are described in table 2 .

Table 2. Demographic characteristics of the participating GPs.

\begin{tabular}{ll}
\hline & Participants \\
\hline$n$ & 11 \\
Mean age in years (SD) & $44(4.7)$ \\
Gender: \% males & $100 \%$ \\
Experience as GP in years (SD) & $13(6.4)$ \\
\hline
\end{tabular}

During the intervention period, the GPs ordered 2498 request forms using the GRIF system with 10139 tests on it (table 3 and 4). It took GPs a median time of 77 seconds (25th and 75 th percentiles 49 and 121 seconds) to complete the request 
form of the GRIF system. The median time to produce the recommendations plus the reaction time of the GP was 13 seconds (25th and 75th percentiles 6 and 18 seconds). Overall, the use of the GRIF system lasted a median of 109 seconds (25th and 75 th percentiles 76 and 161 seconds) including starting the GRIF system, printing the request form and closing the system. The help-function was only used 10 times by 3 different GPs and the background information containing the text of the practice guidelines was viewed 15 times by 5 different GPs.

The system forced the GPs to fill in a working hypothesis and a reason for requests. In $93 \%$ of all request forms an ICPC code was added to the description of the working hypothesis. Fatigue $(5.8 \%)$, hypercholesterolaemia $(5.1 \%)$, diabetes mellitus $(4.2 \%)$, prostate complaints $(4.2 \%)$ and hypertension $(3.9 \%)$ were frequently used working hypotheses. About half of the request forms (1294 in total) contained one or more diagnoses in the medical history of the patient. These diagnoses were transferred from the GPs information system and $96 \%$ of these diagnoses were described with an ICPC code. The differential diagnosis was entered in $19.7 \%$ of the request forms of which $53.0 \%$ was coded. Signs and complaints were entered in $83.5 \%$ of the request forms and appeared to be coded in only $9.4 \%$.

A total number of 2780 recommendations were presented during the intervention period (table 3). The maximum number of recommendations that was given on one request form was 7 and the median number of recommendations per request form, was 0.99. Three percent of the request forms resulted in 5 or more recommendations. These request forms contained a relatively large number of tests, while only one diagnosis was mentioned (in the medical history, working hypothesis or differential diagnosis). Of the presented recommendations $4.3 \%$ were followed and led to direct changes in test ordering behaviour.

Table 3. Number of tests, recommendations and the reaction of the GP on these recommendations (follow or ignore) are presented in relation to the total numbers, the miaximum per request form. median per request form, and the $25^{\text {th }}$ and $75^{\text {th }}$ percentiles per request form

\begin{tabular}{llllll}
\hline & Total $(\%)$ & Maximum & Median & $\begin{array}{l}\text { 25th } \\
\text { percentile }\end{array}$ & $\begin{array}{l}\text { 75th } \\
\text { percentile }\end{array}$ \\
\hline Number of tests & 10139 & 22 & 4.14 & 3.49 & 7.38 \\
Recommendations presiented & 2780 & 7 & 0.99 & 0.60 & 2.05 \\
- Followed & $120(4.3 \%)$ & 4 & 0.04 & 0.02 & 0.18 \\
L Ignored & $2660(95.7 \%)$ & 7 & 0.93 & 0.51 & 2.01 \\
\hline
\end{tabular}

Table 4 shows the individual results of the GPs per region. These results show that, on average, GPs in the Maastricht region produced more request forms using the 
GRIF system, but their request forms contained, on average, less diagnostic tests. No differences between these two regilons were statistically significant.

Table 4. Distribution of number of request forms produced and mean numbier of tests per request forms per participating GP.

\begin{tabular}{lll}
\hline & $\begin{array}{l}\text { Number of } \\
\text { requests forms }\end{array}$ & $\begin{array}{l}\text { Mean number of } \\
\text { tests per request } \\
\text { form }\end{array}$ \\
\hline $\begin{array}{l}\text { Heerlen region } \\
\text { GP } 1\end{array}$ & 123 & 5.72 \\
GP 2 & 247 & 4.77 \\
GP 3 & 250 & 4.14 \\
GP 4 & 257 & 3.49 \\
\hline Total Heerlen & 877 & 4.35 \\
Maastricht region & & \\
GP 1 & 439 & 4.72 \\
GP 2 & 402 & 4.16 \\
GP 3 & 424 & 4.12 \\
GP 4 & 220 & 2.45 \\
GP 5 & 136 & 2.18 \\
Total Maastricht & 1621 & 3.90 \\
\hline
\end{tabular}

Table 5. Presented recommendations (with \% of the total number of presented recommendations) and followed reciommendations (with \% of the number of presented recommendations) per recommendation type.

\begin{tabular}{llll}
\hline Type & Description & $\begin{array}{l}\text { Presented } \\
(\% \text { of total) }\end{array}$ & $\begin{array}{l}\text { Followed } \\
\text { (\% of presented) }\end{array}$ \\
\hline 1 & $\begin{array}{l}\text { Advice not to request a test for a specified } \\
\text { working thypothesis and/or compllaint }\end{array}$ & $182(6.5 \%)$ & $7(3.9 \%)$ \\
2 & $\begin{array}{l}\text { Advice that checks for the presence of a } \\
\text { particular working hypothesis and/or complaint }\end{array}$ & $2015(72.5 \%)$ & $68(3.4 \%)$ \\
3 & $\begin{array}{l}\text { Advice that suggests to remove a test because } \\
\text { another - more appropriate or efficient - test was } \\
\text { also requested }\end{array}$ & $252(9.1 \%)$ & $21(8.3 \%)$ \\
4 & $\begin{array}{l}\text { Advice not to request a of the characteristics of } \\
\text { the patient such as age and/or gender }\end{array}$ & $56(2.0 \%)$ & $4(7.1 \%)$ \\
\hline 5 & $\begin{array}{l}\text { Advice that suggests to order a - more } \\
\text { approprilate or efficient - test instead of the } \\
\text { planned test }\end{array}$ & $275(9.9 \%)$ & $20(7.3 \%)$ \\
\hline Total & & $2780(100 \%)$ & $120(4.3 \%)$ \\
\hline
\end{tabular}


Table 5 presents the percentages of recommendations followed per type of recommendation. Advice containing a concrete recommendation to request only one particular test instead of more tests (type 3 ) or to request an alternative test (type 5) was adhered to most frequently. For example, a type 3 recommendation to request an ALAT (alanine aminotransferase) instead of the combination of ALAT and ASAT (aspartate aminotransferase) liver test was followed in $38 \%$ of the times it was presented (in total 8 times). The type 5 recommendation to request a fasting glucose test instead of a non-fasting glucose test was followed in $31 \%$ of the 39 times it was presented. Although less frequently presented, advice that is related to the patient characteristics (age and gender) was also followed relatively frequently.

A sample of 200 type 2 recommendations was analysed in more detail to find the reason why many of these recommendations were generated, and why the adherence of these recommendations was relatively low. We found that the majority $(73.5 \%)$ of these recommendations were correctly generated, because there were no indications present on the request form to order the tests described in the recommendations. In $7.5 \%$ of the recommendations relevant, but uncoded, information was available and, as a result, this information was not taken into account. In $19 \%$ of the recommendations relevant and coded information was available. This relevant coded information concerned in $55.3 \%$ (longer existing) fatigue as complaint or working hypothesis, which justifies ordering tests such as haemoglobin and glucose according to the practice guidelines. Since the ICPC classification is not able to differentiate between a short and a longer existing fatigue, the system was also not able to differentiate between these situations. The remaining relevant coded information $(44.7 \%)$ concerned diagnoses and/or complaints that should be taken into account in the negative part of the rules in the GRIF knowledge base. In this part of the rule, conditions (i.e. diagnoses and/or complaints) should not appear on the request form. The diagnoses and/or complaints absent in these rules were not explicitly described in the practice guidelines. Using them would lead to mare specific advice to the GP.

Finally, the trends in the mean number of tests per request and the percentage of recommendations followed per GP were analysed over the trial period. No significant trends were observed, but the mean number of recommendations per request form seemed to decrease over time.

\section{Discussion}

GPS in two neighbouring regions of the Netherlands used the GRIF automated feedback system for 12 months during patient consultation (including the one month period to get used to the system). A limited number of recommendations was followed. Recommendations suggesting a test alternative or recommendations that 
were related to patient characteristics (such as age and gender) were followed most frequently:

A relatively high percentage $(52 \%)$ of the GPs dropped out of the trial: Changes in the GP information system resulting in a less stable system were the main cause of drop out. Three GPs dropped out of the trial because they were not able to integrate the system into the GPs' busy daily practice. Outdated hardware in these GP practices resulted in a high response time of the GRIF system and was mentioned as the main reason for the inability of incorporating GRIF into their daily routine.

The first question we wanted to answer was if the time it took the GPs to use the GRIF system in daily practice was acceptable for them. Entering medical patient data into the electronic request form of the GRIF system took the GP a relatively long time (a median of 109 seconds per request form) compared to the average duration of a patient consultation, which is eight minutes. However, we must note that GPS in the Maastricht region were used to complete the special request form where, apart from the laboratory tests, clinical patient data were required. Completing this paper request form also took time (approximately one minute). Since the current study concerns test ordering, and the fact that tests are ordered in about four percent of the patient consultations (22), GPs are not confronted with the GRIF system during every patient contact. This means that the overload is relatively small.

The actual time for the GRIF system to produce a recommendation plus the response time of the GP to this recommendation (to indicate whether the GP followed the advice or not) is very low (median of 13 seconds). AsthmaCritic, a critiquing system that produces recommendations on the GPs management of asthma and COPD in general practices in the Netherlands analysed patient data in the medical record and generated a feedback message in about 31.5 seconds (on average) (23). Here, the data were already entered into the system and data from patient consultations in the past were taken into account. This search for relevant information probably caused part of the difference in response time of the systems. The relatively slow response time of AsthmaCritic resulted in the fact that only $22 \%$ of the GPs waited for the advice of the system. None of the GPs in this study had a prablem with the time spent to generate the advice. Therefore, it was concluded that the time to generate, read and act on the feedback presented was acceptable. Nevertheless, the time a GP spent on entering medical patient information was not acceptable. From this point of view it is important to focus on user friendly and fast data entry methods to provide medical data which can be used by decision support systems to reason with. 
The second question was if GPs followed the recommendation of the GRIF system. Only $4.3 \%$ of the GRIF recommendations was followed. This may seem a relatively low percentage, but we must keep in mind that the GPs in the Maasticht region have been receiving feedback on their test ordering behaviour for many years now (24). Compared to another trial with an automated decision support system in the Netherlands (25), the mean number of requested tests per request form in both regions in this study was already relatively low. The Bloodlink-Guideline system, an automated test ordering module in which a GP can select a working hypothesis from a list of working hypotheses after which a set of relevant tests is presented, resulted In an average of 5.5 tests per request form (25). In this study the GPs in the Heerlen region requested an average of 4.4 tests, while the GPs in the Maastricht region (who receive feedback on test ordering behaviour over a longer period of time (24)) requested on average only 3.9 tests per request form. Reducing the number of requested tests when the mean number of requested tests is already low, is more difficult compared to a situation in which still a relatively large number of tests per request form are ordered. Nevertheless, receiving feedback for many years should result in less recommendations. That this is not the case may be due to the fact that the practice guidelines are too general for experienced users and as a result should be made more specific.

The results of this study show that recommendations that suggest to order a particular test when a better alternative test is available (type 3 and type 5 recommendations), were followed most frequently. Recommendations that only advice the GP not to request a test without providing an alternative (type 2 recommendations), were adhered to less frequently.

The rules that result in a type 2 recommendation check for the presence of a working hypothesis or complaint. As a result these recommendations rely strongly on the information provided by the GP and on the fact whether the GP has coded the information in the GRIF request module. The results of the detailed analysis using a random sample of 200 unspecific (type 2) recommendations showed that the justification for ordering the tests was often missing.

The GPs reported during in-depth semi-structured interviews after the intervention that they mostly agreed with the recommendations of the GRIF system, but they ignored the majority of the recominendations. An explanation for this contradiction may be the fact that GPs order a wide range of tests and use standard test sets to screen the patient on more than the indicated possible diagnosis (5). In these situations GPs did not record all possible working hypotheses they had in mind, because this would take them too much time during patient consultation. In their opinion the recommendation (for example not to order a glucose test when the diagnosis diabetes mellitus is not present) is correctly given, since they didn't indicate on the request form that diabetes mellitus was one of the options they had in mind. 
Miller and Frawley (26) found that relevant feedback could be provided using information from the patient record. They showed that there is a relation between the wealth of available clinical data and the degree of specificity of patient-specific recommendations: In the present study, a high level of specificity is desirable because the GPs are familiar with the feedback and the practice guidelines. Therefore, GPs might appreciate more focused and highly specific recommendations. In our situation it means that guidelines should be described in more detail and that more complete clinical patient data are required:

The results of the trend analyses show a slight (but not significant) decrease in the percentage of followed recommendations over time. Probably, the GPs get used to the advice of the GRIF system and do not read and adhere to the advice after a period of time. Demakis et al. also found a decline over time in compliance to the recommendations over time. Their recommendations concerned adherence to standards of care in an ambulatory setting (23). They mentioned the competing demands on the physicians' time in a busy clinic and the lack of feedback concerning the performance of the physician using their system as two possible explanations. The competing demands in a busy practice could have played a rale in the present intervention, but none of the GPs mentioned the lack of feedback on their own performance as a reason for ignoring the recommendations.

The third question was if GPS were overloaded with information by the number of recommendations presented. The GRIF system produced a median of 0.99 recommendations per request form. Since only half of the recommendations was presented to the GPs (due to the application of the balanced block design) and not all advice from the guidelines was translated into automated recommendations (19), this median number of recommendations can be considered as a minimum. Compared to AsthmaCritic (a critiquing system that produces recommendations on the GP's management of asthma and COPD in general practice) that provided on average 3.4 recommendations per patient consultation (27), the GRIF system produced relatively few recommendations per patient contact.

During the intervention period, the maximum number of recommendations presented per request form was 7 and in $3 \%$ of the request forms 5 or more recommendations were given. Such a large number of recommendations contains too much information to read during a busy practice. Therefore, it may be advisable to limit the maximum number of recommendations presented to the GP. Another solution may be to change the content of the recommendations presented to the GP, for instance to provide different kinds of recommendations during different months. As a result the GP probably less likely gets used to the feedback of the system. Future research needs to explore methods to better sustain the benefits of recommendations. 
Considering the use of the GRIF system in daily practice, it was concluded that the time to generate, to read and act on the presented feedback was acceptable. Entering (coded) medical patient data takes GPS a relatively large part of their patient consultation time. This stresses the need for user friendly and fast data entry methods. Nevertheless; the GRIF system, as used for this research project, does not overload the GP with information by presenting too much recommendations.

Overal $\|_{i}$ a relatively small percentage of recommendations was followed. Advice that suggests to remove a test because another - more appropriate or efficient - test was also requested, was followed most frequently. We therefore conclude that computerised recommendations should contain, if possible, suggestions for alternative tests to improve the application of these recommendations.

\section{References}

1. Grol $R$, Eccles $M$, Maisonneuve $H$, Woolf $S$. Developing clinical practice guidelines: The European experience. Disease Management and Health Outcomes 1998;4(5):255-266.

2. Woolf $S H$, Grol $\mathbb{R}_{*}$ Hutchinson A, Eccles $M_{s}$ Grimshaw J. Clinical guidelines; potential benefits, limitations, and harn's of clinical guidelines. British Medicall Journal 1999;318:527-530.

3. Elsenberg JM. An educational program to modify laboratory use by house staff. Journal of Medical Education 1977;52:578-581.

4. Wong ET, Lincoln TL. Ready! Fire! ... Aim! Journal of the American Medical Association 1983;250(18):2510-2513.

5. Zaat JO, van Eijk JT, Bonte HA. Laboratory test form design influences test ordering by general practitioners in The Netherlands. Medical Care 1992;30(3):189-98.

6. Winkens RAG, Pop P, Bugter-Maessen AMA, Grol RPTM, Kester ADM, Bieusmans GHMI et al. Randomised controlled trial of routine individual feedback to improve rationality and reduce numbers of test request. The Lancet 1995;345:498-502.

7. Tierney WM, Miller ME, MCDonald CJ. The effect on test ordering of informing physicians of the charges for outpatient diagnostic tests. New England Journal of Medicine 1990;322 (21):1499-1504.

8. Pop $P$, Winkens RAG. A diagnostic centre for general practitioners: results of individual feedback on dlagnostic actions. Journal of Royall College of General Practitioners 1989;39:507-508,

9. Winkens RAG, Ament AJ, Pop P. Reniers PH, Grol RP; Knottnerus JA. Routine individual feadback on requests for diagnostic tests: an economic evaluation. Medical Decision Making $1996 ; 16(4): 309-314$.

10. Langton $K B$, Johnston ME, Haynes RB, Methieu A. A critical appraisall of the literature on the effects of computer-based clinical decision support systems on clinician performance and patient outcomes. Proceedings / AMIA Annual Fall Symposium 1992:626-630.

11. Hunt DL, Haynes RB, Hanna SE, Smith K. Effects of computer-based clinical decision support systems on physician performance and patient outcomes: a systematic review. Journal of the American Medical Informatics Association 1998;280(15):1339-1346.

12. Johnston ME, Langton KB, Haynes RB, Mathieu A. Effects of computer-based clinical decision support systems on clinician performance and patient outcome: A critical appraisal of research. Annals of Internal Medicine 1994;120:135-142.

13. Payne TH. Computer decision support systems. Chest $2000: 118$ (2 suppl):47S-52S.

14. Kaplan B. Evaluating informatics applications - clinical decision support systems literature review. International Journal of Medical Informatics 2001;64(1):15-37. 
15. Austin SM, Balas EA, Mitchell $J_{A}$ Ewingman BG. Effect of physician reminders on preventive care: Meta-analysis of randomized clinical trials. Proceedings of the Annuzal Symposium on Computer Applications in Medical Care 1994;18:121-124.

16. Balas EA, Austin SM, Mitchell JA, Ewigman BG, Bopp KD, Brown GD. The clinical walue of computerized information services. A rewiew of 98 randomized dinical trials. Archives of Family Medicine 1996;5(5);271-8.

17. Shea S, DuMouchel W, Bahamonde L. A meta-analysis of 16 randomized controlled trials to evaluate computer-based clinical reminder systems for preventive care in the ambulatory setting. Joumal of the American Medical informatics Association 1996;3(6):399-409.

18. Friedman CP, Wyatt JC. Evaluation Methods in Medical Informatics. New York: SpringerVerlag; 1997.

19. Bindels $R$, de Clercq $P$, Winkens RAG, Hasman $A$. A test ordering system with automated reminders for primary care based on practice guidelines. International Journal of Medical informatics 2000;58-59:219-233.

20. Bindels $R$, Winkens RAG, Pop P. Wersch JW, Talmon J, Hasman A. Validation of a knowledge based reminder system for diagnostic test ordering in general practice. International Journal of Medical Informatics 2001;64(2-4):341-354.

21. Tierney WM, Overhage JM, MCDonald CJ. A plea for controlled trials in medical informatics. Journal of the American Medical informatics Association 1994;1(4):353-355.

22. Leurquin $P$, van Casteren $V_{0}$ Dde Maeseneer J. Use of blood tests in general practice: $A$ collaborative study in eight European countries. British Journal of General Practice $1995 ; 45: 21-25$.

23. Demakis JG, Beauchamp $C$, Cull WL, Denwood R, Eisen SA, Lofgren $R$, et al. Improving Residents" Compliance With Standards of Ambulatory Care. Results From the VA Cooperative Study on Computerized Reminders. Journal of the American Medicall Informatics Association 2000;84:1411-1416.

24. Winkens RAG, Pop P, Grol RPTM, Bugter-Maessen AMA, Kester ADM, Beusmans GHMI, et al. Effects of routine "ndividual feedback over nine years on general practitioners' requests for tests. British Medical Journal 1996;312:490.

25. van Wijk MAM, van der Lel $\Downarrow$, Mosseveld M. Bohnen AM, van Bemmel JH. Assessment af decision support for blood test ordering in primary care. A randomized trial. Annalls of Internal Medicine 2001;134:274-281.

26. Miller $\mathrm{PL}$, Frawley SJ. Trade-offs in producing patient-specific recommendations from a computer-based clinical guideline: A case study. Joumal of the American Medical Informatics Association 1995;2(4):238-242.

27. Kuiboer MM, wan Wijk MA, Mosseveld M, van der Does $E$, Ponsioen BP, de Jongste JC, al al. Feasibility of AsthmaCritic, a decision-support system for asthma and COPD which generates patient-specific feedback on routinely recorded data in general practice. Family Practice $2002 ; 19(5): 442-447$. 


\section{ChAPTER 8}

ORDERING LABORATORY TESTS ACCORDING TO PRACTICE GUIDELINES OR NOT: DOES THE FRACTION OF ABNORMAL TEST RESULTS DIFFER?

Submitted as:

R. Bindels, D. Oerlemans, A. Hasman, J.W.J. van Wersch, R.A.G. Winkens. Ordering laboratory tests according to practice guidelines or not: 


\section{Introduction}

The volume of diagnostic tests has increased over the past decades. By now, it is well known that a relatively large percentage of diagnostic test requests in health care is inappropriate (1). Part of the increase in test consumption can be explained by the ageing of the population and by the growth in the number of preventive tasks in medicine. This part might be seen as understandable and, to a certain extent, appropriate. On the other hand, the increase is also caused by the care demand of the patients and by the increased availability of new diagnostic tests and diagnostic test utilities (2). Diagnostic tests that are requested on the latter two grounds can often be seen as inappropriate.

Inappropriate testing increases the likelihood of generating false positive results and may cause high costs in the health care system (3). In the past, various strategies have been used to change test ordering behaviour (4-8). Review articles that compared different strategies to modify clinicians' test ordering patterns concluded that a wide range of interventions is available but that there are 'no magic bullets' ( 9 11). A combination of interventions seems to be most promising (12).

A substantial proportion of the interventions try to change GPs' test ordering behaviour through retrospective assessment, by one or more experts, of the appropriateness of the requested tests, for instance by means of audit and feedback $(6,8)$. Most interventions try to reduce the number of requested diagnostic tests $(5$, 7). Others focus on improving adherence to practice guidelines (8) or try to reduce costs (6). Computer-based decision support systems are becoming more and more popular (13-15) and several studies concluded that automated decision support systems for diagnostic test ordering are effective (16-21).

After a 15 year period of experience with written individual feedback on test requests (8), an automated feedback system was developed (22) and validated (23). The system assesses whether a test request is according to accepted practice guidelines, using the description of the medical status of the patient as provided by ordering GPs. The rules in the knowledge base of the GRIF system that produce the recommendations are based on accepted national $(24,25)$ and regional (26) practice guidelines which are being used for several years. The system contains roughly three sorts of advice: 1) advice to remove a test because another - more appropriate or efficient - test is also requested, 2) advice to order another - more appropriate or efficient - test and 3) advice that checks for the presence of a particular indication and/or complaint when a certain test is requested and eventually denounce that test.

Compared to written personal feedback where the test results of the diagnostic tests can be taken into account $(8,27)$, an automated feedback system reacts during patient consultation at the time of test ordering , and thus does not have access to 
test results still to come. The advice of a computerised program to refrain from a particular test bears the risk that tests are not ordered which otherwise would lead to a relevant abnormal test result. Potentially, this may have negative medical consequences for the patient. Until now, no studies have been carried out on this subject.

One might expect a simple relation between the appropriateness of a requested test and the test results: when there is a low likelihood of disease in a patient - as is often the case in primary care - it is not appropriate to do a diagnostic test, since the outcome is likely to be negative. Hence, inappropriate tests will likely have a negative outcome. However, this is not necessarily true since there are various reasons for inappropriateness of a test like: the sensitivity and specificity of a test, the severity of the disease, the lack of diagnostic gain (one knows already beyond doubt that the patient has a certain condition) and the lack of impact on physician's management (the result of the test will not influence the GP's course of action). In these latter situations one may even expect abnormal tests results.

In this chapter, the main aim is to answer the question:

Is there a difference in the percentage of abnormal test results between tests discouraged by the automated feedback system (not according to accepted practice guidelines) and tests not discouraged by this system (according to accepted practice guidelines)?

This may also answer the question to what extent abnormal findings go unnoticed when test use is discouraged on the basis of practice guidelines and what the importance of these abnormal tests results is.

\section{Methods}

\section{The GP request forms}

GPs in the Maastricht region who order diagnostic tests have to enter administrative and medical details about the patient (such as medical history, signs, symptoms and medication) and the reason for the request on each request form (26). On the request form, 8 possible reasons for request are suggested: to exclude a disease, to confirm a disease, to check-up for an existing problem, to screen for unknown pathology, to reassure the patient, for general check up, at the patient's request or at a specialist"s request.

The GP uses his or her own terms or descriptions to reflect the medical status of the patient. The GP is free to decide how much medical patient information is provided. The tests on the request form concern various tests like clinical chemistry tests, haematology tests, serology tests and imaging techniques such as $X$-rays, ultrasound and endoscopy. The Diagnostic Centre distributes the requests for 
diagnostic tests to the specialised laboratories within the University Hospital Maastricht. After the test results have been obtained, they are written onto the original request form before the request form will be sent to the ordering GP. A copy is stored in the archive of the diagnostic centre.

Threshold values used to judge if test results are abnormal were obtained from local reference values (28) and the "Diagnostic Handbook" (29). In case the reference values in these sources differed; the local reference value was used.

\section{Study design}

GPs in the Maastricht region (approximately 90 in total) work outside the hospital but are allied to the Diagnostic Centre of the University Hospital Maastricht. Over the period May 1999 until October 1999, a random selection of 250 request forms was obtained from the archives of the Diagnostic Centre. The request forms concerned requests for diagnostic tests for 250 different patients and 88 different GPs. All 250 request forms (including age, gender, medical patient data and the requested tests) were entered into the GRIF automated feedback system. The GRIF system consists of a knowledge base in which computerised rules based on recommendation from regional and national practice guidelines were implemented (22) and validated (23). The recommendations of the automated feedback system were linked to the diagnostic tests they referred to. In this way the tests could be divided into two groups: tests that were ordered in accordance with accepted practice guidelines and tests that were ordered not in accordance with accepted practice guidelines (see figure 1 ).

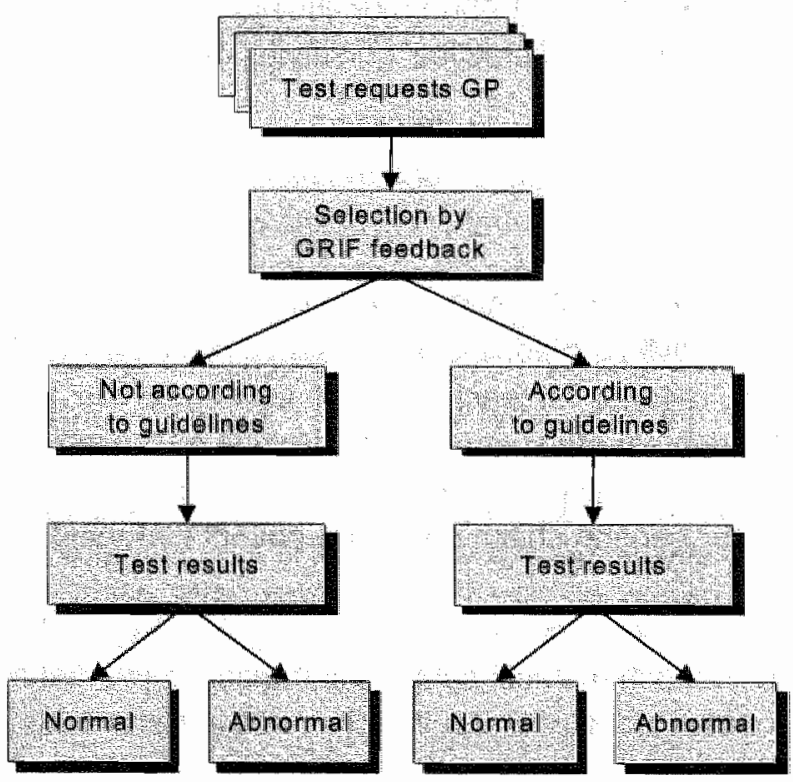

Figure 1. Experimental study design. 
Imaging techniques were excluded because these tests are a different type of diagnostic tests. Imaging techniques have a descriptive outcome while laboratory tests have a quantitative outcome. A separate study was carried out to study imaging tests (see Appendix III). Tests for which no rules were present in the knowledge base of the automated feedback system and thus were outside the domain of the system, were also excluded. Finally, tests for which the system advised an alternative test were excluded from analysis. Acceptance of this type of advice would result in another test being performed. We envision that the alternative test would have similar results as the requested test and hence, no abnormal test would be missed. Finally, tests that were ordered to reassure the patient, at the patient's request or at a specialist's request were also excluded. These tests are by definition appropriately requested according to the GPs point of view.

\section{Analysis}

The percentage normal and abnormal test results were calculated for tests ordered according to accepted practice guidelines and tests ordered not according to accepted practice guidelines.

One factor could affect the findings of the present study, namely the reason for request. Therefore, the percentage abnormal tests results stratified by reason for request was calculated. Two different categories of reasons for requests were compared:

- Category 1: Tests requested to confirm a disease, indicating a relatively high pre-test probability of an abnormal test request.

- Category 2: Tests requested to exclude a disease, screening for unknown pathology or for check-up, indicating a relatively low pre-test probability of an abnormal test request.

The chi-square test (with a level of significance of 0.05) was used for statistical analysis of differences between the groups after 2 by 2 tables containing the test result (positive or negative) and the appropriateness (according to practice guidelines or not) were created. In addition, the test requests with abnormal test results were analysed by type of tests for both groups.

\section{Results}

The 250 request forms contained 1225 test requests. The request forms contained on average 4.8 tests (range 1 to 15). Per GP a mean of 2.8 request forms (range 1 to 7) were present in the random selection. In total 292 tests were excluded. Fiftyseven tests were excluded because they were outside the domain, 99 tests because they concerned imaging techniques, 89 tests because the automated feedback system advised an alternative test and 47 tests because the reason for request was to reassure the patient, at the patient's request or at a specialist's request. The test results of 18 requested tests were missing. Ultimately, 915 test requests were 
included of which $167(18.3 \%)$ had no reason for the request. The reason for request plays a role in about $5 \%$ of the rules in the GRIF knowledge base. When the reason for request can be taken into account this will result in a more specific advice.

Table 1 shows the percentage of abnormal test results for the group of tests requested according to accepted practice guidelines as well as for the group of tests not according to accepted guidelines. A significant difference in percentage abnormal test results between both groups was found $(p=0,02)$. The overall percentual difference in abnormal test results between the two groups was $6.6 \%$. Table 2 shows the results of the analysis stratified for reason for request. The fraction of abnormal test results was significantly different between the two group of tests when the tests were ordered to exclude a disease $(p=0.041)$, but no significant difference was found for tests ordered to confirm a disease $(p=0.571)$.

Table 1. Fraction abnormal test results for test requests ordered according to accepted practice guidelines and for test requests ordered not according to accepted practice guidelines.

\begin{tabular}{lcccc}
\hline & Total & \multicolumn{2}{c}{ Abnormal test results } & $\begin{array}{c}\text { P-value chi- } \\
\text { square test }\end{array}$ \\
\cline { 3 - 5 } & & $n$ & $\%$ & \\
\hline According to guidelines & 423 & 122 & 28.8 & \\
Not according to guidelines & 492 & 109 & 22.2 & \\
Total & 915 & $23 \pi$ & 25.2 & 0.02 \\
\hline
\end{tabular}

Table 2. Fraction abnormal test results for test requests ordered according to accepted practice guidelines and for test requests ordered not according to accepted practice guidelines stratified by reason for request.

\begin{tabular}{lcccccc}
\hline $\begin{array}{l}\text { Reason for } \\
\text { request }\end{array}$ & Total & \multicolumn{2}{c}{ According to guidelines } & Not according to guidelines & $\begin{array}{c}\text { p-value chi- } \\
\text { square test }\end{array}$ \\
\cline { 2 - 6 } & $\mathrm{n}$ & $\%$ Abnormal & $\mathrm{n}$ & $\%$ Abnormal & \\
\hline To confirm & 43 & 26 & 50.0 & 17 & 41.2 & 0.57 \\
To exclude & 513 & 219 & 25.1 & 294 & 17.7 & 0.04 \\
\hline
\end{tabular}

Table 3 shows the 10 most commonly requested diagnostic tests. Leukocyte count and differential count were relatively often classified as tests that were ordered not according to practice guidelines. These tests were also responsible for about one fourth of the number of abnormal test results in the group of tests ordered not according to practice guidelines (29 out of 109). Only a few of the abnormal ESR tests were requested not according to practice guidelines. 
Table 3. Top 10 most requested tests: the total number of tests ordered (and the percentage of the total number of times a test was ordered) and the number of abnormal test resuits according to accepted practice guidelines (CAPG) and not according to practice guidelines (N-CAPG)

\begin{tabular}{|c|c|c|c|c|c|}
\hline \multirow{2}{*}{$\begin{array}{c}\text { Test } \\
\end{array}$} & \multirow[t]{2}{*}{ Total } & \multicolumn{2}{|l|}{ CAPG } & \multicolumn{2}{|l|}{ N-CAPG } \\
\hline & & $\begin{array}{l}\text { Number } \\
\text { ( } \% \text { of total) }\end{array}$ & Abnormal & $\begin{array}{l}\text { Number } \\
(\% \text { of total) }\end{array}$ & Abnormal \\
\hline Leukocyte count & 56 & $2(4 \%)$ & 0 & $54(96 \%)$ & 14 \\
\hline Diffferential count & 38 & $4(11 \%)$ & 4 & $34(89 \%)$ & 15 \\
\hline$y-G T P$ & 49 & $16(33 \%)$ & 4 & $33(67 \%)$ & 3 \\
\hline Creatinine & 77 & $30(39 \%)$ & 7 & $47(61 \%)$ & 7 \\
\hline ALAT & 45 & $18(40 \%)$ & 5 & $27(60 \%)$ & 8 \\
\hline Hemoglobin & 89 & $51(57 \%)$ & 13 & $38(43 \%)$ & 7 \\
\hline TSH & 38 & $23(61 \%)$ & 7 & $15(39 \%)$ & 1 \\
\hline $\mathrm{MCV}$ & 41 & $28(68 \%)$ & 6 & $13(32 \%)$ & 1 \\
\hline Cholesteral & 42 & $30(71 \%)$ & 10 & $12(29 \%)$ & 3 \\
\hline ESR & 96 & $87(91 \%)$ & 24 & $9(9 \%)$ & 3 \\
\hline
\end{tabular}

\section{Discussion}

The quantity and quality of the medical patient information on the request forms influences the quality of advice given by the automated feedback system (23). For example in $20 \%$ of the 1031 requested tests no indication for the requested test was specified on the request form. The absence of a clear working hypothesis may trigger a feedback message. For instance, if the GP requests a liver test $(\mathrm{e.g}$. ALAT) and haemoglobin for a patient and the GP indicates that the patient is tired but (s)he does not indicate that the patient has a liver disorder, the request for ALAT will be assessed as 'not according to practice guidelines' because (s)he did not mention the potential liver disorder. In daily practice, the GP has the opportunity to complete the provided patient information after (s)he has seen the feedback message. Using GRIF in daily practice may lead to a reduction of these feedback messages because part of the data is being automatically transferred from the GPS information system into the GRIF order entry system.

A substantial percentage $(47.2 \% ; 109$ out of 231 in table 1) of the tests with an abnormal result would have gone unnoticed if the GP would have followed the advice of the GRIF system. The percentage inappropriate requested tests (not according to the practice guidelines) does not differ much from the results of other studies. A review by Walraven et al. showed that the majority of studies found a proportion of inappropriate tests that varied between $10 \%$ and $50 \%(30)$. 
The question is then: Is strictly following automated feedback harmful to patients? This chance is considerate to be small. Most of the tests with abnormal test results that go unnoticed are not essential, because the tests are not related to a relevant disease mentioned on the request form. Two different situations can be distinguised: a feedback message was presented because there was no working hypothesis mentioned on the request form (18\% of the abnormal test results in the group of tests ordered not according to the practice guidelines) and a feedback messages was presented that checks for the presence of a particular diagnosis and/or complaint whenever a certain test is requested $(72 \%)$. Thus, $90 \%$ of the feedback messages was given probably because the GP did not enter all relevant information. This means that in only $10 \%$ of the tests that were requested not according to the guidelines, a positive test result was observed that could not be explained. In addition, non-specific tests such as leukocyte count and differential count formed a substantial part of these abnormal tests results in the group of tests requested not according to the guidelines. These tests are less relevant to the GPs decision process. A positive outcome of such a test must be accompanied by a strong pretest probability based on signs and symptoms or accompanied by other positive diagnostic tests to give any direction to the GPs management of the patient's care process.

Solomon et al. (31) studied the effects of a computer-based intervention to reduce unnecessary serologic testing by displaying post-test probabilities. They found that, although there was a relatively large difference in mean values, no significant association between the physicians' pre-test probability and the test result could be found. They also concluded that cancellation of the tests had not affected clinical course, but no test results were collected.

The present study cannot provide a $100 \%$ definite answer to the question mentioned above. We did not investigate what action the physicians have taken after obtaining the results, and whether a different action would have took without the test results. We must keep in mind that an unnoticed abnormal diagnostic test result does not automatically lead to a missed diagnosis. Often more than one information source such as signs or symptoms is used to arrive at a certain diagnosis.

\section{Conclusion}

From a medical point of view, the percentage of tests with an abnormal test result was - although significantly different - not substantially higher in the group of tests requested according to guidelines as compared to the group of tests ordered not according to guidelines. If the advice of the automated feedback system was followed a remarkable percentage of laboratory tests with abnormal test results will go unnoticed. However, a large part of these laboratory tests (for example leukocyte count and differential count) may be less relevant to the GPs' decision. In addition, a relatively large part of the requested tests are classified as 'not according to the 
guidelines" because the GP probably did not mention relevant patient information on the request form. Nevertheless, it was concluded that the thoughtless adherence to accepted practice guidelines is not advised. The physician will always play an important and essential role in the diagnostic and therapeutic process.

\section{References}

1. Kassirer JP. Our stubborn quest for diagnostic certainty. New England Journal of Medicine 1989;320:1489-1491.

2. Mandell HIN. Technological imperative. Or, when your tool is a hammer, everything looks like a nail. Postgraduate Medicine 1983;74(2):24-26.

3. Rang M. The Ulysses syndrome. Canadian Medical Association Jounal 1972;106(2):122-123.

4. Eisenberg JM. An educational program to modify laboratory use by house staff. Journal of Medical Education 1977;52:578-581.

5. Wong ET, Lincoln TL. Ready! Fire! ... Aim! Journal of the American Medical Association 1983;250(18):2510-2513.

6. Tierney WM, Miller ME, McDonald CJ. The effect on test ordering of informing physicians of the charges for outpatient diagnostic tests. New England Journal of Medicine 1990;322 (21):1499-1504.

7. Zaat JO van Eijk JT, Bonte HA. Laboratory test form design influences test ordering by general practitioners in The Netherlands. Medical Care 1992;30(3):189-98.

B. Winkens RAG, Pop P, Bugter-Maessen AMA, Grol RPTM, Kester ADM, Beusmans GHM!, et al. Randomised controlled trial of routine individual feedback to improve rationality and reduce numbers of test request. The Lancet 1995;345:498-502.

9. Fraser $C_{\text {. W }}$ Woodford FP. Strategies to modify the test-requesting patterns of clinicians. Annals of Clinical Biochemistry 1987 24 (Pt 3):223-31.

10. Axt-Adam $P$, van der Wouden JC. Influencing behaviar of physicians ordering laboratory tests; A literature study. Medical Care 1993;31(9):784-794.

11. Oxman AD, Thomson MA, Davis DA, Haynes RB. No magic bullets: A systematic review of 102 trials of interventions to improve professional practice. Canadian Medical Association Journal 1995; $153(10): 1423-1431$.

12. Winkens $\mathbb{R}$, Dinant $G-J$. Evidence base of clinical diagnosis: Rational, cost effective use of investigations in clinical practice. BMJ 2002;324(7340):783-785.

13. Johnston ME, Langton KB, Haynes RB, Mathieu A. Effects of computer-based cinical diecision support systems on clinician performance and patient outcome: $A$ critical appraisal of research. Annals of Internal Medicine 1994;120:135-142.

14. Balas EA, Weingarten S, Garb CT, Blumenthal D, Boren SA, Brown GD. Improving preventive care by prompting physicians. Archives of Internal Medicine 2000;160(3):301-308.

15. Kaplan B. Evaluating informatics applications - clinical decision support systems literature review. International Journal of Medical Informatics 2001;64(1):15-37.

16. McDonald $C J$, Hui $S L$, Smith DM, Tierney WM, Cohen SJ, Weinberger $M$, al. Reminders to physicians from an introspective computer medical record. A two-year randiomized trial. Annals of Internal Medicine 1984;100:130-138.

17. Nightingale $P G$, Peters $M$, Mutimer $D$, Neuberger $\mathbb{N} M$. Effects of a computerised protocol management system on ordering of clinical tests. Quality in Health Care 1994;3:23-28.

18. Tierney WM, McDonald CJ, Hui SL, Martin DK. Computer predictions of abnormal test results: effects on outpatient testing. Journal of the American Medical Association 1988:259(8):11941198.

19. Bates DW, Kuperman GJ, Rittenberg $E_{*}$ Teich JM, Onderdonk $A$, Winkelman J, et al. 
Reminders for redundant tests: results of a randomized controlled trial. Proceedings / The Annual Symposium on Computer Applications in Medical Care 1995:19:93.5.

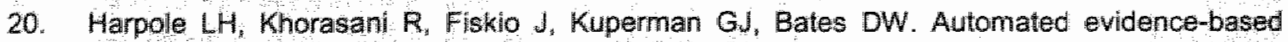
critiquing of orders for abdominal radiographs: impact on utifization and appropriateness. Journal of the American Medical Informatics Association 1997;4(6):511-521.

21. wan Wijk MAM, van der Lei J, Mosseveld $M$, Bohnen AM, van Bemmel $\mathrm{JH}$. Compliance of general practitioners with a guideline-based decision support system for ordering blood tests. Clinical Chemistry $2002 ; 48(1): 55-60$.

22. Bindels $R$, de clerca $P_{v}$ Winkens $R A G$, Hasman $A$. A test ordering system with automated reminders for primary care based on practice guidelines. International Journal of Medicall Informatics $2000,58-59: 219-233$.

23. Bindels $R$, Winkens RAG, Pop P. Wersch JW, Talmon J, Hasman A. Validation of a knowledge based reminder system for diagnostic test ordering in general practice. international Journal of Medical Informatics $2001 ; 64(2-4): 341-354$.

24. Rutten GEHM, Thomas S. NHG-Standaarden voor de huisarts. Utrecht: Bunge; 1993.

25. Thomas S. NHG-standaarden woor de huisarts II. Utrecht. Bunge; 1996.

26. Pop P. Winkens RAG. A diagnostic centre for general practitioners: results of individual feedback on diagnostic actions. Journal of Royal College of General Practitioners 1989;39:507-508.

27. Donabedian A. The role of outcomes in quality assessment and assurance. Quality Review Bulletin 1992; $18(11): 356-360$.

28. Referentiewaarden. Academisch Ziekenhuis Maastricht; $\$ 999$.

29. Diagnostisch Kompas 1997: Ziekenfondsraad; 1997.

30. Walraven C, Naylor D. Do we know what inappropriate laboratory utilization is? Journall of the American Medical Association 1998;280(6):550-558.

31. Solomon D-H, Shmerling R-H, Schur P-H, Lew R, Fisklo J, Bates D-W. A computer based intervention to reduce unnecessary serologic testing. J Rheumatol 1999;26(12):2578-84. 


\section{CHAPTER 9}

\section{USER SATISFACTION WITH GRIF: A QUANTITATIVE AND QUALITATIVE EVALUATION}

Submitted as:

R. Bindels, A. Hasman, M. Derickx, J.W.J. van Wersch, R.A.G. Wirkens, User satisfaction with an automated feedback system for general practitioners: a quantitative and qualitative evaluation. 


\section{Introduction}

Practice guidelines are becoming more and more common in the medical profession (1). However, the implementation of these guidelines and the adherence to them in daily practice are still problematic (2). Some of the reasons for physicians not using or following practice guidelines are lack of awareness of the content of a guideline and lack of familiarity or agreement with these guidelines (3). Different strategies have been developed to improve the adherence to practice guidelines in daily practice (4). In recent years, automated feedback systems, a kind of decision support systems, are used to remind physicians of the content of practice guidelines during patient consultation. Automated feedback systems are being developed to advise physicians on diagnostic test ordering (5-7), drug prescription (8-11), and on preventive actions in an ambulatory care setting (12).

The GRIF automated feedback system was developed and validated (13, 14). GRIF is a Dutch acronym for 'Geautomatiseercle Reminders als Interactieve Feedback' (automated reminders as interactive feedback). The aim of the GRIF system is to stimulate the adherence to practice guidelines on diagnostic test ordering. This system was developed to support and eventually replace the written feedback which had been providing by the Transmural Care Unit (TCU) of the Maastricht University Hospital since $1985(15,16)$. Twice a year, general practitioners (GPs) in the Maastricht region receive personal feedback on the adequacy of their test ordering behaviour. Although this method proved to be effective and was appreciated by the GPs $(16,17)$, a more direct and less laborious method was preferred.

The GRIF system contains an electronic request form to be filled in during patient consultation. It produces recommendations about the appropriateness of the requested diagnostic tests ordered before the request form is beingl submitted to the TCU (13). If a test request is not in accordance with the practice guidelines, the system produces a critical and/or educational recommendation. The GP can indicate whether or not he or she wants to accept or reject the recommendation. If the GP accepts a recommendation the corresponding request form will be changed automatically according to the advice.

The present study was carried out to investigate experiences of GPs with the GRIF system itself and, more specifically, with the recommendations produced by the system as well as their views on the use of such a system in daily practice. In addition, the study focuses on the motives for non-acceptance of the recommendations presented by the GRIF system. These motives may be helpful in tracing factors that influence the implementation process, and may assist in finding better strategies to implement guidelines.

\section{Methods}

We collected data during a trial in a laboratory setting (laboratory trial) and during a 
trial in daily practice (field trial). The laboratory trial was conducted at the Maastricht University. In the field trial, the participating GPS used the system in their own practices. During the laboratory trial, $24 \mathrm{GPs}$ were confronted with the recommendations generated by the GRIF system. A set of 30 request forms the GP submitted earlier that year to the TCU, was randomly selected for each GP. Patient information and requested tests, present on the request form, were entered into the automated feedback system by one of the authors (RB). The request forms were made anonymous to prevent knowledge of the test result influencing the GPs' judgments. Each GPs had to go through the cases one-by-one using the GRIF system within a limited period of time to simulate the time pressure during patient consultation.

A pop-up window was added to the system which appeared whenever the GP rejected a recommendation. In this window the GP had to describe - in free text - the reason why he or she decided to reject the recommendation. The laboratory trial was conducted in 4 sessions with 4 to 8 GPs. After each session, the user satisfaction with the GRIF system was measured using a questionnaire based on the IBM computer usability satisfaction questionnaire (18). The questionnaire consisted of 15 items in total: 6 about usability, 4 about user satisfaction, 3 about the expected change in test ordering behaviour and 2 about the GRIF system compared with the written feedback method. The changes in the IBM scale and the questions which were added to the questions of the IBM scale are listed in Appendix $I V$. The GRIF evaluation questionnaire (in Dutch) is listed in Appendix $V$. All items were scored on a 5 point Likert scale where 1 is 'strongly agree' and 5 is 'strongly disagree'. Finally, a semi structured group discussion led by one of the authors (RW) was conducted to obtain the GPs" opinions about the GRIF system, its recommendations, the obstacles for use in daily practice and suggestions for improvement. The discussions lasted 30 to 45 minutes.

In the field trial, the GRIF automated feedback system was introduced and used in 21 practices (32\% of those eligible). Ten practices with 11 GPs participated in the field trial for one year or more. Fourteen GPs from 11 practices dropped out of the field trial; 10 because of technical problems (mainly caused by an unexpected revision of the GPs' information system by the vendor), 3 because they could not (or did not want to) integrate the routine use of the system into their busy dally practice and one because he suffered from a protracted illness during the trial.

A questionnaire about the user satisfaction with the automated feedback system was sent to all initial participants of the field trial. The same questionnaire as in the laboratory trial was used. In-depth interviews were held by one of the authors (MD) in the GPs' practices. The topics covered in the interviews included: opinions about the automated feedback system, problems during the intervention period and experiences with the produced recommendations. The interviews usually lasted 30 to 45 minutes. 
The sum scores were calculated for: usability, user satisfaction, expectation of change in ordering behaviour and the opinion about the GRIF system vs. the written feedback (Maastricht region only). Median scores and $25^{\text {th }}$ and $75^{\text {th }}$ percentiles for each sum score were determined. Pair wise differences between the three groups (laboratory trial participants, field trial participants and field trial drop outs) were tested using the Mann-Whitney test.

The group discussions and interviews were audio taped, transcribed and analysed using QSR Nud ${ }^{*} \mid S T^{\oplus}$, a software package for analysis of qualitative data. The transcriptions were analysed by selecting and reorganising responses according to topics by one of the authors (RB) (19).

\section{Results}

GP characteristics are listed in table 1. The random selection of request forms for the laboratory trial contained 4196 tests (mean 5.6 tests per form) and in the field trial 10139 tests were ordered (mean 4.1 tests per form).

Table 1. Characteristics of GPs in laboratory trial and field trial.

\begin{tabular}{llll}
\hline & $\begin{array}{l}\text { Laboratory } \\
\text { trial }\end{array}$ & Fleld trial & \\
\cline { 4 - 4 } & & Participants & Drop out \\
\hline Mean age (SD) & 24 & 11 & 12 \\
Mean experience in years (SD) & $19(7.0)$ & $13(6.4)$ & $15(8.6)$ \\
Percentage males & $75 \%$ & $100 \%$ & $83 \%$ \\
\hline
\end{tabular}

\section{User satisfaction questionnaire}

All GPs participating in the field and the laboratory trial and $86 \%$ of those GPs who dropped out of the field trial completed the questionnaire. The results presented in table 2 show that not all GPs completed the whole questionnaire. All questionnaire aspects were considered positive by the laboratory participants (median scores and $75^{\text {th }}$ percentile below 3.0 ). Both, field trial participants and drop outs were less positive about the measured aspects. The drop outs were even more negative about the GRIF system compared to the written feedback (median scores and $75^{\text {th }}$ percentile equal to or above 4.0).

Compared to those GPs who took part in the field trial (participants and drop outs), GPS in the laboratory trial were significantly more positive about the user friendliness ( $p<0.01$ for both drop outs and participants) and more satisfied with the GRIF system ( $p<0.01$ for drop outs and $p=0.02$ for participants) (table 3 ). Also, opinions on the influence of the GRIF system on the GPs test ordering behaviour 
$(p=0.02$ for drop outs and $p<0.01$ for participants) and on the substitution for the written feedback method with the GRIF system $(p=0.03$ for drop outs and $p<0.01$ for participants) were significantly different compared with those of the laboratory trial participants. No significant differences were found for the above mentioned analyses between the GPs who dropped out of the field trial and the GPs who used the GRIF system for one year or more.

Table 2. Median, $25^{\text {th }}$ and $75^{\text {th }}$ percentile scores for the sum scores of 4 topics of the questionnaire.

\begin{tabular}{|c|c|c|c|c|c|c|c|c|c|c|c|c|}
\hline & \multicolumn{4}{|c|}{ Laboratory trial } & \multicolumn{2}{|c|}{ Field trial } & & & \multicolumn{4}{|c|}{ Drop out field trial } \\
\hline & \multirow[t]{2}{*}{$n$} & \multirow[t]{2}{*}{ Median } & \multicolumn{2}{|c|}{ Percentiles } & \multirow[t]{2}{*}{$n$} & \multirow[t]{2}{*}{ Median } & \multicolumn{2}{|c|}{ Percentiles } & \multirow[t]{2}{*}{$n$} & \multirow[t]{2}{*}{ Median } & \multicolumn{2}{|c|}{ Percentiles } \\
\hline & & & 25 th & 75 th & & & 25 th & 75 th & & & 25 th & 75 th \\
\hline User friendliness & 24 & 1.6 & 1.0 & 2.2 & 11 & 2.5 & 2.0 & 3.2 & 11 & 2.8 & 2.0 & 3.8 \\
\hline User satisfaction & 23 & 2.0 & 1.8 & 2.5 & 11 & 2.5 & 23 & 3.3 & 12 & 2.9 & 2.3 & 3.5 \\
\hline $\begin{array}{l}\text { Expected change } \\
\text { in behaviour }\end{array}$ & 24 & 2.2 & 1.8 & 2.7 & 10 & 3.2 & 2.7 & 3.3 & 9 & 3.0 & 2.6 & 3.1 \\
\hline $\begin{array}{l}\text { Automated ws. } \\
\text { written feedback }\end{array}$ & 24 & 2.0 & 1.0 & 2.0 & 10 & 2.5 & 2.0 & 3.0 & 9 & 4.0 & 1.9 & 4.6 \\
\hline
\end{tabular}

Table 3. P-values of Mann-Witney tests for comparisons of different groups.

\begin{tabular}{llll}
\hline & $\begin{array}{l}\text { Laboratory trial } \\
\text { vs. field trial }\end{array}$ & $\begin{array}{l}\text { Laboratory trial } \\
\text { vs. drop out field trial }\end{array}$ & $\begin{array}{l}\text { Fileld trial } \\
\text { vs. drop out field trial }\end{array}$ \\
\hline User friendliness & $<0.01$ & $<0.01$ & 0.48 \\
User satisfaction & 0.03 & 0.02 & 0.26 \\
Expected change in behavior & 0.01 & 0.02 & 0.85 \\
Automated vs. written feedback & $<0.01$ & 0.03 & 0.38 \\
\hline
\end{tabular}

\section{Opinions and experiences}

The results of the group discussion (laboratory trial) and the in-depth interviews (field trial) are divided in: 1) Views about and experiences with the GRIF system, 2) experiences with recommendations (accuracy and effectiveness) and 3) substitution of the written feedback method for the GRIF system.

All discussion groups of the laboratory trial regarded the feedback during the test ordering process as a major advantage. The respondents considered the system to be more effective than the written feedback, because it is possible to adjust the request form based on the feedback immediately. GPs expected this to have a stimulating effect on their test ordering behaviour. In contrast, feedback and the critical reflection on one's own test ordering behaviour was only mentioned as a 
positive issue a few times during the interviews (field trial). One respondent mentioned: The recommendations of the automated feedback system could suppont me in explaining to the patient why a particular diagnostic test is not necessary". GPs in the field trial often mentioned the background information available in the GRIF system as being a positive aspect of the system. However, almost all GPS admitted that they did not read this background information during patient consuitation. In the field trial, the readability and the improved structure of the printed request form were appreciated features of the GRIF system.

Most GPS considered the dependence of the system on the amount and quality of the provided medical patient information an important problem. A few respondents mentioned that, instead of being corrected by recommendations of the GRIF system, they prefer to be guided by the system. A majority of the field trial participants mentioned that the GRIF system took too much time during patient consultation due to the coding of the medical patient information, the slowness of their own computer system and searching for (difficult to find) infrequently requested tests. Another negative aspect mentioned was the need to enter a specific and concrete working hypothesis on the electronic request form.

\section{Experiences with recommendations}

Almost all GPs, in both trials, found that the recommendations presented were given correctly in most of the situations. Some GPs in the field trial thought that the use of the system had not changed their test ordering behaviour. An important reason was that GPs grew accustomed to the recommendations and ignored them, sometimes even without reading the recommendation. In the field trial, only three GPs mentioned that recommendations that were given repeatedly, sometimes irritated them. Five GPs said their behaviour had indeed changed. They mentioned that they took out some routinely ordered diagnostic tests such as the leukocytes and liver tests.

\section{Substitution for written feedback}

All GPs indicated that they considered the GRIF system a good alternative for the written feedback. Some GPs mentioned that the GRIF system could be an additional method for providing feedback, but could never replace the personal character of the written feedback. Because of the anonymous character of the automated feedback system, it was regarded to have less impact on their test ordering behaviour. A few GPs mentioned that they missed the overviews of tests ordered in a particular period of time as present in the written feedback.

\section{Motives for non-acceptance of recommendations}

Five main topics emerged from the data in the laboratory trial and the in-depth interviews of the field trial. In the laboratory trial, GPs had to indicate a reason for non-acceptance each time they ignored a recommendation of the system (table 4). 
Table 4. Motives of non-acceptance of the recommendations of the GRIF system and the number (and percentage) of times the explanation was given in the laboratory trial.

\section{Motives for non-acceptance}

Practice guidelines

- Disagreement with the recommendation

$n(\%)$

- Not familiar with the practice guideline

$75(27 \%)$

$6(2 \%)$

\section{Prowided information}

- Although this diagnosis was suspected, it was not indicated on the request form

- The recommendation was given incorrectly because the automated feedback system did not take into account relevant information

- Doubt about the correctness of the recommendation due to missing information

Medical

- More information about the patlent was needed (risk assessment)

- The specialist suggested the diagnostic test

$\mathrm{GP}$ and practice characteristics

- Although agreement with the recommendation, the diagnostic test was ordered

- Organisation of practice (e.g. blood taking, distance to lab)

\section{Patient}

- The test was ordered on the patient's demand

$17(6 \%)$

Total

\section{Practice guidelines}

If the GPs in the laboratory trial ignored a recommendation, they mostly did so because they simply did not agree with the recommendation. A few times they admitted they were not familiar with a particular practice guideline. In contrast, GPs interviewed in the field trial indicated to agree to the majority of the recommendations. Three GPs mentioned that advice about vague complaints such as fatigue was often ignored. One of them mentioned: "I want to order more tests than mentioned in the practice guidelines because this might help me to come up with an explanation for this fatigue in a later phase of the diagnostic process:

\section{Provided information}

A number of recommendations indicated that a test is ordered not according to the guidelines, because there is no indication for a certain disease or complaint. GPs in the laboratory trial frequently indicated that they did not mention the particular disease or complaint on the request form, but they did have one in mind. In addition, the amount of information they provided and its quality were sometimes not sufficient enough to assess the appropriateness of the recommendation.

In a number of situations a recommendation was presented incorrectly according to the GPs of both the laboratory and the field trial. The fact that the automated 
feedback system did not take into account relevant information (such as the duration of the complaint) was most frequently the cause of an incorrectly presented recommendation according to the GPS. In the field trial, GPs also mentioned that they did not code all relevant medical information (mostly concerning complaints) using the ICPC coding module of the GRIF system due to lack of time or because they could not find a satisfying corresponding ICPC description. ICPC is the International Classification of Primary Care (20).

\section{Medical motives}

Relatively frequently GPS indicated they want more information about the patient for check ups or preventive screening. A recurring recommendation of several GPS was: I want to have a general impression of the patient's health status.' In the laboratory trial, twice a GP could not agree with the recommendations presented because a specialist had advised her to order the test.

\section{GP and practice characteristics}

In some instances, GPs wanted to order tests although they knew it was not according to the guidelines. They needed more certainty to exclude a particular working hypothesis. For example: "1 just don't dare to rely on a rectal examination only, when I suspect a benign prostate hyperplasia'.

In a few situations, the GPs also indicated that they did not adhere to the advice of the recommendation because of logistic reasons. For example, when a fasting glucose was ordered instead of a non-fasting glucose, one of the GPs mentioned: 'The elderly patient lives in a retirement home. The time the blood sample is taken depends on the geriatric helper'.

\section{The patient}

A minor part of the motives for rejection of the recommendations concerned test requests that were on the patient's demand. In the field trial the GPs' relationship with the patient was mentioned more often than in the laboratory trial. One GP mentioned: 'Yes, I easily go along with the patient: I find it difficult to say no to the patient and explain why l do not order the test. l'm left behind with a strange feeling about it'. Another GP mentioned: 'I order a few simple and general diagnostic tests to break out of an impasse:.

\section{Discussion}

We focused on two aspects of the use of the GRIF automated feedback system: 1) the user satisfaction (including perceived user friendliness of the system and views and opinions about the system) and 2) the motives of the GPs to reject the recommendations.

The questionnaire showed that the GPs in the laboratory trial were positive about 
the GRIF system and more positive compared to the participants and the drop outs of the field trial. The use of the system in the laboratory trial differed from the use in daily practice in a number of aspects. The GPs in the laboratory trial did not have to enter and/or code any medical patient data or diagnostic tests and they did not have to print the request form. The extra time the use of the system and the use of coding the medical information takes, in combination with the relatively short time for patient consultation, was seen as the main obstacle for the use of the GRIF system in daily practice. Coding medical terms using ICPC codes takes time and an additional disadvantage is the fact that the GP cannot translate all medical context of the request for diagnostic tests into the ICPC codes $(21,22)$.

Although most of the respondents of the laboratory trial were positive about the written feedback method, they all thought that the GRIF system could be a good alternative for that method. Some GPs preferred a decision support system that could give them more guidance during the test ordering process referring to proactive decision support. The re-active GRIF system assesses the GP's decision afterwards, while other pro-active systems suggest a list of possibilities based on the patient's medical problem such as the Bloodlink system (23). Using a more protocol based approach, the rules in the GRIF knowledge base and the GRIF system itself can easily be changed into a system that supports both approaches, allowing a GP to choose the approach he or she prefers.

Also, the suggestion to add overviews of the tests requested and recommendations presented could be beneficial to the whole feedback process. This is in line with the results of other researchers who have concluded that a combination of multiple intervention methods achieved a more adequate use of diagnostic tests $(4,24)$.

Apart from medical motives other important motives for non-acceptance appeared to be the content of and the disagreement with the practice guidelines, and the generation of general recommendations as a result of the poor quality of the medical patient information provided. GP characteristics such as habitual test ordering routines, tolerance of diagnostic uncertainty and attitude towards the guidelines also play a role in this process. Grol et al. identified that a positive attitude towards practice guidelines and the use of these guidelines in daily practice is an important prerequisite for a successful implementation of practice guidelines (25). External factors such as practice organisation, costs of the tests and time pressure are mentioned relatively less often. Motives as presented in this study, are also mentioned in other qualitative studies about the implementation of evidence into general practice $(26,27)$ and about test ordering behaviour specifically $(28)$.

Litzelman and Tierney (29) analysed reasons for non-acceptance of automated recommendations in a hospital environment in more detail. They found that the recommendations were rejected because they were 'not applicable' ( $41 \%)$, "reacted 
upon in the next visit because the physician was too busy' $(41 \%)$ and 'were refused by the patient' (18\%). Van Wijk (30) concluded that non-compliance to advice of an automated decision support system based on guidelines for diagnostic blood test ordering seemed to be partially based on the fact that GPs applied new medical insights before this knowledge was incorporated in a revision of the practice guidelines. in the present study, only one of the GPs mentioned this motive for noncompliance. The results of this study show that GP characteristics such as tolerance to diagnostic uncertainty and attitude towards the guidelines also are important motives for non-adherence to the automated guideline recommendations. Finally, the influence of the patient was mentioned relatively frequently in the field trial. The role of the patient, nowadays, is considered as 'the key medical decision maker' in the decision process and is becoming more and more important (31).

One of the aims of this study was to identify motives why GPs rejected recommendations. Although these motives are related to the content of the recommendations and thus the content of the guidelines, there may be more general motives why GPs reject advice of automated feedback systems. To overcome resistance to guidelines and to improve adherence to the automated advice presented, the motives why GPs reject these must be clear. Reassurance of his or her own capacity to come up with the right diagnosis or treatment is a motive that needs a totally different approach to overcome disagreement with the content of the guideline. During the implementation of guidelines, these different types of behavioural aspects need to be taken into account.

\section{Conclusion}

It was concluded that it takes more than 'satisfied customers' to have practice guidelines implemented through an automated system that provides feedback directly during the test ordering process. In general, non-acceptance of the automated recommendations is mainly caused by not taking (or not being able to take) time to provide sufficient information and by disagreement with the guidelines involved. Therefore, it is recommended to pay much more attention to one of the steps in the implementation cycle, namely the promotion of the guidelines and the stimulation of a positive attitude towards the guidelines among users.

\section{References}

1. Woolf SH, Grol R, Hutchinsoin $A_{i}$ Eccles M, Grimshaw J. Clinical guidelines: potential benefits, limitations, and hams of clinical guidelines. British Medical Joumal 1999;318:527-530.

2. Grol $R$, Eccles $M$, Maisonneuve $H$, Woolf $S$. Developing clinical practice guidelines: The Europeran experience. Disease Mianagement and Health Outcomes 1998;4(5):255-266.

3. Cabana MD, Rand CS, Powe NR, Wu AW. Wilson MH, Abboud PC, et al. Why don't physicians follow clinical practice guidelines?: A framework for improvement. Journal of the American Medical Assoctation $1999 ; 282: 1458-1465$. 
4. Wensing $M$, wan der Weijden $T$. Grot R. Implementing guidelines and innovations in genaral practice: Which interventions are effective? British Joumal of General Practice 1998;48:991-997.

5. Tiemey WM, McDonald CU, Hui SL, Martin DK. Computer predictions of abnomal test results: effects on outpatient testing. Journal of the American Medical Association 1988;259(2):11941198.

6. Bates DW, Kuperman G. R. Rittenberg E, Teich JM, Onderdonk A, Winkelman J, et al. Reminders for redundant tests: results of a randomized controlled trial. Proceedings / The Annual Symposium on Computer Applicationsi in Medical Care 1995;19:935.

7. Moda: I, Sigler M. A computerized laboratory alerting system in a psychogeriatric unit. MD Computing 1998; 15(2):95-99.

8. Persson M, Morndal T. Carlberg B, Bohlin J, Lindhalm LH. Evaluation of a computer-based decision support system for treatment of hypertension with drugs: retrospective, nonintervention testing of cost and guidetine adherence. Journal of Internal Medicine 2000;247(1):87-93.

9. Teich JM, Merchia PR, Schmiz JL, Kuperman GJ, Spurt CD, Bates DW. Effects of computerized physician order entry on prescribing practices. Archives of Internal Medicine 2000;160(18):27412747 .

10. Walton RT, Harvey $E L$, Dovey $S$, Freemantle $N$. Computerised advice on drug dosage to improve prescribing practice (Cochrane Review). In.: The Cochrane Library, Issue 1, $200 \%$. Oxford: Update Software.; 2001.

11. Evans RS, Pestotnik SL, Classen DC, Clemmer TP, Weaver LK, Orme JF, et al. A computerassisted management program for antibiotics and other anti infective agents. New England Journal of Medicine 1998;338(4):232-238.

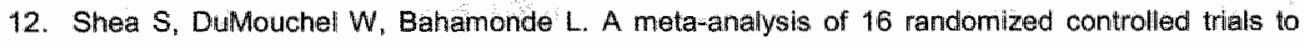
evaluate computer-based clinical reminder systems for preventive care in the ambulatory setting. Journal of the American Medical Informatics Association 1996;3(6):399-409.

43. Bindels $R$, de Clercq $P$, Winkens $R A G$, Hasman $A$. A test ordering system with automated reminders for primary care based on practice guidelines. International Journal of Medical Informatics 2000;58-59:219-233.

14. Bindels $R$, Winkens RAG, Pop $P$, Wersch JW, Talmon J, Hasman A. Validation of a knowledge based reminder system for diagnostic test ardering in general practice. International Journal of Medical Informatics 2001;64(2-4):341-354.

15. Pop P. Winkens RAG. A diagnostic centre for general practitioners: results of individual feedback on diagnostic actions. Journal of Royal College of General Practitioners 1989;39:507508.

16. Winkens RAG, Pop P, Bugter-Maessen AMA, Grol RPTM, Kester ADM, Beusmans GHMI, at al. Randomised controlled trial of routine individual feedback to improve rationality and reduce numbers of test request. The Lancet $1995 ; 345 ; 498-502$.

17. Winkens RAG, Pop P, Grol RPTM, Bugter-Maessen AMA, Kester ADM, Beusmans GHMl, et al. Effects of routine individual feedback over nine years on gemeral practitioners' requests for tests. British Medical Journal 1996;312:490.

18. Lewis JR. IBM computer usability satisfaction questionnaires: psychometric evaluation and instructions for use. International Journal of Human-Computer Interaction 1995;7(1):57-78.

19. Mays $N$, Pope $C$. Qualitative research in health care. Assessing quality in qualitative research. British Medical Journal 2000;320:50-52.

20. Lamberts $\mathrm{H}$, Wood $\mathrm{M}$. International Classification of Primary Care. 3rd ed. Oxford: Oxford University Press; 1987.

21. Hofman-Okkes IM, Lamberts $H$. The International Classification of Primary Care (ICPC): new applications in research and computer-based patient records in family practice. Family Practice $1996 ; 13(3): 294-302$.

22. Gebel RS. De ICPC-1: Stand van zaken, praktische problemen en oplossinglen. Huisarts en 
Wetenschap 2000;41(1):20-22, 28.

23. wan Wijk MAM, van der Lell J, Mosseveld M, Bohnen AM, van Bemmel $H H$. Assessment of decision support for blood test ordering in primary care. A randomized trial. Annals of internal Medicine 2001:134:274-281.

24. Wensing $M$, Grol $R$. Single and combined strategies for implementing changes in primary care: a literature review. International Jounal for Quality in Health Care 1994;6(2):115-132.

25. Grol $R_{1}$ Dahuijsen. Thomas $S$, Veld $C_{1}$. Rutten $G$, Mokkink H. Attributes of clinical guidelines that influence use of guidelines in general practice: observational study. Britisch Medical Journal $1998 ; 317(7162) ; 858-61$.

26. Freeman $\mathrm{AC}_{\mathrm{B}}$ sweeney $\mathrm{K}$. Why general practitioners do not implement evidence: qualitative study. BMJ 2001:323(7321):1100-1102.

27. Veldhuis $M$. Wigersma ${ }_{\text {, }}$ Okkes 1. Deliberate departures from good general practice: a study of motives among Dutch general practitioners. British Joumal of Generall Practice 1998;48 (437): $1833-1836$

28. van der Weijden T, van Bokhoven L, Dinant G-J, van Hasselt CM, Grol RPTM. The symbolic bargain: Understanding superfluous laboratory testing in general practice. Submitted for publication.

29. Litzelman DK, Tiemey WM. Physicians' reasons for failing to comply with computerized preventive care guildelines. Joumal of Internal Medicine 1996;1 1(8):497-499.

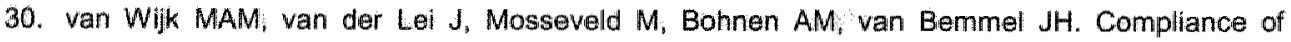
general practitioners with a guideline-based decision support system for ordering blood tests. Clinical Chemistry $2002 ; 48(1): 55-60$.

31. Deyo RA. A key medical decision maker: the patient: British Medical Joumal 2001;3:23:466-467. 


\section{Chapter 10}

GENERAL DISCUSSION 


\section{Introduction}

This thesis focuses on the development and evaluation of an automated feedback system that is based on recommendations formulated in practice guidelines. The research described in this thesis focuses on the validation of the knowledge base, on the acceptance of the system and its recommendations as well as on the influence of the system on test ordering behaviour of general practitioners (GPs). In this chapter, the results of the evaluation studies are related to the objective of this thesis, the methodological aspects are discussed and finally, recommendations for implementation in daily practice and future research are presented.

\section{Development and validation of GRIF}

Formalisation of the recommendations (present in the practice guidelines) into rules that can be implemented into a knowledge base and the validation of these rules are important aspects in the development of an automated feedback system such as the GRIF system. A problem encountered in the formalisation process was that the advice in the practice guidelines was not always explicit enough and thus left room for differences in interpretation. If-then rules in a knowledge base of automated systems cannot use criteria such as 'elderly' but need specific age groups instead. As a result, only $33 \%$ of the advice in the practice guidelines concerning test ordering was implemented into the GRIF knowledge base (Chapter 3). Unclear and not well-defined advice in the practice guidelines may lead to unspecific or general rules. Unspecific advice may also lead to rules that produce recommendations which will not be in line with the philosophy of the guideline and which will not be accepted by GPs due to possibly different interpretations of the recommendations. If it had been possible to implement all advice from the practice guidelines into the GRIF knowledge base, even more specific recommendations could have been given. Therefore, more emphasis should be put on creating practice guidelines, protocols or standards that can be formalised to be used in automated systems.

Another problem concerns inconsistencies in different guidelines concerning the same topic and even within one guideline (1). This hinders the process to reach a consistent advice. In the development of the GRIF knowledge base the advice of the regional guidelines was followed in case of differences between the regional and national guidelines. When feedback systems like GRIF are to be implemented for routine use, this decision has to be reassessed.

Technological choices, user involvement and consequences for daily practice are important issues in system development which influence the success of the system (2). The available GP information systems, the accessibility of these systems and the hardware used in GP practices influenced the technical choices in this project. As none of the GP information systems contained a module to request diagnostic 
tests, a test ordering module had to be developed: Since the practice guidelines in the knowledge base use medical patient data $a_{\text {inese }}$ data were imported from the GP information system to prevent unnecessary reproduction and retyping of these patient data. Only one of the frequently used GP information systems in our area could retrieve patient data in real-time, therefore the implementation was limited to this system (the MicroHis ${ }^{\circ} \mathrm{GP}$ information system).

It was decided to develop a re-active clinical decision support system (CDSS), namely a system that produces feedback after the GP has indicated what test(s) he or she wants to request. This type of system should resemble the written feedback method that was in routine use. Other researchers in the field of influencing test ordering behaviour have developed a pro-active system (3). Their system suggests certain tests to the physician according to a given working hypothesis. GRIF on the other hand, mainly focuses on appropriateness of requested tests, leaves the decision to the GP and only reacts if the requested test is not in accordance with the guidelines. However, this particular pro-active system offers a number of test alternatives so a GP may be inclined to request more tests than necessary. Nowadays, the GRIF system is able to provide both re-active and pro-active support. It remains an issue for future research which type of decision support is most effective for the task a physician has to complete, e.g. diagnostic test ordering.

CDSS should give accurate and specific advice to the physician (4). This statement is related to one of the question of this thesis: What is the accuracy of the feedback produced by the GRIF system? The results of the validation study (Chapter 5) showed that the recommendations produced by the GRIF system were accurate. According to the experts only few recommendations $(7 \%)$ given by the system were incorrect. For critiquing systems, such as the GRIF system, the accuracy and the wealth of the patient data provided are very important to be able to react correctly. More complete patient data also makes more specific feedback possible (4). In this study, specific recommendations are desired because the GPs are familiar with the feedback (and the practice guidelines). As a result, they will appreciate more focused and highly specific recommendations. This means that the guidelines must be more specific and lead to more detailed and more specific recommendations. GPs must also be encouraged to record as much (coded or standardised) patient data as possible.

\section{Evaluation of GRIF}

The literature review (Chapter 2) showed that critiquing and reminder systems, two types of systems that produce recommendations, improve physicians" performance in a hospital environment. The impact of such a system in a primary care setting has only been evaluated in a few studies. None of these studies mentioned in the review 
focused on the reasons for non-adherence to the advice of the system. Therefore, the evaluation of GRIF focused as well as on the impact of the system as on the question why physicians do or do not follow the advice of an automated feedback system. Insight into these reasons may give guidance on how to improve the recommendations the system generates.

What consequences does GRIF have for GPS and their daily work? An interesting question for which no valid answer has been found for yet. Due to technical problems a large percentage of GPs dropped out of the triall (Chapter 7). The absence of a control group made it impossible to give a valid answer to the question If the use of the GRIF system was effective in changing the GPs' test ordering behaviour. Therefore, the evaluation focuses on the use of the GRIF system and its user satisfaction.

During the intervention period, the median number of tests per request form was 4.14 , the median number of recommendations per request form was 0.99 and only three percent of the request forms resulted in 5 or more recommendations. Overall, GPs were satisfied with the GRIF system and receiving automated feedback during the test ordering process was seen as an advantage. It was concluded that the GRIF system, as used during this research project, does not overload the GP with information (Chapter 7). However, if all advice from the practice guidelines is formalised and if automated feedback is also generated on other topics, such as the prescription of drugs, the GP might be overloaded with recommendations. A large number of recommendations might cause the feedback to be ignored because it takes too much time to read all these recommendations during a busy practice. Therefore, it is advisable to limit the maximum number of recommendations presented to the GP or to provide different kinds of recommendations during different periods of time (for example different months of the year). Then, the GP will less likely become used to the feedback of the automated feedback system. Further research is needed to explore methods to better maintain the benefits of automated recommendations to GPS.

Considering the use of the GRIF system in daily practice, it was concluded that the time to generate, to read and act on the presented feedback was acceptable. Nevertheless, the time a GP had to spend on entering medical patient information was not acceptable (Chapter 7). Entering (coded) medical patient data takes a relatively large part of a GP's patient consultation time. This stresses the need for user friendly and fast data entry methods.

In order to assess the safe use of GRIF, the number of abnormal test results among tests requested according to the guidelines was compared with the number of abnormal test results among tests requested not according to the guidelines 
(Chapter 8). This part of the study showed that restricting test requests to those according to practice guidelines results in a higher percentage of abnormal test results. A number of abnormal test results observed for tests requested not according to practice guidelines might have gone unnoticed. However, the relevance of these test results for the GP's diagnostic process seems to be low.

To answer the question why physicians do or do not follow the advice of an automated feedback system the acceptance (percentage of recommendations that was followed) of different types of recommendations was analysed. In addition, the reasons why GPs ignored computer-generated recommendations were investigated. The percentage of recommendations that was followed varied between 3.4 and 8.3 percent depending on the type of recommendation that was given. Advice that suggested to remove a test because another - more appropriate or efficient - test was also requested was followed most frequently (Chapter 7). Five important motives for GPS not foliowing the recommendations of the system were found (Chapter 9):

- the GP disagrees with the content of the practice guidelines;

- relevant medical information was not recorded on the request form;

- the GP's medical motives (for example the need to obtain a general impression of the patient);

- the GP's characteristics (such as his risk-taking attitude),

- the patient's influence in daily practice.

Earlier studies in the Netherlands showed that motives for deliberate departures from good clinical practice were mostly related to the physician-patient relationship: the wish to be kind and considerate and to prevent a conflict $(5,6)$. The most important non-relational motive Veldhuis et al. mentioned was clinical uncertainty ( 5 , 6). These motives also play a role in the present study, but the other factors such as the disagreement with the content of the practice guidelines and not recording clinical relevant patient information on the (paper or electronic) request form seem to play a more important role.

The wide range of reasons for non-adherence to the recommendations expressed by the GPs implies that different types of behavioural aspects need to be taken into account during the implementation of practice guidelines and of systems that support the use of such guidelines. Reassurance of his or her own capacity to come up with the right diagnosis or treatment needs a totally different approach than disagreement with the content of the guideline. Therefore, different approaches to stimulate guideline adherence must be combined ( 7 ). The Department of General Practice of the Maastricht University is currently investigating the effect of discussion groups on test ordering behaviour. GPs compare their test ordering behaviour and discuss the differences in these groups. Such an indirect but personal approach combined with a direct and impersonal approach such as 
automated feedback might be a valuable strategy to influence the test ordering behaviour of GPS more efficiently: one approach focuses on strategic issues, the other on the operationall level. In addition, all steps of the implementation cycle described by Grol et al. must be considered in this process (8). Important steps in this cycle are the promotion of the guidelines and the stimulation of a positive attitude towards the guidelines among the users of the practice guidelines.

The difference in the percentage of recommendations followed when GRIF is used in daily practice compared to the situation in which GRIF is used in a laboratory setting is remarkable. The results of the use of GRIF in daily practice show that few recommendations were followed $(4.3 \%)$, whereas in a laboratory environment the participating GPs followed $50 \%$ of the recommendations presented. The relatively large difference in effects of two similar studies in different environments may imply that, in daily practice, other factors influence the test ordering behaviour of the GP. An important factor may be the patient. Nowadays the patient has more knowledge with respect to the possibilities to diagnose or treat diseases. The patient may 'demand' that the GP requests more diagnostic tests than are strictly necessary (9). Another possible factor might be the growing fear to miss a patient's diagnosis. This effects test ordering in daily practice, but not in a laboratory setting. For example, in the United States the number of law suits of patients claiming malpractice in their care management and diagnostic processes is still growing (10). In The Netherlands, where there is very little malpractice litigation, studies indicate that a desire to prevent problems in the doctor-patient relationship is a major cause of defensive behaviour by GPs (5).

In general, considering the changes already achieved in our region due to earlier interventions (11), large effects in daily practice were not expected and any additional effect was important: But, why does the GRIF system still generate a median number of 0.99 recommendations per request form while GPs have been receiving feedback for several years? The results of the evaluation of GRIF in daily practice (Chapter 7) show that more than $70 \%$ of the recommendations given to the GPs refer to a-specific recommendations which check for the presence of a working hypothesis or complaint when a particular test is ordered.

During in-depth semi-structured interviews after the intervention the GPs reported that they mostly agreed with the recommendations of the GRIF system (Chapter 9 ), but the results of the use of GRIF in daily practice show that they ignored the majority of the recommendations (Chapter 7). Bouaud et al. also reported that although physicians agreed on $96 \%$ of the recommendations, they only followed $65 \%$ of them (12). They reported no reasons for these discrepancies. A possible explanation for this discrepancy may be the fact that GPs use standard test sets to screen the patient.for more than the indicated possible diagnosis. In this study, GPs indicated that they do not record all possible working hypotheses in these situations 
(Chapter 9). In their opinion the recommendation (for example not to order a glucose test when the diagnosis diabetes mellitus is not present) is correctly given. The GPs did not indicate (on the request form) that diabetes mellitus was one of the options they had in mind, because it belongs to their standard screening method. The reason the GPS did not provide all relevant medical information and that this information was not always coded, was probably due to the rather time-consuming process of entering and coding medical information. A recently published paper of Eccles et al. also stresses that integrating CDSS into clinical consultations where busy practitioners manage patients with complex, multiple conditions is problematic (13). The current study shows that the provision of (coded) patient information is crucial and therefore, as mentioned earlier, the development, implementation and evaluation of user friendly and fast data entry methods are essential.

\section{Methodological considerations}

A methodological weakness appeared in the validation study (Chapter 5). In this study an objective 'gold standard' was lacking. Experts did not study the exact formulation of the advice in the practice guidelines for every assessment they completed. As a result, and because guidelines can be interpreted differently by each physician, the assessments of the appropriateness of requested tests were variable.

The results of the study describing the reliability of the assessment of appropriateness of requested diagnostic tests (Chapter 4), indicate that 16 physicians are necessary to create a reliable reference standard for each individual case. The lack of a sufficient number of expert physicians as well as the large amount of time needed for establishing such a standard, prohibited the expansion of the study with an additional 13 reviewers. Hence, the majority decision of the three reviewers was taken as a starting point to compare the disparities between GRIF and the experts. These disparities were then analysed in more detail using the written guidelines as a reference standard.

Investigators encountered various problems measuring the effect of a CDSS on physicians' performance and patient outcome. The standard method to evaluate medical interventions - a randomised controlled trial (RCT) - cannot always be carried out and does not always explain why interventions are effective or not. Therefore, the evaluation of CDSS in daily practice should not only focus on effectiveness of the system. The reasons for following or ignoring the computerised recommendations are at least as important.

The present study used different data collection methods to study the impact of the GRIF system on the test ordering behaviour of the GPs in daily practice. By using both a qualitative research technique and quantitative techniques obstacles regarding the use of the GRIF system in daily practice could be identified. Many of 
the problems and obstacles that were mentioned in the discussion groups (laboratory trial) and in the in-depth interviews (field trial) may not have been discovered using quantitative approaches only.

On the other hand, the results of qualitative research techniques are more difficult to generalise outside the study population than the results of quantitative methods (14). In addition, the fact that all participating GPS work in the Maastricht and Heerlen region and use the MicroHis GP information system can contribute to this problem of not being able to generalise the results. Therefore, it is not known if the findings of this study can be generalised to other regions.

A factor that was not evaluated in the present study is the effect of automated feedback on patient outcome. In research that focuses on a wide range of diagnostic tests in general practice and therefore involves a broad range of clinicall problems, this aspect is difficult to study. To perform a diagnostic test is only one aspect of effective patient management. A single test is often not the onlly indication for a condition that requires medical attention. Hence, effects on patient outcome are very indirect. The outcome of a single test may only affect the management of the condition of a few patients. Further, other factors, such as the GP's attitude towards guidelines, may interfere with carrying out the advice of the system. An impression of the potential impact of use of the system on patient outcome has been obtained from the comparison of the number of abnormal test results in a group of request forms that is in agreement with the guidelines and in a group of request forms that is not in agreement with the guidelines as presented in Chapter 8 of this thesis.

\section{Recommendations for implementation in dailly practice}

The automated feedback procedure, as described in the present thesis, can be used on a larger scale. The following considerations are important:

- In the development phase of practice guidelines, protocols or standards, developers should take into account that the information in the practice guidelines can be used in a formal way. For instance, unspecific terms must be made explicit, when possible, to avoid differences in interpretation by different physiclans. This formalisation makes knowledge acquisition and validation of the recommendations of critiquing systems easier and faster:

- The knowledge in the knowledge base of the GRIF system should be updated whenever a practice guideline changes. The GRIF software that was used, makes it possible to change the rules in the knowledge base without the need of programming experience. Using a graphical knowledge acquisition tool, physicians (affiliated with the TCU) are able to modify the rules in the knowledge base. It is advisable to access the knowledge base from a central server so that the information used by all GPs in the region affiliated with the 
TCU is always the same. In addition, continuous modification of the knowledge base requires continuous validation.

- The evaluation of the GRIF system showed that GPs appreciate the addition of summaries and/or statistics regarding their test ordering behaviour and their acceptance of the recommendations of the GRIF system. These data on the GPs behaviour are useful as input in GP discussion groups discussing their test ordering behaviour.

- GPs also indicated that they would like the ordered tests to be registered into their GP information system. This implies that the GP information system should be more open for communication with other systems. Well-described procedures to securely access patient data in the GP information system are availlable and should be implemented in GP information systems.

- The quality and the amount of information provided (by patients as well as by physicians) determine the specificity of the advice presented by the GRIF system to a large extent. Therefore, it is important to find new ways to facilitate data entry by physicians. Coding of medical data (or having a standardised vocabulary) as part of the data entry process is essential.

\section{Recommendations for future research}

This thesis answers several questions, but also new questions are raised which need further research:

- It is clear that comparative studies are needed to determine which type of decision support is most effective and accurate for diagnostic test ordering. Both, re-active and pro-active decision support systems have their advantages and disadvantages. More research is needed with regard to practitioners' characteristics and their use of and preference for different types of decision support systems.

- A question still difficult to answer is the effect of an intervention like automated feedback on patient outcome. Is the patient really better off when tests are requested more conform practice guidelines? Appropriate measures for patient outcome still need to be determined. The answer to such a question has to be weighed against the potential reduction in costs that may be achieved.

- Combined interventions of different approaches to stimulate the application of practice guidelines in daily practice seem to be promising. More research is needed to identify which types of combinations are most effective.

\section{Concluding remarks}

It is possible to generate accurate automated recommendations for test ordering in general practice. Use of systems that generate these recommendations based on practice guidelines in general practice potentially changes test ordering behaviour of GPs. Computerised recommendations should contain, if possible, suggestions for 
alternative tests to improve the application of these recommendations. Furthermore, creative solutions must be developed to avoid GPS becoming used to the recommendations of critiquing systems and to stimulate a better application of these recommendations in daily practice.

\section{References}

1. van Wijk MAW, Bohnen $\mathrm{AM}_{\text {, }}$ wan der Lei J. Analysis of the practice guidelines of the Dutch College of General Practitioners with respect to the use of blood tests. Journal of the American Medical Informatics Association 1999;6(4):322-331.

2. Sicotte $\mathrm{C}$, Denis $\mathrm{JL}$, Lehoux. $\mathrm{P}$. The computer based patient record: a strategic issue in process Innovation. Journal of Medical Systems 1998;22/6):431-443.

3. Van Wijk MAM, van der Lei d, Mosseveld M, Bohnen AM, van Bemmel JH. Coimpliance of general practitioners with a guideline-based decision support system for ordering blood tests. Clinical Chemistry $2002 ; 48(1): 55-60$.

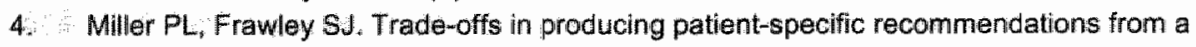
computer-based clinical guideline: A case study. Joumal of the American Medical Informatics Association 1995:2(4):238-242.

5. Veldhuis M. Defensive behavior of Dutch family physicians. Widening the concept. Family Medicine 1994;26(1):27-29.

6. Veldhilis $M$, Wigersma L, Okkes I. Deliberate departures from good general practice: a study of motives among Dutch general practitioners. British Journal of General Practice 1998;48. (437):1833-1836.

7. van der Weijden T, Grol $R$, Winkens $R$, Buntinx $F$, ter Riet $G$, Klazinga $N$. Interventions aimed at influencing the use of diagnostic tests. The relevance of attention for contextual factors. The Cochrane Library 2001.

8. Grol R, Dalhuijsen J, Thomas $S$, Veld $C$, Rutten $G$, Mokkink H. Attributes of clinical guidelines that influence use of guidelines in general practice: observational study. British Medical Journal $1998,317(7162): 858-61$.

9. Deyo RA. A key medical decision maker: the patient. British Medical Journal 2001;323:466467 .

10. Hicksan GB, Federsplel CF. Pichert JW" Miller CS, Gauld-Jaeger d, Bost P. Patient complants and maipractice risk. Journal of the American Medical Association 2002;287(22):2951-2957.

11. Winkens RAG, Pop P, Grol RPTM, Bugter-Maessen AMA, Kester ADM, Beusmans GHMI, et al. Effects of rautine individual feedback over nine yeiars on general practitioners' requests for tests. British Medical Journal 1996;312:490.

12. Bouaud J, Séroussi $B$; Antoine E-C, Zelek $L$, Spleimann $M$. A before-after study using OncoDoc, a guideline-based decision support-system on breast cancer management: Impact upon physician prescribing behaviour. In: Patel VL, Rogers R, Haux R, edilors. Medinfo 2001; 2001 2-5 September 2001; London: IOS Press; 2001. p. 420-424.

13. Ecoles M, McColl E, Steen N Rousseau N, Grimshaw J. Parkin D, et al. Effect of computerised vvidence based guidelines on management of asthma and angina in adults in primary care: cluster randomised controlled trial. BMJ 2002;325(7370):941-.

14. Pope $C$, van Royen $P$, Baker $\mathbb{R}$. Qualitative methods in research on healthcare quality. Qual Saf Health Care 2002;11(2):148-152. 
APPENDICES 


\section{APPENDIX I}

\section{TEST REQUEST FORM}

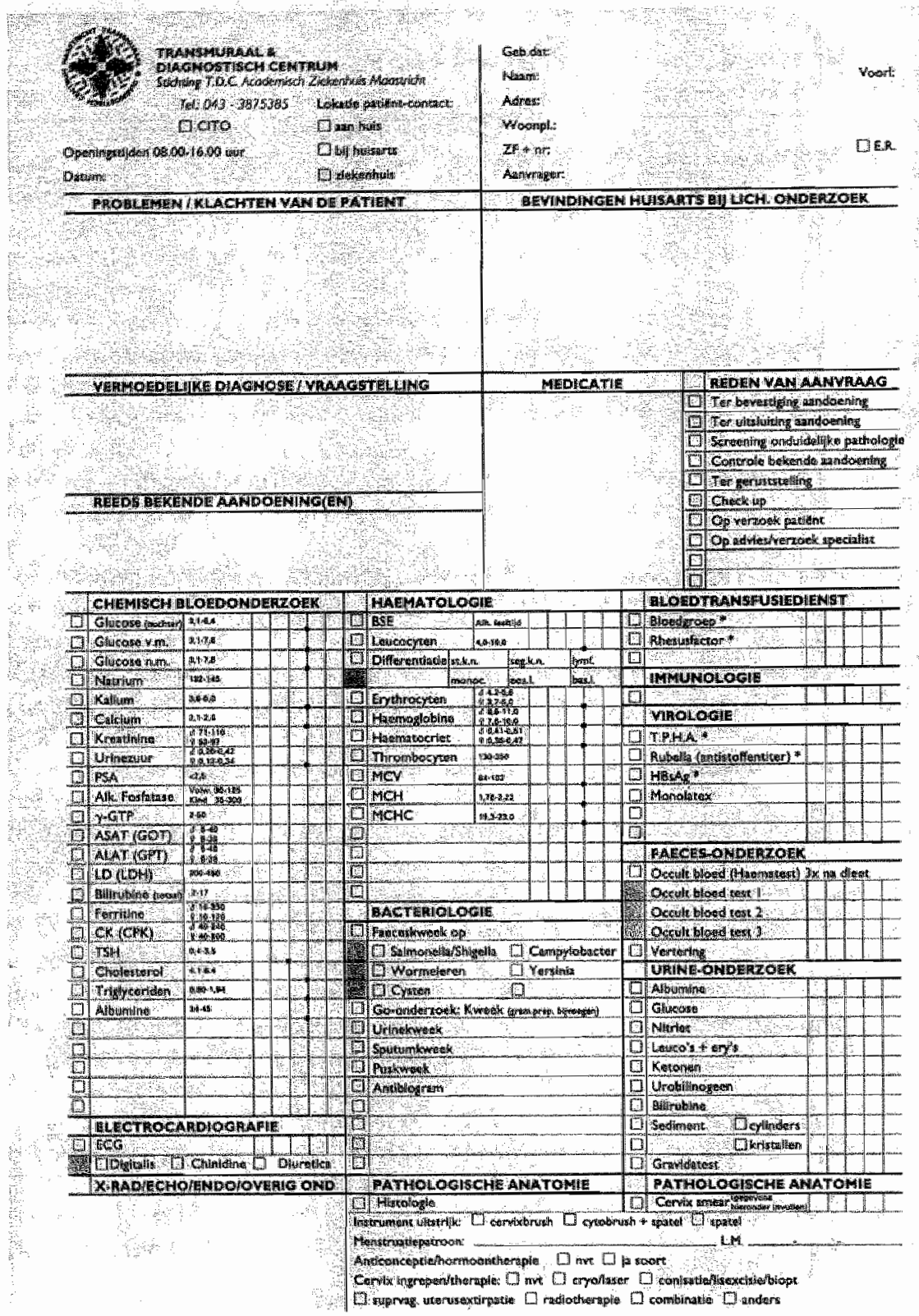

The request form for diagnostic tests of the Maastricht Diagnostic Centre. The administrative patient data are situated on the upper section of the form, the medical patient data in the middle section and diagnastic tests in the lower section. 


\section{APPENDIX II}

Frequency of appearance and non-performance (number of rules that fired incorrectly) of the validated rules in the knowledge base. Reminders indicated with "are 'soft' reminders.

\begin{tabular}{|c|c|c|}
\hline Computerised rules (n) & $\begin{array}{l}\frac{3}{5} \\
\frac{5}{5} \\
\frac{9}{4} \\
\frac{1}{4}\end{array}$ & 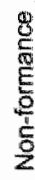 \\
\hline ASAT/ALAT (1) & 8 & \\
\hline ASAT (2) & $\mathbb{1}$ & \\
\hline Creatinine (4) & 2 & \\
\hline Glandular fever (11) & 9 & \\
\hline Glandular fever (12) & 1 & \\
\hline Cholesteral (14) & 12 & 2 \\
\hline Allergy (24) & 4 & 1 \\
\hline Anemia (26) & 3 & \\
\hline Diarrhea $(28)$ * & 2 & 2 \\
\hline Thyroid gland (31)* & 13 & 3 \\
\hline Gout $(33)$ & 7 & 1 \\
\hline Viral infection (39) & 1 & \\
\hline Liver tests (43) & 1 & \\
\hline Gall bladder (45) & 3 & 1 \\
\hline Sinusitis (51) & 1 & \\
\hline $\operatorname{ECG}(55)$ & 2 & \\
\hline Rheumatism (57) & 2 & \\
\hline Rlleumatism (58) & 2 & \\
\hline Liver tests $(59)$ & 5 & \\
\hline Anemia $(62)$ & 26 & 2 \\
\hline$X$-ray knee $(65)$ & 1 & \\
\hline$X$-ray hip $(69)$ & 1 & \\
\hline X-ray shoulder $(74)$ & 1 & \\
\hline Cough $(75)$ & 5 & 1 \\
\hline Hypertension $(77)^{*}$ & 3 & \\
\hline Glandular fever (80) & 6 & \\
\hline Cholesterol (81) & 1 & 1 \\
\hline LDL-Chollesterol (82) & 15 & \\
\hline Preumonia (84) & 1 & \\
\hline Gall bladder (92) & 1 & \\
\hline Gall bladder $(93)$ & 1 & \\
\hline Urine complaints (94) ${ }^{*}$ & 3 & \\
\hline
\end{tabular}

\begin{tabular}{|c|c|c|}
\hline Computerised rulies (n) & $\begin{array}{l}\mathrm{Z} \\
\mathrm{E} \\
\mathrm{g} \\
\mathrm{g} \\
\mathrm{E}\end{array}$ & $\begin{array}{l}\frac{g}{2} \\
\frac{E}{5} \\
\frac{E}{5} \\
\frac{D}{2}\end{array}$ \\
\hline Gall bladder $(95)$ * & 2 & \\
\hline Arthrosis (96) & 5 & \\
\hline COPD $(97)$ & 1 & 1 \\
\hline Bleeding $(100) *$ & 14 & 1 \\
\hline Liver tests (104) & 39 & 3 \\
\hline Creatinine (105) * & 36 & 4 \\
\hline$x$-ray foot $(106)^{*}$ & 2 & 1 \\
\hline Thyroid gland (109) "t & 2 & \\
\hline PSA test $(113)^{*}$ & 1 & \\
\hline PSA test (114) & 1 & \\
\hline $\operatorname{HNP}(116)$ & 1 & \\
\hline Glandular fever $(\| 17)$ & 2 & \\
\hline Glandular fever $(120)$ & 6 & \\
\hline Hypertension $(125)^{*}$ & 10 & \\
\hline Hypertension $(126)$ * & 5 & 2 \\
\hline Gout (127) & 1 & \\
\hline$x$-ray spine $(130)$ & 1 & \\
\hline Diabetes $(135) *$ & 17 & 1 \\
\hline Potassium (136) * & 10 & \\
\hline Leukocytes $(138)$ & 16 & \\
\hline Leukocytes (139) & 32 & 1 \\
\hline Glucose test (1.40) * & 10 & \\
\hline TSH test $(141)^{*}$ & 4 & 1 \\
\hline Anemia $(1.42)^{*}$ & 16 & \\
\hline Glucose test (143) & 33 & \\
\hline Anemia (144) & 13 & \\
\hline Diarthea (145) " & 9 & 1 \\
\hline Diarnea $(146)^{*}$ & $\|$ & \\
\hline Diarmea $(147)$ * & 1 & \\
\hline Diarthea (149) * & 7 & 2 \\
\hline Total & 442 & $32(7 \%)$ \\
\hline
\end{tabular}


ORDERING IMAGING TECHNIQUES ACCORDING TO PRACTICE GUIDELINES OR NOT: DOES THE FRACTION OF ABNORMAL TEST RESULTS DIFFER?

\section{Introduction}

The GRIF automated feedback system judges the appropriateness of diagnostic tests, including laboratory tests and imaging techniques. In Chapter 8 the difference in the fraction of abnormal test results between laboratory tests ordered according to guidelines and tests ordered not according to practice guidelines was studied in an experimental setting. In this appendix the requests for X-rays and ultra-sound scans are presented in a similar way. These test types were studied separately "because imaging techniques have a descriptive outcome while laboratory tests have a quantitative result. The outcomes of imaging techniques are subjective and there are no absolute reference values available. In addition, the assessment of these techniques relies strongly on the fact whether a particular hypothesis was confirmed or excluded.

The same methodology as described in the study on laboratory tests (Chapter 8) was used. The assessment of abnormality was based on the reports of the different imaging technique departments. An experienced physician reviewed the reports.

The question whether or not there is a difference in percentage abnormal test results between imaging tests that are discouraged by the automated feedback system (are not according to accepted practice guidelines) and imaging tests that are not discouraged (are according to accepted practice guidelines) was addressed. This may also answer the question to what extent abnormal findings go unnoticed when test ordering would take place strictly according to the guidelines and redundant tests will not be requested anymore. The importance of these missed abnormal tests results will be discussed as well. Finally, the results of the study on laboratory tests will be compared with the results of the present study.

\section{Methods}

The methodology of this study is described in the methods section of Chapter 8 . 


\section{Results}

A total of 99 imaging test requests were included. In 18 cases $(18.2 \%)$ the reason for the request was missing. Table 1 shows the results. There was no significant difference in the fraction of abnormal test results between the group of tests requested according to practice guidelines and the group of tests not requested according to practice guidelines $(p=0.72)$.

Table 1. Fraction abnormal test results for test requested according to accepted practice guidelines and tests requested not according to accepted practice guidelines.

\begin{tabular}{|c|c|c|c|c|}
\hline \multirow[t]{2}{*}{ 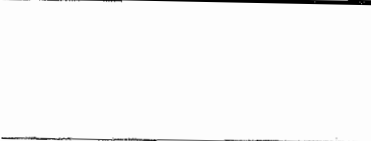 } & \multirow[t]{2}{*}{ Total } & \multicolumn{2}{|c|}{ Abnormal test results } & \multirow{2}{*}{$\begin{array}{l}\text { p-value chil- } \\
\text { square test }\end{array}$} \\
\hline & & $n$ & $\%$ & \\
\hline According to guidelines & 73 & 28 & 38.4 & \\
\hline Not according to guidelines & 26 & 10 & 38.5 & \\
\hline Total & 99 & 38 & 38.4 & 0.72 \\
\hline
\end{tabular}

Table 2. Fraction abnormal test results for test requests according to accepted practice guldelines and not according to accepted practice guidelines stratified by reason for request.

\begin{tabular}{|c|c|c|c|c|c|c|c|}
\hline \multirow[t]{3}{*}{$\begin{array}{l}\text { Reason for } \\
\text { request }\end{array}$} & \multicolumn{3}{|c|}{ According to guidelines } & \multicolumn{3}{|c|}{$\begin{array}{l}\text { Not according to } \\
\text { guidelines }\end{array}$} & \multirow[t]{3}{*}{$\begin{array}{l}\text { p-value chi- } \\
\text { square test }\end{array}$} \\
\hline & \multirow[b]{2}{*}{ Total } & \multicolumn{2}{|c|}{$\begin{array}{l}\text { Abnomal test } \\
\text { results }\end{array}$} & \multirow[b]{2}{*}{ Total } & \multicolumn{2}{|c|}{$\begin{array}{l}\text { Abnormal test } \\
\text { results }\end{array}$} & \\
\hline & & $n$ & $\%$ & & n & $\%$ & \\
\hline To confirm $(n=17)$ & 14 & 7 & 50.0 & 3 & 1 & 33.3 & 0.60 \\
\hline To exclude $(n=59)$ & 44 & 18 & 34.1 & 15 & 8 & 55.5 & 0.19 \\
\hline
\end{tabular}

The results of the analysis stratified by reason for request are presented in table 2 . It shows that, for the purpose of excluding and comfirming the diagnosis, the fraction abnormal test results for the group of tests not according to accepted guidelines is not significantly different from the fraction observed in the group of tests requested according to guidelines in both subgroups.

Table 3 shows the imaging tests for which an abnormal test result was obtained while ordered not according to practice guidelines. The $X$-ray of the spine and the $X$ ray of the thorax were most often abnormal in this group of tests. Of the 10 abnormal test results (requested not according to the guidelines), three had an inaccurate clinical indication resulting in a recommendation. For example when a GP indicates that the patient has a cough for more than 3 weeks without indicating that pneumonia is being suspected, the computer system comments that there is no 
indication for an $X$-ray of the thorax. The recommendation would probably not have appeared when the GP would have provided a more detailed working hypothesis instead of 'coughing'. For one test the GRIF system displayed a general recommendation (that the predictive value of abdominal complaints for the presence of gall stones is low) and for four imaging tests the outcome of the test has no impact on clinical management as was also mentioned by the feedback message. The result of only one test out of the ten test requiests that received a recommendation of the GRIF system might affect clinical patient management (table 3). However, the regional guidelines that were used as a basis for the GRIF recommendations indicated that requesting an $X$-ray for low back pain is not advised.

Table 3. Indication, reason for requests and test result for imaging techniques with abnormal test results ordered not according to accepted practice guidelines.

\begin{tabular}{|c|c|c|c|c|c|}
\hline & TEST & Indication & Reason for & Test result & Comment \\
\hline 1 & $X$-ray spine & $\begin{array}{l}\text { Cervical spine } \\
\text { syndrome }\end{array}$ & To exclude & $\begin{array}{l}\text { Strong spondyloarthro- } \\
\text { sis C5-Th } 11\end{array}$ & $\begin{array}{l}\text { No impact on clinical } \\
\text { management }\end{array}$ \\
\hline 2 & $X$-ray spine & Arthrosis spine & To confirm & Low cerwical arthrosis & $\begin{array}{l}\text { No impact on clinical } \\
\text { management }\end{array}$ \\
\hline 3 & $X$-ray spine & Arthrosis spine & To exclude: & Degenerative arthrosis & $\begin{array}{l}\text { No impact on clinical } \\
\text { management }\end{array}$ \\
\hline 4 & X-ray spine & Arthrosis spine & To exclude & Degenerative arthrosis & $\begin{array}{l}\text { No impact on climical } \\
\text { management }\end{array}$ \\
\hline 5 & X-ray thorax & Nol specified & To exclude & Diaphragmatic hernia & $\begin{array}{l}\text { Inaccurate indication } \\
\text { entered }\end{array}$ \\
\hline 6 & X-ray thorax & Cough & Missing & Infilltration & $\begin{array}{l}\text { Inaccurate indication } \\
\text { entered }\end{array}$ \\
\hline 7 & $X$-ray thorax & Heart complaints & Screening & Cardiomegally & $\begin{array}{l}\text { Inaccurate indication } \\
\text { entered }\end{array}$ \\
\hline 8 & $X$-ray LUSA & Low back pain & Missing & Discopathy L4-L5 & $\begin{array}{l}\text { According to advice in } \\
\text { practice gluideline }\end{array}$ \\
\hline 9 & X-ray hip & Arthosis hip & Screening & Narrow joint gap & $\begin{array}{l}\text { No impact on clinical } \\
\text { management }\end{array}$ \\
\hline 10 & $\begin{array}{l}\text { Ultrasound } \\
\text { gallbladder }\end{array}$ & Gall stones & To exclude & Gall stones & General comment \\
\hline
\end{tabular}

\section{Discussion}

We found that there was no difference in percentage abnormal test results between imaging tests that are discouraged by the system and tests that are not discouraged. The overall difference between the two groups was $3.9 \%$. 
Remarkable is the fact that when imaging tests are requested to exclude a disease, the percentage of abnormal test results is even higher for the group of tests ordered not according to guidelines compared to tests ordered according to these guidelines.

$X$-rays ordered for the exclusion or confirmation of arthrosis are a substantial part of the test requests that were requested not according to practice guidelines and turned out to be abnormal. However, we found that although 10 tests were abnormal, only one was relevant for clinical practice. In the practice guidelines there is no indication for an X-ray when arthrosis is expected since the relevance of the test outcome for further treatment is questionable. Therefore the request is discouraged by the system. No description about the relevance of the information gained from the results of imaging techniques is present in the practice guidelines. These two findings point toward a careful re-evaluation and/or adjustment of the practice guidelines for imaging techniques in a way that the relevance of the tests and the impact of the tests on clinical management are clearly described.

Harpole et al. studied the effect of an automated evidence-based critiquing system on physicians for abdominal radiographs in a prospective study (1). They found that, with low-yield films (films that were likely to have little value), the fraction of positive test results was significantly lower for films that received a critique as opposed to those that did not receive a critique. In phase 2 of their study 769 films were included in the analysis and their reports were examined afterwards. Six of the twelve positive films that were requested but did receive a recommendation had a significant effect on clinical outcome. Three of these recommendations were given due to an inaccurate indication, one because of a rule malfunction and two would have affected patient outcome. The authors state that none of the truly cancelled tests appeared to affect clinical management. In our study 1 out of 99 imaging tests might have affected clinical management significantly.

We must remark that, in contrast with the study of Harpole et al. where 864 films were analysed in the second phase of the study, there was a relatively small number of imaging tests in the random sample of request forms (only 99 imaging tests were included). In addition, Harpole et al. used a prospective study in which physicians could cancel requests for films while our study is retrospective; recommendations about earlier requested tests that were already performed were generated. In future investigations it is advisable to carry out the study using a larger sample of imaging techniques.

There is a clear difference between the results of the present study with the results of the study about ordering laboratory tests (Chapter 8). The percentage of abnormal laboratory test results increased significantly when the recommendations of the practice guidelines in the GRIF system are strictly adhered to. No such effect was measured for diagnostic imaging tests. 
In conclusion, this study shows that a low number of abnormal imaging test results will be missed when the advice of the automated feedback system would be followed. The unthinking adherence to accepted imaging technique practice guidelines is not advised nor that a rejection of such guidelines is warranted. Physicians do and always will play an important and essential role in the diagnostic and therapeutic process. Finally, these findings indicate that careful re-evaluation of some of the practice guidelines for imaging techniques seems to be necessary.

\section{References}

1. Harpole $L H$, Khorasani $R$, Fiskio J, Kuperman GJ, Bates DW. Automated evidence-based critiquing of orders for abdominal radiographs: impact on utilization and appropriateness. Journal of the American Medical informatics Association 1997;4(6):511-521. 


\section{CHANGES GRIF QUESTIONNAIRE COMPARED WITH IBM SCALE!}

We changed the following questions:

- Question 10 of the IBL scale was divided into two questions in the GRIF questionnaire. A question about the ease of recovering mistakes and a question about quickness of recovering mistakes.

- Question 11 of the IBL scale was divided into two questions in the GRIF questionnatre. A question about the on-line help and a question about the paper manual.

- Question 12 of the IBL scale was divided into two questions in the GRIF questionnaire. A question about the ease of finding information and a question about quickness of finding information.

- Question 14 of the IBL scale was divided into two questions in the GRIF questionnaire. A question about the reduction of the number of requested tests as a result of using GRIF and a question about the change in type of requested tests as a result of using GRIF.

- Question 17 of the IBL scale was nut used in the GRIF questionnaire, because translation of this question would lead to about the same formulation as question 16 of the IBL scale.

We added the foliowing statements/questions:

- The ease of use of the electronic guidelines in the GRIF system.

- The overall usefulness of the GRIF system.

- The ease of performing complex requests for diagnostic tests using GRIF.

- Are the presented recommendations of GRIF correctly given.?

- Does the GRIF system present too less recommendations?

- The satisfaction with the ICPC-module.

- Ease of finding the right terms using the ICPC-module.

- Using a computer makes me request tests more consciously.

- The satisfaction with the GRIF system compared with the written feedback.

- The usefulness of the GRIF system compared with the written feedback.

- The usefulness of the GRIF system for the patient.

- The preference to receive recommendation before ordering tests in stead of afterwards.

- Being prepared to code more medical information in order to use decision support.

- The desire to send the request form electronically.

- Registering the requested tests in the GP information system.

i Lewis JR. IBM computer usability satisfaction questionnaires: psychometric evaluation and instructions for use. International Journal of Human-Computer Interaction 1995;7(1):57-72. 


\section{GRIF EVALUATION QUESTIONNAIRE (IN DUTCH)" \\ $1=$ volledig mee eens \\ $5=$ volledig oneens \\ $\mathrm{nvt}=$ niet van toepassing}

\section{Algemeen}

1. Naam huisarts:

2. Geboortejaar:

$19 \ldots$

3. Aantal jaren ervaring als huisarts:

jaren

4. Aantal jaren werkzaam in huidige praktijk: jaren

5. Hoeveel uren per week werkt u als huisarts: uren

6. Wat is de gemiddelde duur van uw consulten: minuten

\section{Ondersteuning}

7. Ik raakte snel vertrouwd met Grif. ${ }^{7}$

8. De handleiding van Grif is duidelijk. "

9. De help-functie in Grif is duidelijk. ${ }^{11}$

10. Het is makkelijk de richtlijnen/werkafspraken binnen Grif te raadplegen.

\section{Gebruikersvriendelijkheid}

11. In het algemeen ben ik tevreden over de gebruikerswriendelijkheid van Grif."

12. Het was eenvoudig om Grif te gebruiken. ${ }^{2}$

13. Ik kon mijn taak effectief uitvoeren door gebruik te maken van Grif. $^{3}$

14. Ik kon mijn taak snel uitvoeren door gebruik te maken wan Grif. ${ }^{4}$

15. Ik kon mijn taak efficiënt uitvoeren door gebruik te maken van Grif. $^{5}$

16. Ik raakte snel gewend aan het werken met Grif. ${ }^{8}$

$\begin{array}{llllll}1 & 2 & 3 & 4 & 5 & \text { nvt }\end{array}$

17. De adviezen (feedback) die Grif gaf zijn makkelijk te begrijpen. ${ }^{3}$

$\begin{array}{llllll}1 & 2 & 3 & 4 & 5 & \text { nvt }\end{array}$

18. De ordening van de informatie op de schermen was overzichtelijk. ${ }^{15} 1 \begin{array}{lllllll}1 & 2 & 3 & 4 & 5 & \text { nvt }\end{array}$

19. Het was eenvoudig de informatie die ik nodig had te vinden binnen $\begin{array}{lllllll}1 & 2 & 3 & 4 & 5 & \text { nvt }\end{array}$ Grif. ${ }^{12}$

20. De informatie die ik nodig had was snel te vinden binnen Grif. ${ }^{12}$

21. Ik kon eenvoudig fouten herstellen binnen Grif. ${ }^{10}$

22. Ik kon snel fouten herstellen binnen Grif. ${ }^{10}$

23. De schermen van Grif waren gebruikersvriendelijk. ${ }^{16}$

\section{Instemming}

$\begin{array}{llllll}1 & 2 & 3 & 4 & 5 & \text { nvt }\end{array}$

$\begin{array}{lllllll}1 & 2 & 3 & 4 & 5 & \text { nvt }\end{array}$

$\begin{array}{llllll}1 & 2 & 3 & 4 & 5 & \text { nvt }\end{array}$ $\begin{array}{llllll}1 & 2 & 3 & 4 & 5 & \text { nvt }\end{array}$ $\begin{array}{llllll}1 & 2 & 3 & 4 & 5 & \text { nvt }\end{array}$

$\begin{array}{llllll}1 & 2 & 3 & 4 & 5 & \text { nvt }\end{array}$

$\begin{array}{llllll}1 & 2 & 3 & 4 & 5 & \mathrm{nvt}\end{array}$

$\begin{array}{llllll}1 & 2 & 3 & 4 & 5 & \text { nvt }\end{array}$ $\begin{array}{llllll}1 & 2 & 3 & 4 & 5 & \text { nvt }\end{array}$

\footnotetext{
1 The numbers behind the questions in the GRIF evaluation questionnaire match the corresponding
} questions of the IBM scale. 


\section{Tevredenheid}

24. In het algemeen was ik tevreden over Grif. ${ }^{19}$

25. Ik vind Grif over het algemeen nuttig.

26. Grif had alle functies en mogelijkheden die ik ervan verwachtte. "8

27. Complexe aanvragen vraag ik niet via Grif aan.

28. Grif geeft terechte adviezen voor de meeste patiënten.

29. Ik krijg te weinig adviezen van het systeem.

30. Ik ben tevreden over het ICPC-module van GRIF.

31. Ik vind de juiste termen met de ICPC-module van Grif.

$\begin{array}{llllll}1 & 2 & 3 & 4 & 5 & \text { nvt }\end{array}$

$\begin{array}{llllll}1 & 2 & 3 & 4 & 5 & \mathrm{nvt}\end{array}$

$\begin{array}{llllll}1 & 2 & 3 & 4 & 5 & \text { nvt }\end{array}$

$\begin{array}{llllll}1 & 2 & 3 & 4 & 5 & \text { nvt }\end{array}$

$\begin{array}{llllll}1 & 2 & 3 & 4 & 5 & \mathrm{nvt}\end{array}$

$\begin{array}{llllll}1 & 2 & 3 & 4 & 5 & \text { nvt }\end{array}$

$\begin{array}{llllll}1 & 2 & 3 & 4 & 5 & \text { nvt }\end{array}$

$\begin{array}{llllll}1 & 2 & 3 & 4 & 5 & \text { nvt }\end{array}$

\section{Ondersteuning bij de aanvraag van diagnostiek}

32. Doordat ik aanvragen doe via de computer ben ik bewuster gaan aanvragen.

33. Door de feedback van Grif ga ik minder testen aanvragen. ${ }^{14}$

34. Door de feedback van Grif ga ik andere testen aanvragen. ${ }^{14}$

$\begin{array}{llllll}1 & 2 & 3 & 4 & 5 & \text { nvt }\end{array}$

35. Ik ben meer tevreden over Grif dan over de schriftelijke feedback.

$\begin{array}{llllll}1 & 2 & 3 & 4 & 5 & \text { nvt }\end{array}$

36. Ik vind Grif meer nut hebben dan schriftelijke feedback

$\begin{array}{llllll}1 & 2 & 3 & 4 & 5 & \mathrm{nvt}\end{array}$

37. Ik ben me bewust van het nut van het Grif-systeem voor de patiënt.

$\begin{array}{llllll}1 & 2 & 3 & 4 & 5 & \text { nvt }\end{array}$

38. Ik heb liever vooraf aanbevelingen over testen die ik moet

$\begin{array}{llllll}1 & 2 & 3 & 4 & 5 & \text { nvt }\end{array}$ aanvragen dan achteraf feedback op mijn aanvraaggedrag.

39. I $\mathrm{k}$ ben bereid meer medische informatie in mijn HIS te gaan

$\begin{array}{llllll}1 & 2 & 3 & 4 & 5 & \text { nvt }\end{array}$ coderen voor het gebruik van beslissingsondersteuning in de huisartspraktijk.

40. tk zou het aanvraagformulier elektronisch willen versturen.

$\begin{array}{llllll}1 & 2 & 3 & 4 & 5 & \text { nvt }\end{array}$

41. Ik zou de aangevraagde testen willen registreren in mijn HIS.

$\begin{array}{llllll}1 & 2 & 3 & 4 & 5 & \text { nvt }\end{array}$ 



\section{SUMMARY}

Over the past 20 years, the number of diagnostic tests that are ordered by general practitioners (GPS) has increased. A relatively large percentage of test requests in health care is ordered inappropriately when compared with practice guidelines. Although sufficient guidelines on appropriate diagnostic testing are available, it is well-known that implementation strategies are needed to make physicians to adhere to these guidelines and thus improve their test ordering behaviour. Results of previous studies are promising, but there is insufficient evidence that computerised interventions are effective implementation strategies. Apart from the scientific 'drive' to study the effects of an automated feedback system in health care, there was also a rather practical reason. Although the individual written feedback provided by the Diagnostic Centre in Maastricht improved the quality of the test ordering behaviour of GPs and this feedback method was appreciated by GPs in the Maastricht region, a more direct (related to each test order) and less laborious method of feedback was desired. Therefore, it was suggested to develop an automated feedback system that would directly assist in the test ordering process. This thesis reports on the development, validation, implementation and evaluation of an automated feedback system on test ordering in general practice.

Chapter 2 presents an overview of the literature on systems that produce real-time, patient-specific advice using on screen recommendations to physicians. This review focused on three aspects: the impact on the physician, the impact on the patient and the impact on the organisation. Besides the effectiveness of the system the physician's user acceptance of and/or user satisfaction with the system was also analysed. Thirty-eight papers were selected for complete review. These papers described different types of clinical decision support systems (CDSSs) such as reminder, alerting, suggesting or critiquing systems. Several study designs were identified but controlled before-after studies and randomised controlled trials were applied most frequently. The impact on the performance of the physician of critiquing and reminder systems in a hospital environment has been studied extensively over the past years. These studies clearly show that the physician's performance improves when these systems are used. It was concluded that the impact on the patient and the health care organisation need to be studied more extensively. In addition, researchers should focus on the question why physicians do or do not accept the advice of the CDSS.

1 GRIF is the Dutch acronym for 'Geautomatiseerde Reminders als Interactieve Feedback' (Automated Reminders as Interactive Feedback). 
In Chapter 3 the development of the GRIF automated feedback system is described. First, the selection of national or regional guidelines, the translation of the practice guidelines into computerised rules and the verification of these rules are described. The GRIF system consists of a knowledge base in which the computerised rules were implemented, as well as an order entry system and modules to provide passive and active decision support. The knowledge base consists of 149 rules applying to various medical problems. The system generates critical comments (as a result of the rules) about the appropriateness of the ordered diagnostic tests at the moment the GP orders a test that is not in line with the practice guidelines. Demographic patient data and medical data (medical history, medication and symptoms) were retrieved from the GP information system. Other relevant information had to be entered directly into the order entry system.

Chapter 4 describes the reliability of assessments of appropriateness of ordered diagnostic tests by three experts. These assessments were to be used as a reference standard in the validation process of the GRIF knowledge base (described in Chapter 5). A random selection of 253 request forms (with 1217 tests on it) completed by general practitioners in the Maastricht region was used. Three reviewers independently assessed the appropriateness of each requested test. Interrater kappa values ranged from 0.33 to 0.42 and kappa values of intrarater agreement ranged from 0.48 to 0.68 . The joint reliability coefficient of the three reviewers was 0.66 . This reliability is sufficient to review test ordering over a series of cases but is not sufficient to make reliable case-by-case assessments. In conclusion, there is substantial variation in assessments of the appropriateness of requested diagnostic tests. Computer support may be beneficial to make the process of peer review more uniform.

In Chapter 5 the validation of the recommendations of the GRIF system is described. The comments of human experts were compared with the comments of the recommendations of the GRIF system using a retrospective random selection of 253 request forms. A panel of three expert physicians judged the requested tests independently based on their interpretations of the practice guidelines. The majority assessment of the physicians was compared with the assessment of the GRIF system. In case the system's output differed from the majority assessment the written practice guidelines were consulted.

On average 1.75 recommendations were produced per form. In total $32(7 \%)$ of the 442 given recommendations were given incorrectly. The amount of information and the level of detail (the specificity of the terms) in which the GP describes the patient's medical status are crucial for the GRIF system to react correctly.

Chapter 6 describes the first part of the evaluation of the GRIF system. In this chapter the efficacy of the system in a laboratory setting is studied. A randomised 
controlled trial (RCT) with balanced block design was used to study the potential effect of the GRIF system. The GPs reviewed a random sample of 30 request forms they had filled in and sent to the Diagnostic Center earlier that year. If deemed necessary, they could make changes in the tests requested: Next, the system displayed critical comments about their non-adherence to the guidelines as apparent from the (updated) request forms. Twenty-four randomily selected GPs participated.

The number of requested diagnostic tests decreased with $17 \%(95 \% \mathrm{Cl}: 12-22 \%)$ due to the comments of the GRIF system. In addition, the fraction of tests ordered not in accordance with the practice guidelines decreased with $39 \%(95 \% \mathrm{Cl}: 28-$ $51 \%)$. The GPs accepted $362(50 \%)$ of the 729 recommendations. Although the experiment cannot predict the size of the actual effect of the GRIF system in daily practice, this percentage of $50 \%$ is assumed to be most feasible.

The effectiveness of GRIF in daily practice is described in Chapter 7. Eleven GPs in two regions of the Netherlands (the regions Maastricht and Heerlen) used the system from August 2000 to July 2001. The GRIF system was implemented on the workstations at the offices of the participating GPs. The GPs were asked to use GRIF during patient consultation instead of filling in the paper request form. An analysis of usage behaviour, of the quality of information provided and of the fraction of recommendations that had been followed were presented.

During the intervention period, the GPs produced 2498 request forms using the GRIF system with 10139 tests on it. Of the 2780 recommendations, the percentage of recommendations followed varied between 3.4 and 8.3 percent depending on the type of recommendation that was given. Advice to remove a test because another more appropriate or efficient - test was also requested and recommendations to request an alternative test were followed most frequently. Therefore, it was concluded that computerised recommendations should contain, if possible, suggestions for alternative tests to improve the application of these recommendations. The median time to generate, read and act on the feedback comments presented was 13 seconds. Entering (coded) medical patient data took GPs a relatively large part of their patient consultation time. This stresses the need for user friendly and rast data entry methods. As a result of the relatively low percentage of recommendations that were followed, creative solutions must be developed to stimulate a better adherence to these recommendations.

In Chapter 8 the fraction of abnormal test results in tests that are ordered according to the practice guidelines are compared with the fraction of abnormal tests in tests ordered not in accordance with the practice guidelines. The outcomes of laboratory tests can seldom be equated with a diagnosis, while the outcome of imaging is often diagnostic. Hence, test requests of both domains are studied separately (the results of the study concerning imaging tests are described in Appendix (II). 
A random sample of 250 request forms that were submitted to the Diagnostic Centre by GPs was taken. These forms contained patient data (administrative and medical), the laboratory tests requested and the reason for request. The GRIF system was used to assess whether test requests are in accordance with practice guidelines.

The fraction of abnormal laboratory test results in the group of tests requested not according to the practice guidelines was significantly lower than in the group of tests requested according practice guidelines $(p=0.02)$. For tests ordered to exclude a disease, the group of tests requested not according to the practice guidelines was also significantly lower than in the group of tests requested according to the practice guidelines $(p=0.04)$. For tests ordered to confirm a disease there was no significant difference between the two groups ( $p=0.57$ ).

Chapter 9 describes the user satisfaction with, the experiences with and the views on the GRIF system. This chapter combines the results from both the trial in a laboratory setting (Chapter 6) and the trial in daily practice (Chapter 7). GPs' user satisfaction was measured using a questionnaire. in addition, group discussions (in the laboratory trial) and in-depth interviews (in the field trial) were conducted to elicit the opinions about and experiences with the system. Finally, the motives for nonacceptance of the recommendations presented by the GRIF system are explared.

The results show that the GPs in the laboratory trial had more positive attitudes towards the system compared with the participants of the field trial. All discussion groups and most of the GPs in the field trial regarded receiving feedback during the test ordering process as an important advantage. The most frequently used motive not to adhere to the practice guidelines was disagreement with its the content and/or its recommendations. Apart from establishing agreement on content of the guidelines, a requirement for using GRIF in daily practice on a large scale is that more attention should be paid to the promotion, the adoption and to the stimulation of a positive attitude towards them among users.

In Chapter 10 the conclusions of this thesis are presented and general aspects of its results discussed. This thesis shows that it is possible to generate accurate automated recommendations on tests ordering in general practice. It is advised that computerised recommendations should contain, if possible, suggestions for alternatives to improve the application of these recommendations. Furthermore, creative solutions must be developed to avoid GPs frequently ignoring the recommendations of critiquing systems. This thesis ends with recommendations for implementation in daily practice and future research. 
De afgelopen 20 jaar is het aantal door huisartsen aangevraagde diagnostische tests gestaag toegenomen. Een relatief groot percentage van deze testaanvragen binnen de gezondheidszorg worden, vergeleken met geaccepteerde richtlijnen, onterecht aangevraagd. Hoewel er voldoende richtlijnen voor het rationeel aanvragen van diagnostische tests beschikbaar zijn, is het bekend dat implementatie strategieën nodig zijn om artsen te stimuieren om zich aan deze richtlijnen te houden en dus het aanvraaggedrag van diagnostische tests te verbeteren. De resultaten van voorgaande onderzoeken zijn veelbelovend, maar er is onvoldoende wetenschappelijk bewijs dat computer-gebaseerde interventies effectieve implementatie strategieën zijn. Naast de wetenschappelijke 'drang' om de effecten van geautomatiseerde feedback systemen te onderzoeken, was er een praktische reden voor het uitvoeren van dit onderzoek. Door het Transmuraal \& Diagnostisch Centrum in Maastricht (tegenwoordig Behandel \& Zorgeenheid Transmurale Zorg van het Academisch Ziekenhuis Maastricht genoemd) wordt al enige jaren, aan huisartsen individuele papieren feedback gegeven. Hoewell de kwaliteit van het aanvraaggedrag van de huisartsen verbeterde en deze methode gewaardeerd werd door de bij het Diagnostisch Centrum betrokken huisartsen, zocht het Diagnostisch Centrum maar een meer directe (gerelateerd aan elke testaanvraag) en minder arbeidsintensieve methode. Vandaar dat een geautomatiseerd feedback systeem, genaamd $\mathrm{GRIF}^{1}$, ontwikkeld werd dat huisartsen tijdens het aanvraagproces kan ondersteunen in het rationeel aanvragen van aanvullende diagnostiek. Dit proefschrift beschrijft de ontwikkeling, validatie, implementatie en evaluatie van een geautomatiseerd feedback systeem betreffende het aanvragen van aanvullende diagnostiek in de huisartspraktijk.

Hoofdstuk 2 presenteert een overzicht van de literatuur met betrekking tot systemen die voor medici direct op het scherm, patiëntspecifiek advies genereren. Het hoofdstuk richt zich op drie aspecten: de invloed op de zorgverlener, de invloed op de patiënt en de invloed op de organisatie. Naast de effectiviteit van de systemen werden ook de zorgverleners' acceptatie en/of tevredenheid met het systeem geanalyseerd. Achtendertig artikelen werden opgenomen in de analyses. Deze artikelen beschreven verschillende typen beslissingsondersteunende systemen zoals reminder-, alert-, advies- of kritieksystemen. Verschillende studie designs werden geïdentificeerd, maar gecontroleerde voor-na studies en RCTs (gerandomiseerde en gecontroleerde trials) werden het meest frequent toegepast.

${ }^{1}$ GRIF is een afkorting voor Geautomatiseerde Reminders als Interactieve Feedback. 
De invloed van kritiek- en remindersystemen op de arts in een ziekenhuisomgeving werd uitgebreid bestudeerd in de afgelopen jaren. Deze studies tonen aan dat het gebruik van dergelijke systemen een verbetering in medisch handelen teweeg brengt. Concluderend kan gesteld worden dat de invloed op de patiënt en de gezondheidsorganisatie meer frequent bestudeerd dienen te worden. Daarnaast zal meer aandacht besteed moeten worden een antwoord te vinden op de vraag waarom zorgverleners de adviezen van beslissingsondersteunende systemen al dan niet opvolgen.

In Hoofdstuk 3 is de ontwikkeling van het GRIF systeem beschreven. De selectie van landelijke en regionale richtlijnen, de vertaling van deze richtlijnen in gecomputeriseerde regels en de verificatie van de regels wordt beschreven. Het GRIF systeem beschikt over een kennisbestand waarin regels zijn geîmplementeerd, een invoermodule en modules die passieve en actieve beslissingsondersteuning leveren. Het kennisbestand bestaat uit 149 regels die betrekking hebben op verscheidene medische problemen. Het systeem genereert kritische commentaren (als gevolg van de regels) betreffende de juistheid van aangevraagde diagnostische tests op het moment dat de huisarts een test aanvraagt die niet in overeenstemming is met de richtlijnen. Demografische patiëntgegevens en medische patiëntgegevens (voorgeschiedenis, medicatie en klachten) worden overgehaald uit het huisarts informatie systeem. Andere relevante informatie dient direct in de invoermodule ingevoerd te worden.

Hoofdstuk 4 beschrijt de betrouwbaarheid van de beoordeling betreffende de juistheid van de diagnostische tests door drie medische experts. Deze standaard zal als basis dienen bij het validatieproces van het kennisbestand van het GRIF systeem (beschreven in Hoofdstuk 5). Een gerandomiseerde steekproef van 253 aanvraagformulieren, die 1217 tests bevatten, werd hiervoor gebruikt. Drie beoordelaars beoordeelden, onafhankelijk van elkaar, de juistheid van elke aangevraagde test. $D e$ interbeoordelaar Kappa-waarde varieerde van 0,33 tot 0,42 en de Kappa-waarde voor intrabeoordelaar overeenstemming varieerde van 0,48 tot 0,68 . De gezamenlijke betrouwbaarheidscoëfficiënt van de drie beoordelaars bedroeg 0,66 . Deze waarde van de betrouwbaarheidscoëfficiënt is voldaende om de kwaliteit van het aanvraaggedrag over een serie van aanvragen te beoordelen, maar is niet voldoende hoog om de kwaliteit van afzonderlijke testaanvragen te beoordelen. Concluderend kan gesteld worden dat er een substantiële variatie bestaat in de beoordeling van correctheid van aangevraagde diagnostische tests. Computer-ondersteuning kan een toegevoegde waarde zijn om het beoordelingsproces meer uniform te maken. 
In Hoofdstuk 5 wordt de validatie van de commentaren van het GRIF systeem beschreven. Commentaren van medische experts werden in deze studie vergeleken met de commentaren van het GRIF systeem door gebruik te maken van een retrospectieve gerandomiseerde steekproef van 253 aanvraagformulieren. Een panel van drie experts beoordeelden de aangevraagde tests op basis van hun interpretatie van de richtlijnen. Het meerderheidsoordeel van de medici werd vervolgens vergeleken met het oordeel van het GRIF systeem. In die gevallen waarbij de beoordelling van het systeem verschilde van het meerderheidsoordeel van de experts, werd de tekst van de richtijnen nogmaals aandachtig bestudeerd. Het GRIF systeem produceerde gemiddeld 1,75 commentaren per aanvraagformulier. in totaal werden $32(7 \%)$ van de 442 gegeven commentaren niet correct gegeven. De hoeveelheid informatie op het aanvraagformulier en het niveau van detaillering (de specificiteit van de termen) waarmee de huisarts de medische gesteldheid van de patiënt beschrijft "zijn cruciaal voor het GRIF systeem om op de correcte manier te reageren.

Hoofdstuk 6 beschrijft het eerste deel van de evaluatie van het GRIF systeem. In dit hoofdstuk is de effect van het systeem in een laboratorium omgeving bestudeerd. Een RCT met een gebalanceerd blok design werd gebruikt om het potentiële effect van het systeem te onderzoeken. De huisartsen $(n=24)$ beoordeelden een gerandomiseerde steekproef van 30 aanvraagformulieren die zij eerder dat jaar hadden ingestuurd naar het Diagnostisch Centrum. Wanneer zij het nodig achtten, konden de huisartsen de tests op het aanvraagformulier wijzigen. Vervolgens presenteerde het GRIF systeem kritische commentaren betreffende het niet opvolgen van de richtijnen op basis van het (aangepaste) aanvraagformulier.

Het aantal aangevraagde aanvullende tests daalde met $17 \%(95 \%$ BI: $12-22 \%$ ) als gevolg van de commentaren van het systeem. Daarnaast daalde de fractie tests die niet in overeenstemming met de richtlinnen werd aangevraagd met $39 \%(95 \% \mathrm{Bl}$ : $28-51 \%$ ). De huisartsen volgden $362(50 \%)$ van de 729 gepresenteerde adviezen op. Hoewel dit experiment het effect van het GRIF systeem in de praktijk niet kan voorspellen, kan geconcludeerd worden dat de geobserveerde effecten gezien kunnen worden als het maximaal bereikbare effect van het systeem in de dagelijkse praktijk.

De effectiviteit van GRIF in de dagelijkse praktijk is beschreven in Hoofolstuk 7. Elf huisartsen in twee regio's (de regio's Maastricht/Heuvelland en Heerlen) gebruikten het systeem van augustus 2000 tot juli 2001. Het GRIF systeem werd geímplementeerd op de Pc's in de praktijken van de deelnemende huisartsen. De huisartsen werd gevraagd het GRIF systeem tijdens het consult met de patiënt te gebruiken in plaats van het papieren aanvraagformulier. Het gebruik van het systeem, de kwaliteit van de geleverde patièntinformatie en de fractie commentaren die niet werden opgevolgd, werd geanalyseerd. 
Gedurende de interventie periode produceerden de huisartsen 2498 aanvraagformulieren, die 10139 tests bevatten, middels het GRIF systeem. Van de 2780 commentaren die het GRIF systeem genereerde, varieerde het percentage commentaren dat werd opgevolgd tussen 3,4 en 8,3 procent afhankelik van hel type commentaar dat gegeven werd. Commentaren die adviseren een test te verwijderen omdat een andere - meer geschikte of meer efficiènte - test ook aangevraagd werd en commentaren die een alternatieve test voorstellen, werden het meest frequent opgevolgd. Dientengevolge wordt geconcludeerd dat geautomatiseerde commentaren, indien mogelijk, een alternatieve test dienen aan te bevelen om zo de toepassing van de adviezen te stimuleren.

De mediane tijd om een commentaar te genereren, te lezen en erop te reageren bedroeg 13 seconden. Het invoeren vam (gecodeerde) medische patiëntinformatie kostte de huisartsen een relatief groot deel van de tijd die huisartsen hebben tijdens het patientconsult. Dit benadrukt de noodzaak om gebruikersvriendelijke en snelle methoden voor gegevensinvoer te ontwikkelen. Als gevolg van het relatief lage percentage commentaren dat werd opgevolgd door de huisartsen dienen creatieve oplossingen gezocht te worden om een betere overeenstemming met de richtilinen te stimuleren.

In Hoofdstuk 8 wordt de fractie afwijkende testuitslagen in de groep tests die aangevraagd zijn volgens richtlijnen vergeleken met de fractie afwijkende testuitslagen in de groep tests die niet volgens de richtlijnen zijn aangevraagd. De uitslag van laboratorium tests leidt zelden direct tot een diagnose, terwijl de uitslagen van beeldvormende technieken meestal diagnostisch zijn. Daarom zijn tests uit deze twee domeinen afzonderlijk bestudeerd (de resultaten van de studie betreffende beeldwormende technieken zijn beschreven in Appendix (II). Een gerandomiseerde steekproef van 250 aanvraagformulieren "die eerder naar het Diagnostisch Centrum verzonden waren, werd genomen. Deze aanvraagformulieren bevatten (administratieve en medische) patiëntgegevens, de aangevraagde laboratorium tests en de reden van aanvraag. Het GRIF systeem werd gebruikt om te beoordelen of de aangevraagde tests in overeenstemming met de richtlijnen waren. De fractie afwijkende laboratoriumuitslagen in de groep tests die niet volgens de richtijnen werden aangevraagd, was significant lager vergeleken met de fractie afwijkende uitslagen binnen de groep tests die aangevraagd werden volgens de richtlijnen $(p=0,02)$. Voor tests die aangevraagd werden om een aandoening uit te sluiten, was de fractie afwijkende uitslagen binnen de groep tests niet volgens de richtlijnen ook significant lager vergeleken met de fractie afwijkende uitslagen van de groep tests die aangevraagd werden volgens de richtlijnen $(p=0.04)$. Voor tests die aangevraagd werden om een aandoening aan te tonen was er geen significant effect tussen de twee groepen $(p=0,57)$. 
Hoofdstuk 9 beschrijt de tevredenheid met, de ervaring met en de mening over het GRIF systeem. Dit hoofdstuk combineert de resultaten van het onderzoek in een laboratorium omgeving (Hoofdstuk 6) en het onderzoek in de dagelijkse praktijk (Hoofdstuk 7). De gebruikerstevredenheid werd gemeten door gebruik te maken van een vragenlijst. Daarnaast werden door middel van groepsdiscussies (in de laboratorium omgeving) en diepte-interviews (in de dagelijkse praktijk) de meningen met betrekking tot en de ervaringen van huisartsen met het systeem onderzocht. Tenslotte zijn de redenen voor het niet opvolgen van de commentaren van het systeem geëxploreerd.

De resultaten laten zien dat huisartsen in een laboratoriumomgeving positiever waren ten aanzien van het GRIF systeem vergeleken met de deelnemers aan het onderzoek in de dagelijkse praktijk. Alle discussiegroepen en de meeste huisartsen die deelnamen aan het onderzoek in de praktijk, beschouwden het krijgen van feedback tijdens het aanvraagproces als een belangrijk voordeel van het systeem. De meest frequent genoemde reden om de adviezen van het GRIF systeem niet op te volgen was het oneens zijn met de inhoud van het advies in de richtlijnen. Naast het verkrijgen van overeenstemming over de inhoud van de richtlijnen, is een voorwaarde voor het gebruik van het GRIF systeem op een grotere schaal dat er meer aandacht wordt besteed aan de promotie van de richtlijnen, het volgen van de richtlijnen en het stimuleren van een positievere houding jegens richtijinen onder gebruikers.

In Hoofdstuk 10 worden de conclusies van deze studie gepresenteerd en worden algemene aspecten van de resultaten bediscussieerd. Dit proefschrift toont aan dat het mogelijk is om accurate, geautomatiseerde adviezen over het aanvragen van diagnostische tests in de huisartspraktijk te genereren. Geadviseerd wordt om geautomatiseerde adviezen, indien mogelijk, te voorzien van suggesties voor alternatieve tests om de toepassing van de adviezen te stimuleren. Daarnaast wordt geadviseerd om creatieve oplossingen te ontwikkelen om te voorkomen dat adviezen van kritieksystemen, zoals het GRIF systeem, veelvuldig worden genegeerd. Dit proefschrift eindigt met adviezen voor verdere implementatie van het GRIF systeem in de dagelijkse praktijk en adviezen voor verder onderzoek. 
$\therefore \quad \therefore \quad$ -

a

अ : 


\section{DANKWOORD}

Na heel wat werk ligt mijn proefschrift dan voor jullie. Weliswaar staat mijn naam op de kaft en ben ik verantwoordelijk voor de inhoud en uitvoering van het proefschrift, echter, zonder de hulp van mensen in mijn directe omgeving en al diegene die hebben bijgedragen aan de wetenschappelijke waarde van dit proefschrift, was het proefschrift nooit geworden tot wat het nu is. Daarom wil ik iedereen bedanken die een bijdrage heeft geleverd aan dit proefschrift en een paar mensen wil ik daarbij in het bijzonder noemen.

Allereerst wil ik mijn promotor Arie Hasman bedanken. Arie, jouw enthousiasme en jouw commentaren waren soms onophoudelijk, maar zorgden er wel voor dat ik bleef volhouden in het promotietraject en de puntjes op de i gezet werden. Ook de co-promotoren Ron Winkens en Jan van Wersch wil ik bedanken voor alle steun, de begeleiding en de kritische blik op de opzet, uitvoering en beschrijving van het uitgevoerde onderzoek.

Op de tweede plaats dank ik de huisartsen uit de regio Maastricht/Heuvelland en Heerlen die deelgenomen hebben aan het GRIF-project voor het gebruik van het GRIF-programma en de medewerking aan de evaluatie van programma. Dankzij jullie heeft het GRIF-programma de vorm gekregen die het nu heeft en hebben we gegevens kunnen verzamelen over het gebruik van een beslissingsondersteunend systeem in de huisartspraktijk.

Verder wil ik alle andere personen die in de afgelopen periode betrokken zijn geweest bij het GRIF-project bedanken. Jan Talmon en in de eerste jaren van het project Paul Höppener, Marieke Vissers en Francois Dupuits voor hun inbreng in de GRIF-projectgroep. Mieke Derickx en Dennis Oerlemans voor hun ondersteuning als respectievelijk onderzoeksassistent en studentassistent binnen het project. Anja Winkens voor de gegevensinvoer ten behoeve van de "labtrial". En tenslotte Paul de Clercq, Sjef Roos en Alfons Schroten die het technische gedeelte van het GRIF programma realiseerden voor mij. Paul, mijn oude $\mathrm{WW}$ golfje bracht ons toch maar mooi iedere keer naar al die huisartsen waar wij als een heus team alle software installeerden en de training verzorgden. De afgelopen periode werd 'het proefschrift' en alles daaromheen vaker gespreksonderwerp, want voor ons allebei moest een promotie er nu toch maar van komen. Allen, bedankt voor jullie inzet, inbreng en gezelligheid! 
De rest van mijn collega's bij Medische Informatica, maar ook bij BZe Transmurale Zorg (voorheen Transmuraal en Diagnostisch Centrum Maastricht) wil ik bedanken voor de medewerking en steun. In het bijzonder Mirjan van der Meijden, met wie ik vier jaar een kamer en alle promotieperikelen deelde. Bedankt voor je tips, je luisterend oor en je gezelligheid.

Daarnaast wil ik Carla Peeters bedanken voor de hulp bij de laatste loodjes van het proefschrift: het controleren en corrigeren van een aantal hoofdstukken op het gebruik van de engelse taal.

Mijn vrienden en vriendinnen wil ik bedanken voor alle gezelligheid en ontspanning naast de promotie. Carry en Annette, ik ben heel biij dat jullie mijn paranimfen willen zijn. Annette, de eetafspraken moeten we gewoon continueren tot we echt alle restaurants in Maastricht bezocht hebben. En Carry, jij was mijn promotie-maatje op afstand Nu is het jouw beurt om als paranimf op te treden.

Ook al mijn korfbalmaatjes (in Milsbeek en Maastricht) hebben gezorgd voor de nodige ontspanning. Een promotie met SPES 1 zit er helaas niet in, maar hopelijk kunnen we nog een aantal jaartjes met veel plezier op landelijk niveau presteren en de titels binnen blijven halen.

Pap en mam, jullie wil ik bedanken voor de steun en het vertrouwen dat jullie me altijd geschonken hebben. Jullie waren er, samen met Caroline en Leontine, telkens wanneer het nodig was en stonden (en staan nog steeds) altijd voor me klaar. Al hebben we het niet makkelijk gehad het afgelopen jaar....samen komen we er well doorheen.

Lieve Eric, voor jouw was mijn promotie-avontuur ook een hele ervaring. Eerst ging je vriendin 4 jaar lang 130 kilometer verderop wonen, daarna moest ons huisje verbouwd worden en wilde ik ook nog heel veel van onze kostbare tijd samen in thet volbrengen van mijn proefschrift stoppen. Bedankt voor je geduld "je steun en liefde, je relativeringsvermogen en de ontelbare telefoontjes naar Maastricht. 


\section{CURRICULUM VITAE}

Rianne Bindels werd geboren op 14 augustus 1972 te Nijmegen. De lagere school volgde zij in haar woonplaats Milsbeek. Na het behalen van het V.W.O. diploma aan het Merletcollege te Cuijk in 1990, studeerde zij van 1990 tot 1996 Biomedische Gezondheidswetenschappen aan de Katholieke Universiteit te Nijmegen met de afstudeerrichting Bewegingswetenschappen. Daarnaast volgde zij binnen deze studie een aantal extra vakken binnen de afstudeerrichting Epidemiologie.

Aansluitend werkte zij als Trial Assistant voor Bicom Medical in 1996 en 1997 in diverse huisartsenpraktijken in Limburg en Noord-Brabant. Zij zette dit werk vervolgens voort als freelance automatiseringsmedewerkster in Gezondheidscentrum 'De Lindeholt' te Nijmegen in 1997 en 1998.

Het in dit proefschrift beschreven onderzoek is uitgevoerd binnen de afdeling Medische Informatica van de Universiteit van Maastricht. Vanaf 1998 was de auteur daar 4 jaar fulltime en $1 / 2$ jaar partime werkzaam als Assistent In Opleiding.

Vanaf 1 april 2002 keerde zij terug naar Nijmegen alwaar zij nu werkzaam is in het Universitair Medisch Centrum St Radboud als projectadviseur binnen de stafdienst Informatievoorziening. Op dit moment houdt zij zich daar bezig met het vormen van beleid op het gebied van het verpleegkundig en paramedisch deel van het elektronisch patiëntendossier (EPD) voor de stafdienst Zorg binnen het UMC St Radboud.

Daarnaast is zij vanaf 1 december 2002 als onderzoeker voor de afdeling Medische Informatica van de Universiteit Maastricht betrokken bij het project E-Gooz (EPDGerelateerd onderwijs in opleidingen voor de zorg) naar de huidige en wenselijke EPD-gerelateerde onderwerpen binnen het medisch onderwijs in Nederland. 
$5+$

$\therefore \quad \therefore$ 


\section{PUBLICATIONS}

\section{Full Papers}

Bindels, R. Hasman, A., Winkens, R.A.G. De invloed van een computer remindersysteem op het aanvraaggedrag van huisartsen. Informatie \& Zorg 1999; 28 (4) pp. 140-144.

Bindels, R., Winkens, R.A.G., van Wersch, J.W.J.. Höppener, P. Hasman. A. Computer helpt huisarts beslissen. Medisch Contact 2000, 55 (23) pp. 851-854.

Bindels, R., de Clencq. P.A., Winkens, R.A.G., Hasman, A. A test ordering sirstem with automated reminders for primary care based on practice guidelines. Int J Med Inform 2000; 58-59 pp. 219. 233.

Bindels, R., Winkens, R.A.G. "Pop, P. van Wersch, J.W.J., Talmon, J., Hasman, A. Validation of a knowledge based reminder system for diagnostic test ordering in general practice. Int $J$ Med Inform 2001; 64 pp. 341-354.

Bindels, R., Hasman, A., van Wersch, J.W.J., Pop. P., Winkens, R.A.G., The reliability of assessing the appropriateness of requested diagnostic tests. Med Dec Making 2003; 23 (1) pp. 31-37.

\section{Abstracts}

Bindels, R., Hasman, A., Winkens, R.A.G. Development of a reminder system for generall practitioners. In: Kokol, P., Zupan, B., Stare, J., Premik, M. and Engelbrecht, R., editors. Proc Medical Informatics Europe; Ljubljana: IOS Press: 1999. pp. 745-748.

Bindels, R. Hasman, A., Winkens, R.A.G. De invloed van computer reminder systeem op het aanvraaggedrag van huisartsen. In: Koppelman, Y.J.M. and Helder, J.C., editors. Proc Medische informatica Congres; Veldhoven: VMB/; 1999. pp. 39-46.

Bindels, R., Hasman, A., Winkens, R.A.G. Am automated reminder system for general practitioners based on practice guidelines. In: 16th annual meeting of the International Sociaty of Technology Assessment in Healthcare; The Hague, The Netherlands: 2000 . p. 10.

Bindels, R., Winkens, R.A.G., van Wersch, J.W.J., Pop, P., Hasman, A. Comparing assessment of appropriateness of diagnostic tests between a human expert and an automated reminder system. In: Hasman, A., Blobel, B., Dudeck, J., Engelbrecht, R., Gell, G. and Prokosch, H.U., editors. Proc Medical Informatics Europe; Hannover: 10 S Press; 2000. pp. 239-243.

Hasman, A., Bindels, R., de Clercq. P.A. On the use of reminder systems in healthcare. In. Proc 26th EuroMicro Conference Sept 5-7, 2000; Maastricht: IEEE; 2000. pp. 20-25.

Bindels, R., Winkens, R.A.G. Wersch, J.W.J. Hasman, A. Validatie van een computer remindersysteem ter bevordering van het rationeler aarivragen van aanwullende diagnostiek. $1 m$. De Moor, G. and De Clercq, E., editors. Proc Medisch Informatica Congres november, 2000; Brugge: MM: 2000. pp. 121-127.

Bindels, R., Winkens, R.A., Wersch, J.W., Pop. P., A., H. Ontwikkeling en validatie van een computer reminder-systeem om het aanvraaggedrag van huisartsen te beïnvloeden. In: van der Lei, $J_{\text {, }}$ editor. EMO 2000; Ede: Erasmus Universiteit Rotterdam; 2000. pp. 55-62.

Bindels, R., Winkens, R.A.G.,Wersch, J.W.J., Pop. P., Hasman. A. Reliability of the assessment of appropriateness of diagnostic test request behavior. In: Patel. V.L., Rogers, $R$. and HauX, $R$., editors. Proc Medinfo 2-5 September 2001; London: IOS Press; 2001. pp. 1112-1115.

Bindels, R., Winkens, R.A. Wersch, J.W., Hasman, A. Het beoordelen van de rationaliteil wan aangevraagde diagnostiek. In. Helder, J.C., editor. Proc Medische Informatica Congres; 2001. 